\title{
Evaluating clinical teaching through cognitive apprenticeship
}

Citation for published version (APA):

Stalmeijer, R. E. (2011). Evaluating clinical teaching through cognitive apprenticeship. [Doctoral Thesis, Maastricht University]. Datawyse / Universitaire Pers Maastricht. https://doi.org/10.26481/dis.20110707rs

Document status and date:

Published: 01/01/2011

DOI:

10.26481/dis.20110707rs

Document Version:

Publisher's PDF, also known as Version of record

\section{Please check the document version of this publication:}

- A submitted manuscript is the version of the article upon submission and before peer-review. There can be important differences between the submitted version and the official published version of record.

People interested in the research are advised to contact the author for the final version of the publication, or visit the DOI to the publisher's website.

- The final author version and the galley proof are versions of the publication after peer review.

- The final published version features the final layout of the paper including the volume, issue and page numbers.

Link to publication

\footnotetext{
General rights rights.

- You may freely distribute the URL identifying the publication in the public portal. please follow below link for the End User Agreement:

www.umlib.nl/taverne-license

Take down policy

If you believe that this document breaches copyright please contact us at:

repository@maastrichtuniversity.nl

providing details and we will investigate your claim.
}

Copyright and moral rights for the publications made accessible in the public portal are retained by the authors and/or other copyright owners and it is a condition of accessing publications that users recognise and abide by the legal requirements associated with these

- Users may download and print one copy of any publication from the public portal for the purpose of private study or research.

- You may not further distribute the material or use it for any profit-making activity or commercial gain

If the publication is distributed under the terms of Article $25 \mathrm{fa}$ of the Dutch Copyright Act, indicated by the "Taverne" license above, 


\section{Evaluating clinical teaching through cognitive apprenticeship}

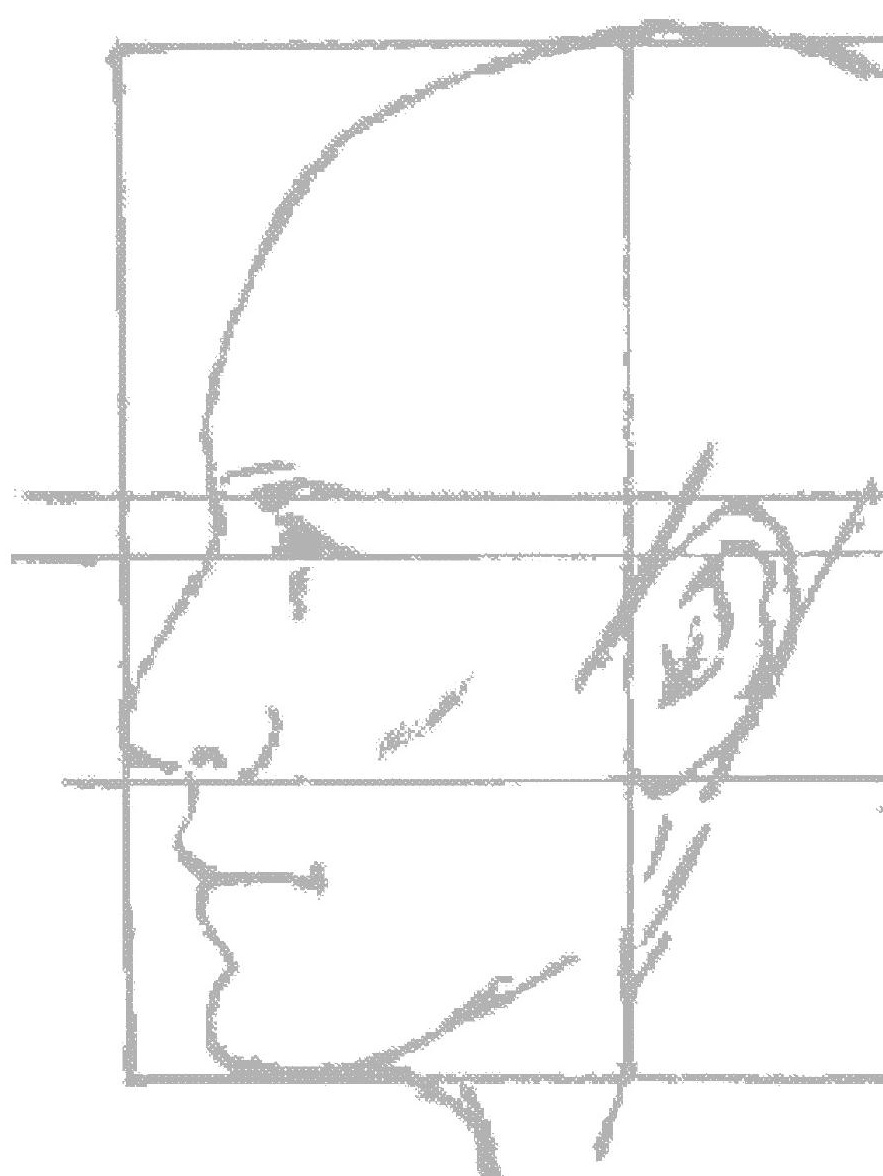


The research reported here was carried out at

in the School of Health Professions Education



(C) Renée E. Stalmeijer, Maastricht ISBN 978-94-6159-067-1

Cover design: Simone Meesters

Production: Datawyse | Universitaire Pers Maastricht 


\title{
Evaluating clinical teaching through cognitive apprenticeship
}

\author{
PROEFSCHRIFT
}

ter verkrijging van de graad van doctor, aan de Universiteit Maastricht, op gezag van de Rector Magnificus, Prof. mr. G.P.M.F. Mols volgens het besluit van het College van Decanen, in het openbaar te verdedigen op donderdag 7 juli 2011 om 16.00 uur

door

Renée Elisabeth Stalmeijer

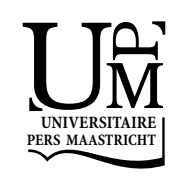




\section{PROMOTOR}

Prof. dr. A.J.J.A. Scherpbier

\section{COPROMOTORES}

Dr. D.H.J.M. Dolmans

Dr. H.A.P. Wolfhagen

\section{BEOORDELINGSCOMMISSIE}

Prof. dr. C.P.M. van der Vleuten (voorzitter)

Prof. dr. T. Dornan, Manchester University

Prof. dr. G.G.M. Essed

Dr. M.G.A. Oude Egbrink

Dr. P. Teunissen 


\section{Table of Contents}

$\begin{array}{lll}\text { Chapter } 1 & \text { General introduction } & 7\end{array}$

Chapter 2 Cognitive apprenticeship in clinical practice: Can it stimulate $\quad 19$ learning in the opinion of students?

Advances in Health Sciences Education: Theory and Practice, 14 (4), 535-546, 2009.

Chapter 3 The development of an instrument for evaluating clinical teachers: Involving stakeholders to determine content validity Medical Teacher, 30 (8), e272-277, 2008.

Chapter 4 The Maastricht Clinical Teaching Questionnaire (MCTQ) as a valid and reliable instrument for the evaluation of clinical teachers

Academic Medicine, 85 (11), 1732-1738, 2010.

Chapter 5 Combined student ratings and self-assessment provide useful 65 feedback for clinical teachers Advances in Health Sciences Education: Theory and Practice, 15 (3), 315-328, 2010.

Chapter 6 Factors influencing clinical teaching from the perspective of the Maastricht Clinical Teaching Model: Views of experienced clinical teachers Submitted.

Chapter 7 General discussion

Summary

Samenvatting (Summary in Dutch)

Dankwoord (Acknowledgements)

Curriculum vitae 

Chapter 1

General introduction

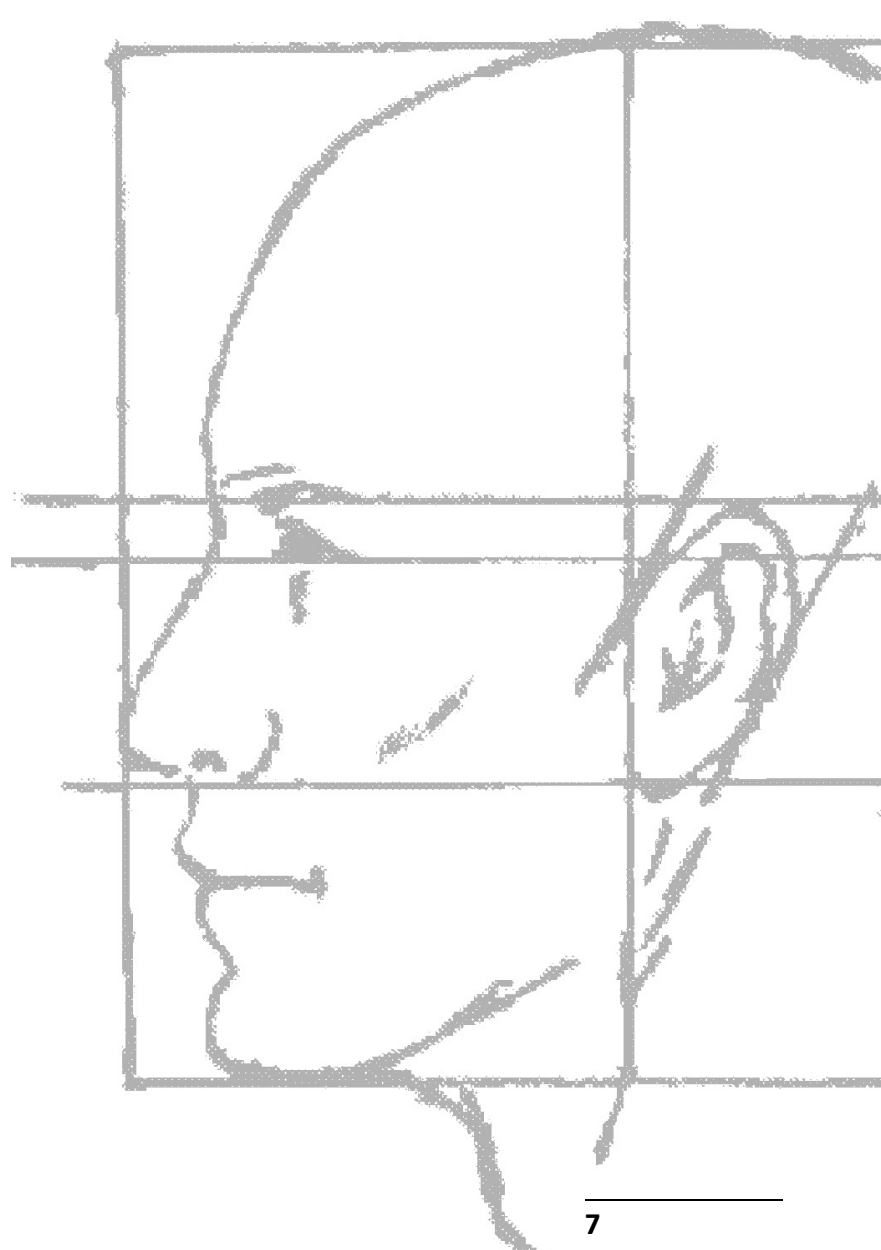


CHAPTER 1 


\section{THEORETICAL BACKGROUND}

\section{Clerkships}

For the final years of the undergraduate medical curriculum students move from the classrooms of the medical school to the clinical setting. They enter a period of clinical training consisting of clerkships in different disciplines, different hospitals and different clinical settings. Here they learn how to apply in the care of real patients the knowledge and skills they have already partly acquired (Dent, 2005; Spencer, 2003). Clerkships expose students to several learning experiences by which they acquire skills for clinical reasoning (Eva, 2005; Schmidt, Norman, \& Boshuizen, 1990) and patient and information management (Dent, 2005; Slawson \& Shaughnessy, 2005) while they also start to develop the domain-specific ways of thinking and acting that mark the medical expert.

Clerkships are experienced by medical students as a very rich and motivating learning environment (Gordon et al., 2000). The clinical workplace provides an abundance of settings where students can learn by observing attending physicians and residents, by practising and performing skills, by being part of a team and by engaging and communicating not only with patients but also with peers and supervisors (Dent, 2005). The authenticity of learning in professional practice where students can actively apply knowledge and skills to real life problems is highly motivating for them (Diemers, Dolmans, Verwijnen, Heineman, \& Scherpbier, 2008; Spencer, 2003).

All in all, clerkships have tremendous potential for offering effective and rewarding learning experiences. Unfortunately, research tells us that learning in the clinical workplace is not only motivating and exciting but also more often than not haphazard and informal (Eraut, 2004). This is not surprising, for in the clinical workplace the first priority is patient care not student learning. Hoffman and Donaldson (2004) describe learning and teaching in the clinical environment as an 'open system' that it is subject to multiple forces. For example, physicians are under increasing time pressure as they are contending with competing demands of service, research, administration and teaching (Spencer, 2003). So, for students, the clinical workplace is a learning environment that is as exciting and stimulating as it is demanding, unstructured and confusing.

In order to better understand what stimulates and hampers learning during clerkships researchers have sought answers to questions like 'what influences the perceived quality of clerkships according to students' (Dolmans, Wolfhagen, Essed, Scherpbier, \& Vleuten, 2002) and 'which factors influence the actual outcomes of clerkships' (Wimmers, Schmidt, \& Splinter, 2006). The central message from these studies is that the quality of supervision is the crucial factor for the quality of student learning. Supervision can indeed be seen as 'the vital key to unlocking learning 
from clerkships' (Crossley, 2006). Sadly, it has been revealed by several studies that clinical settings fall short in giving students the supervision they need. Grant et al. (2006) investigated the coverage and frequency of several supervisory activities, such as monitoring performance and providing feedback (Grant, Kilminster, Jolly, \& Cottrell, 2006) and concluded that these activities were of rather infrequent occurrence. There may be a connection between the scarcity of effective supervision and the fact that physicians generally receive little formal preparation for their clinical teaching tasks during their training as a medical expert (Cottrell, Killminster, Jolly, \& Grant, 2002; Ramani \& Leinster, 2008).

\section{Clinical teaching}

Studies of clinical teaching and clinical teachers have focused on several topics. Ample attention has been bestowed on the search for the essential qualities of effective clinical teachers (Dolmans, Wolfhagen, Gerver, Grave de, \& Scherpbier, 2004; Irby, 1994; Irby \& Bowen, 2004; Kilminster \& Jolly, 2000; Rolfe \& SansonFisher, 2002; Snell et al., 2000; Ullian, Bland, \& Simpson, 1994). Studies of this type have looked at teachers' 'personal qualities', such as being supportive, helpful, accessible and friendly (Snell et al., 2000; Ullian et al., 1994), at 'teaching qualities', such as being a good role model (Elzubeir \& Rizk, 2001), providing constructive feedback and promoting reflection (Branch \& Paranjape, 2002), at providing a safe learning environment (Buchel \& Edwards, 2005) or at a combination of these qualities (Dolmans et al., 2004; Irby \& Bowen, 2004).

The design of faculty development programmes for clinical teachers is another important research topic for clinical teaching (McLean, Cilliers, \& Van Wyk, 2008). This line of research meshes characteristics of good clinical teachers with 'educational theory' to inform the design of effective faculty development programmes (Kaufman \& Mann, 2010). It has generated models of clinical teaching that describe practical activities for clinicians, such as the 'one-minute preceptor' (Neher, Owen, McArdle, \& Duffy, 1992), tips for bedside teaching and teaching in outpatient/ambulatory settings (Irby, 1995) as well as an overview of the various roles that physicians can perform as medical teachers (the twelve roles of the medical teacher (Harden \& Crosby, 2000)). A third topic that has gained prominence during recent decades is the design of evaluation instruments aimed at providing feedback to clinical teachers on how they supervise students in clinical practice.

\section{Evaluation of clinical teaching}

Physicians need appropriate tools to aid them in identifying and developing effective ways of supervising students so as to optimize the learning potential of the workplace. Evaluation of clinical teaching can be such a tool, provided it is con- 
ducted well and in an appropriate manner. Two extensive literature reviews have revealed an abundance of instruments designed to generate useful feedback that physicians can use to improve their clinical teaching skills. Beckman and colleagues (2004) reviewed 21 instruments for the evaluation of teachers by undergraduate and postgraduate students and six years later Fluit and colleagues (2010) identified at least 34 instruments. These are quite impressive numbers, but both reviews revealed flaws and problems in the instruments. They noted lack of validity, failure to consult important stakeholders in the design process or limited effectiveness due to too broadly defined items. A striking flaw in many instruments is the absence of a sound underpinning by theories of clinical teaching. According to Bowden and Marton (1998) a good theoretical framework can help to improve feedback specificity and effectiveness as it can point to direct actions for improvement. However, the existing instruments are rarely based on theories describing effective teaching activities for learning in the workplace.

\section{Cognitive Apprenticeship}

Through most of its history, the medical profession has transmitted the knowledge and skills of the profession to new generations of physicians in (traditional) apprenticeship type settings. Novices are apprenticed to experts whom they observe while performing professional tasks. The expert helps the novice to practice tasks and gradually allows him/her to perform parts of those tasks. As the novice learns and becomes more skilful, the expert gradually grants the learner more independence and support slowly fades. Collins, Brown and Newman (1989) introduced the concept of cognitive apprenticeship as a way to rethink this traditional apprenticeship model, shifting the focus from observation and increasingly independent task performance to the cognitive processes that experts use in handling complex tasks. Cognitive apprenticeship stresses the notion of 'learning through guided experience'. It centres around the cognitive processes of experts when performing a task and around meta-cognitive skills and processes that are used in monitoring and guiding students' experiences (Collins, Brown, \& Newman, 1989).

The key feature of cognitive apprenticeship is to make the expert's internal (tacit) cognitive processes explicit in order to better enable students to observe, enact and practise these with the help of their teacher. Collins and colleagues (1989) suggest several teaching methods that support cognitive apprenticeship (Table 1). The first method is modelling where students observe expert task performance as demonstrated by the teacher. The important difference between 'traditional apprenticeship modelling' and 'cognitive apprenticeship modelling' is that the latter emphasizes the externalization of the teacher's thinking processes. While the student observes the teacher who performs a task the teacher is expected to think aloud and explain the judgement and reasoning processes involved in that 
task. Another teaching method is coaching. During coaching the teacher observes the student and helps him/her in learning and performing a task by providing feedback and modelling whenever this is deemed useful. Scaffolding is a teaching method in which the teacher provides support and selective help to the student who has not yet fully mastered a task. The teacher first assesses the student's skill level and stimulates and helps the student to move beyond it. As the student's proficiency increases, support gradually fades until the student is considered ready to perform the task independently. During modelling, coaching and scaffolding, the teacher should stimulate meta-cognitive skills and self-directed learning. The latter is achieved by the teaching methods articulation, reflection and exploration.

Table 1: Cognitive apprenticeship teaching methods (based on Collins et al., 1989, Collins et al., 1991)

\begin{tabular}{|c|c|}
\hline Teaching Method & Description \\
\hline Modelling & $\begin{array}{l}\text { Expert performs task so that student can observe; while performing the task, the } \\
\text { expert externalizes heuristics and control processes they use in applying their } \\
\text { basic conceptual and procedural knowledge. }\end{array}$ \\
\hline Coaching & $\begin{array}{l}\text { Expert observes student during task performance and offers hints, scaffolding, } \\
\text { feedback, modelling, reminders and new tasks aimed at bringing the student's } \\
\text { performance closer to expert performance. }\end{array}$ \\
\hline Scaffolding & $\begin{array}{l}\text { Expert diagnoses student's current skill level and the availability of an intermedi- } \\
\text { ate step at the appropriate level of difficulty in carrying out the target activity. } \\
\text { Expert provides support to student for parts of the task the student cannot yet } \\
\text { manage. Support is gradually faded until student is on his/her own. }\end{array}$ \\
\hline Articulation & $\begin{array}{l}\text { Expert stimulates student to articulate his/her knowledge (and or understand- } \\
\text { ing), reasoning or problem-solving processes. }\end{array}$ \\
\hline Reflection & $\begin{array}{l}\text { Expert stimulates student to compare his/her problem-solving process with } \\
\text { those of an expert, another student, and ultimately, an internal cognitive model } \\
\text { of expertise. }\end{array}$ \\
\hline Exploration & $\begin{array}{l}\text { Expert stimulates student to move to a mode of more independent problem } \\
\text { solving by setting general goals for the student and then encourage him/her to } \\
\text { focus on particular subgoals of interest to them and which will help them to } \\
\text { overcome weaknesses and build on strengths. }\end{array}$ \\
\hline
\end{tabular}

In articulation the teacher stimulates the student to think aloud and articulate his or her knowledge, reasoning and problem-solving processes. The student is also encouraged to ask questions. Similarly, during reflection the teacher asks the student to reflect on the strengths and weaknesses of his/her knowledge and skills while exploration stimulates the student to formulate learning goals to overcome weaknesses and build on strengths. The appeal of the cognitive apprenticeship for the domain of clinical teaching lies in its focus on explication of the generally tacit cognitive processes of experts. Students can benefit from insight into these processes 
because they can reproduce them when performing clinical tasks themselves (Taylor \& Care, 1999). Although cognitive apprenticeship seems a valuable concept for clinical teaching, its relevance and practical usefulness for medical education remain to be established.

Besides the teaching methods of the cognitive apprenticeship model, providing a safe learning environment is an important component of supervision and clinical teaching. A safe learning environment can be described as an environment in which the teacher shows respect for and a genuine interest in the student and in which the student feels safe to ask questions and seek support when desired (Beckman, Lee, Rohren, \& Pankratz, 2003; Litzelman, Stratos, Marriott, \& Skeff, 1998). The importance of providing a safe learning environment for students has been extensively demonstrated in the medical education literature (e.g. (Boor et al., 2008; Dornan, Boshuizen, King, \& Scherpbier, 2007; Kilminster \& Jolly, 2000; Ramani \& Leinster, 2008).

\section{MAIN ARGUMENT \& RESEARCH AIMS}

Although the clerkship period is essential for educating our future doctors, it is not self-evident students do learn from participating in clinical practice. Research has established that physicians have a central role in this learning process. If this role is performed well, it enhances both the perceived effectiveness of the clerkship period and the actual learning outcomes of students (Dolmans et al., 2002; Wimmers et al., 2006). There is however a need for appropriate tools such as evaluation instruments and theoretical models to provide clinical teachers with useful feedback to aid them in creating an effective learning environment in the workplace. Therefore the aim of this dissertation is twofold:

1. To design and validate an instrument and theoretical model that can be used to provide feedback and guidance to clinical teachers on how they supervise students in clinical practice.

2. To investigate how clinical teachers evaluate the usefulness of the instrument and the theoretical model.

The focus of this dissertation is clinical teaching in the hospital setting during clerkship rotations. For the purpose of this dissertation clinical teaching is defined as teaching that occurs formally and informally in in-patient and out-patient settings of different clinical disciplines in the (clinical) workplace. The teachers are attending physicians and residents and the learners are medical students who have completed the preclinical curriculum. The aim of clinical teaching is to impart the knowledge, skills and attitudes that are deemed necessary for students to become good medical doctors (Table 2). 
Table 2: Clinical teaching during clerkships

\begin{tabular}{|c|c|c|c|}
\hline Context & $\begin{array}{l}\text { Teacher } \\
\text { (who teaches) }\end{array}$ & Student & Educational content \\
\hline Clinical workplace & Physicians & Medical students & Domain specific competencies \\
\hline $\begin{array}{l}\text { Hospital } \\
\text { In-patient (wards) }\end{array}$ & $\begin{array}{l}\text { - } \quad \text { Attending } \\
\text { physicians }\end{array}$ & Undergraduate & $\begin{array}{ll}- & \text { Clinical Knowledge } \\
\text { - } & \text { Clinical Skills }\end{array}$ \\
\hline Out-patient & - $\quad$ Residents & & Professional Attitudes \\
\hline
\end{tabular}

\section{OVERVIEW OF THE STUDIES AND RESEARCH QUESTIONS}

In order to achieve the research aims a total of five studies were conducted, which will be described briefly to provide an outline of the dissertation (Figure 1). Designing and validating an instrument and model to inform good clinical teaching Chapters 2 to 4 address the first research aim. They describe the design and validation process of an instrument and a model that can inform good clinical teaching practices. In Chapter $\mathbf{2}$ the potential of cognitive apprenticeship as a theoretical framework for clinical teaching is explored. Focus group interviews with senior medical students are conducted to explore the following questions: 'Do senior medical students experience the teaching methods of cognitive apprenticeship during their clinical training?', 'How do they describe the use of the cognitive apprenticeship teaching methods and which problems and suggestions do they mention with regard to the teaching methods?'.

Chapter 3 builds on the findings of Chapter 2 and uses the principles of cognitive apprenticeship as the starting point for designing a student questionnaire as a source of feedback on teaching skills for clinical teachers. The principal question that is addressed is how do three groups of stakeholders rate the relevance and wording of an instrument developed to be used by students to evaluate individual doctors' clinical teaching? As part of the design process and to further establish the instrument's content validity, three groups of stakeholders (doctors, educationalists and students) are asked to rate the relevance of the items of the questionnaire on a five-point scale ( $1=$ highly irrelevant, 5 =highly relevant). The stakeholders also comment on content, wording and omission of items. The construct validity and reliability of the questionnaire and a potential causal model of the underlying factors are investigated in Chapter 4. The questionnaire (as described in Chapter 3) is piloted in two teaching hospitals and confirmatory factor analysis is performed to answer the question 'what is the construct validity of the instrument?' and 'how are the different factors underlying the instrument related to one another and to the overall teaching effectiveness score?'. Also, the generalizability coefficient and standard error of measurement are calculated to answer the question 'how many student ratings of one teacher are required for the ratings to be reliable?'. 


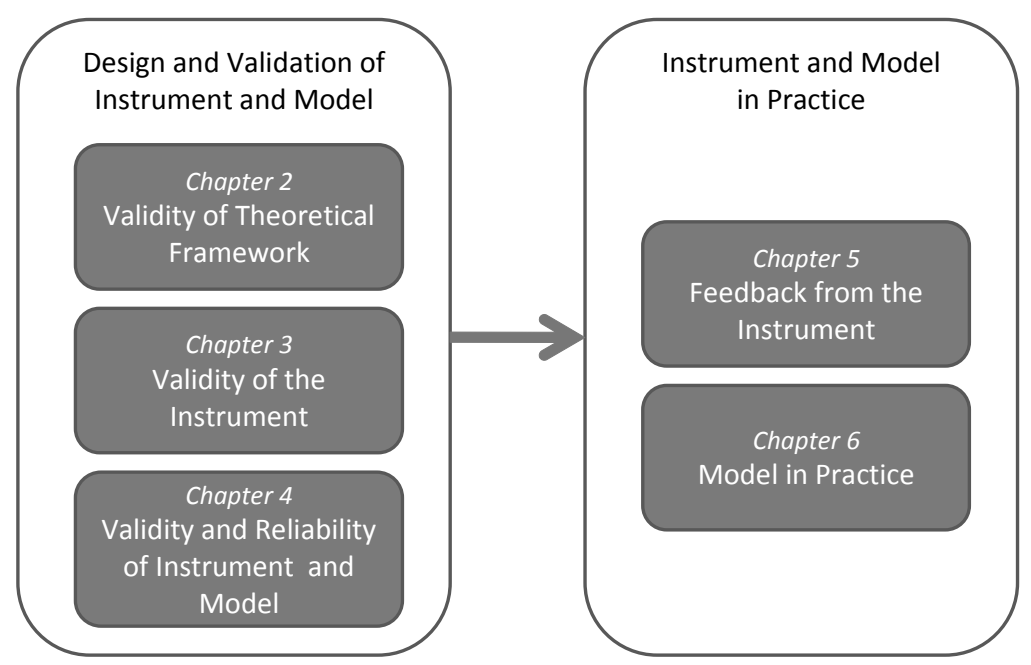

Figure 1: Overview of chapters and studies as presented in dissertation

\section{Investigating the usefulness of the instrument and model in practice}

The second aim of this dissertation is addressed in Chapters 5 and 6 where the usefulness of the questionnaire and a causal model for clinical teaching practice are discussed. The topic of interest in Chapter $\mathbf{5}$ is the usefulness of the questionnaire as a feedback instrument for attending physicians and residents. In order for written feedback to be effective (a physician decides to alter his/her behaviour based on the feedback), it should at least provide specific, descriptive and diagnostic feedback (Braskamp \& Ory, 1994). Furthermore, extensive reflection is considered indispensible for effectuating a change in behaviour in response to feedback (Richardson \& Placier, 2001). In Chapter 5, clinicians are first asked to self-assess their performance. Thereafter they receive written specific and diagnostic feedback in which their self-assessment scores are given together with student ratings in order to stimulate them to reflect on their teaching skills. The research question is: 'Is the combination of written feedback (student ratings) and self-assessment perceived as an incentive for changing clinical teaching behaviour?' The effectiveness of this approach is evaluated with a short questionnaire and semi-structured interviews with the clinicians involved.

While Chapter 5 focuses on the usefulness of the feedback instrument, Chapter 6 investigates the usefulness of the designed model for teaching practices. Through semi-structured interviews with experienced clinical teachers the following research questions are investigated: 'How does the model fit with the practice of experienced clinical teachers?' and 'Which factors influence the use of the model in clinical teaching practices in clerkships?'. From the perspective that clinical teaching does not take place in a vacuum and is influenced by many different factors (Hoff- 
man \& Donaldson, 2004), the interviews also explore the influence of factors related to the clinical teachers, the students and the environment with regard to the fit of the model to clinical teaching practices. In Chapter 7 the main findings of Chapters 2 to 6 are summarized and discussed. Finally, suggestions are presented for future research and clinical teaching practice.

Since Chapters 2 to 6 are published journal papers, repetitions and overlap across chapters were inevitable. 


\section{REFERENCES}

Beckman, T. J., Ghosh, A. K., Cook, D. A., Erwin, P. J., \& Mandrekar, J. N. (2004). How reliable are assessments of clinical teaching? A review of the published instruments. Journal of General Internal Medicine, 19(9), 971-977.

Beckman, T. J., Lee, M. C., Rohren, C. H., \& Pankratz, V. S. (2003). Evaluating an instrument for the peer review of inpatient teaching. Medical Teacher, 25(2), 131-135.

Boor, K., Scheele, F., Van der Vleuten, C. P. M., Teunissen, P. W., Den Breejen, E. M. E., \& Scherpbier, A. J. J. A. (2008). How undergraduate clinical learning climates differ: a multi-method case study. Medical Education, 42(10), 1029-1036.

Bowden, J., \& Marton, F. (1998). Quality and qualities. In J. Bowden \& F. Marton (Eds.), The university of learning (pp. 211-245). London: Kogan Page Limited.

Branch, W. T., \& Paranjape, A. (2002). Feedback and reflection: teaching methods for clinical settings. Academic Medicine, 77(12), 1185-1188.

Braskamp, L. A., \& Ory, J. C. (1994). Assessing faculty work: enhancing individual and institutional performance. San Francisco, CA: Jossey-Bass.

Buchel, T. L., \& Edwards, F. D. (2005). Characteristics of effective clinical teachers. Family Medicine, 37(1), 30-35.

Collins, A., Brown, J. S., \& Holum, A. (1991). Cognitive apprenticeship: making thinking visible. American Educator, 1-18.

Collins, A., Brown, J. S., \& Newman, S. E. (1989). Cognitive Apprenticeship: Teaching the crafts of reading, writing, and mathematics. In L. B. Resnick (Ed.), Knowing, learning, and instruction: Essays in honor of Robert Glaser (pp. 453-494). Hillsdale, New Jersey: Lawrence Erlbaum Associates, Inc.

Cottrell, D., Killminster, S., Jolly, B., \& Grant, J. (2002). What is effective supervision and how does it happen? A critical incident study. Medical Education, 36(11), 1042-1049.

Crossley, J. (2006). Do the supervision needs of 'clerkship students' change as they become more experienced? Medical Education, 40(10), 1053.

Dent, J. A. (2005). AMEE Guide No 26: Clinical teaching in ambulatory care settings: making the most of learning opportunities with outpatients. Medical Teacher, 27(4), 302-315.

Diemers, A. D., Dolmans, D. H. J. M., Verwijnen, M. G. M., Heineman, E., \& Scherpbier, A. J. J. A. (2008). Students' opinions about the effects of preclinical patient contacts on their learning. Advances in Health Sciences Education: Theory and Practice, 13(5), 633-647.

Dolmans, D. H. J. M., Wolfhagen, H. A. P., Gerver, W. J., Grave de, W., \& Scherpbier, A. J. J. A. (2004). Providing physicians with feedback on how they supervise students during patient contacts. Medical Teacher, 26(5), 409-414.

Dolmans, D. H. J. M., Wolfhagen, I. H. A. P., Essed, G. G. M., Scherpbier, A. J. J. A., \& Vleuten, v. d., C.P.M. (2002). The impacts of supervision, patient mix, and numbers of students on the effectiveness of clinical rotations. Academic Medicine, 77(4), 332-335.

Dornan, T., Boshuizen, H., King, N., \& Scherpbier, A. (2007). Experience-based learning: a model linking the processes and outcomes of medical students' workplace learning. Medical Education, 41(1), 8491.

Elzubeir, M. A., \& Rizk, D. E. E. (2001). Identifying characteristics that students, interns and residents look for in their role models. Medical Education, 35(3), 272-277.

Eraut, M. (2004). Informal learning in the workplace. Studies in Continuing Education, 26(2), 247-273.

Eva, K. W. (2005). What every teacher needs to know about clinical reasoning. Medical Education, 1(39), 98-106.

Fluit, C. R., Bolhuis, S., Grol, R., Laan, R., \& Wensing, M. (2010). Assessing the quality of clinical teachers: a systematic review of content and quality of questionnaires for assessing clinical teachers. Journal of General Internal Medicine, 25(12), 1337-1345. 
Gordon, J., Hazlett, C., Ten Cate, O., Mann, K., Kilminster, S., Prince, K., et al. (2000). Strategic planning in medical education: enhancing the learning environment for students in clinical settings. Medical Education, 34(10), 841-850.

Grant, J., Kilminster, S., Jolly, B., \& Cottrell, D. (2006). Clinical supervision of SpRs: where does it happen, when does it happen and is it effective? Medical Education, 37(2), 140-148.

Harden, R. M., \& Crosby, J. (2000). AMEE Guide No 20: The good teacher is more than a lecturer - twelve roles of the teacher. Medical Teacher, 22(4), 334-347.

Hoffman, K. G., \& Donaldson, J. F. (2004). Contextual tensions of the clinical environment and their influence on teaching and learning. Medical Education, 38(4), 448-454.

Irby, D. M. (1994). What clinical teachers in medicine need to know. Academic Medicine, 69(4), 333-342.

Irby, D. M. (1995). Teaching and learning in ambulatory care settings: a thematic review of the literature. Academic Medicine, 70(10), 898-931.

Irby, D. M., \& Bowen, J. L. (2004). Time-efficient strategies for learning and performance. The Clinical Teacher, 1(1), 23-28.

Kaufman, D. M., \& Mann, K. V. (2010). Teaching and learning in medical education: how theory can inform practice. In T. Swanswick (Ed.), Understanding medical education: evidence, theory and practice. Oxford, UK: Wiley-Blackwell.

Kilminster, S. M., \& Jolly, B. C. (2000). Effective supervision in clinical practice settings: a literature review. Medical Education, 34(10), 827-840.

Litzelman, D. K., Stratos, G. A., Marriott, D. J., \& Skeff, K. M. (1998). Factorial validation of a widely disseminated educational framework for evaluating clinical teachers. Academic Medicine, 73(6), 688695.

McLean, M., Cilliers, F., \& Van Wyk, J. M. (2008). Faculty development: yesterday, today and tomorrow. Medical Teacher, 30(6), 555-584.

Neher, J. O., Owen, A. C., McArdle, P. J., \& Duffy, K. A. (1992). A five-step "microskills" model of clinical teaching. Journal of the American Board for Family Practice, 5(4), 419-424.

Ramani, S., \& Leinster, S. (2008). AMEE Guide no. 34: Teaching in the clinical environment. Medical Teacher, 30(4), 347-364.

Richardson, V., \& Placier, P. (2001). Teacher Change. In V. Richardson (Ed.), Handbook of research on teaching. Washington: American Educational Research Association.

Rolfe, I. E., \& Sanson-Fisher, R. W. (2002). Translating learning principles into practice: a new strategy for learning clinical skills. Medical Education, 36(4), 345-352.

Schmidt, H. G., Norman, G. R., \& Boshuizen, H. P. (1990). A cognitive perspective on medical expertise: theory and implication. Academic Medicine, 65(10), 611-621.

Slawson, D. C., \& Shaughnessy, A. F. (2005). Teaching evidence-based medicine: should we be teaching information management instead? Academic Medicine, 80(7), 685-689.

Snell, L., Tallett, S., Haist, S., Hays, R., Norcini, J., Prince, K., et al. (2000). A review of the evaluation of clinical teaching: new perspectives and challenges. Medical Education, 34(10), 862-870.

Spencer, J. (2003). Learning and teaching in the clinical environment. ABC of learning and teaching in medicine. British Medical Journal, 326, 591-594.

Taylor, T. K., \& Care, W. D. (1999). Nursing education as cognitive apprenticeship: A framework for clinical education. Nurse Education, 24(4), 31-36.

Ullian, J. A., Bland, C. J., \& Simpson, D. E. (1994). An alternative approach to defining the role of the clinical teacher. Academic Medicine, 69(10), 832-838.

Wimmers, P. F., Schmidt, H. G., \& Splinter, T. A. W. (2006). Influence of clerkship experiences on clinical competence. Medical Education, 40, 450-458. 


\section{Chapter 2}

\section{Cognitive apprenticeship in clinical practice: Can it stimulate learning in the opinion of students?}

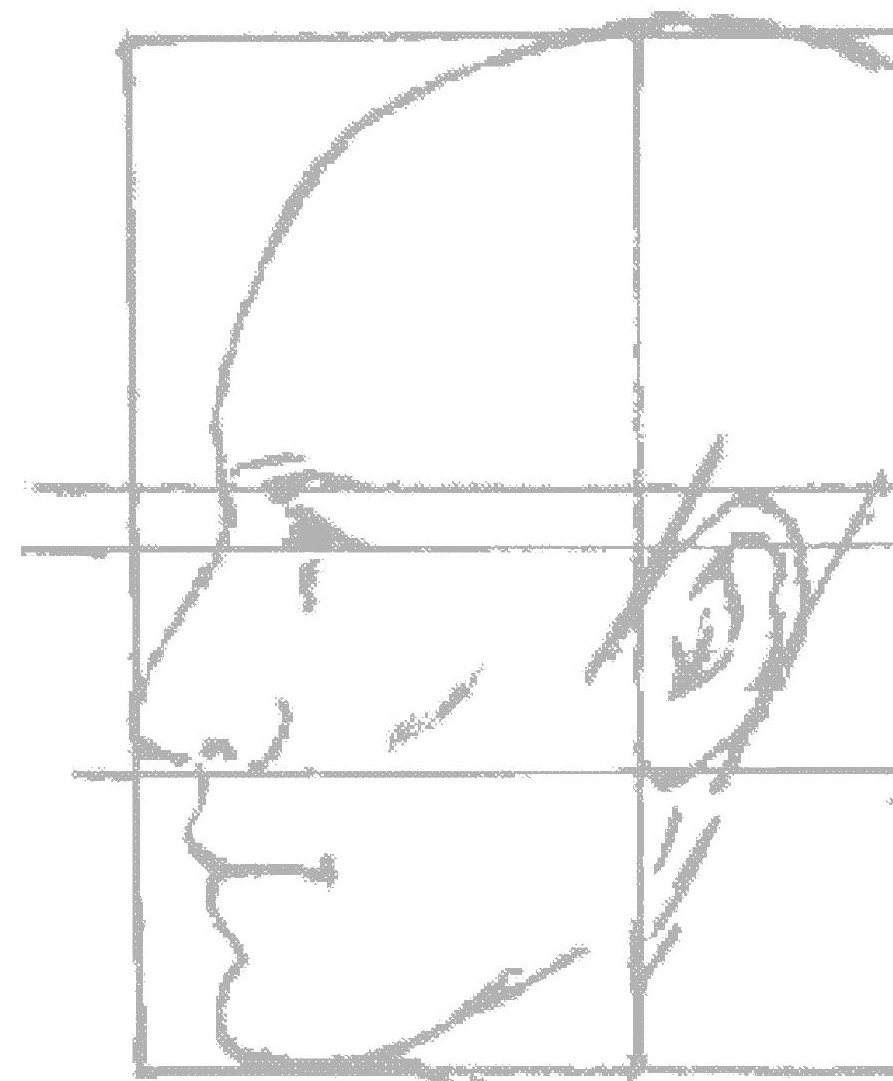




\section{ABSTRACT}

\section{Context}

Learning in clinical practice can be characterised as situated learning because students learn by performing tasks and solving problems in an environment that reflects the multiple ways in which their knowledge will be put to use in their future professional practice. Collins et al. introduced cognitive apprenticeship as an instructional model for situated learning comprising six teaching methods to support learning: modelling, coaching, scaffolding, articulation, reflection and exploration. Another factor that is looked upon as conducive to learning in clinical practice is a positive learning climate. We explored students' experiences regarding the learning climate and whether the cognitive apprenticeship model fits students' experiences during clinical training.

\section{Method}

In focus group interviews, three groups of $6^{\text {th }}$ Year medical students $(N=21)$ discussed vignettes representing the six teaching methods and the learning climate to explore the perceived occurrence of the teaching methods, related problems and possibilities for improvement.

\section{Results}

The students had experienced all six teaching methods during their clerkships. Modelling, coaching, and articulation were predominant, while scaffolding, reflection, and exploration were mainly experienced during longer clerkships and with one clinical teacher. The main problem was variability in usage of the methods, which was attributed to teachers' lack of time and formal training. The students proposed several ways to improve the application of the teaching methods.

\section{Conclusion/Discussion}

The results suggest that the cognitive apprenticeship model is a useful model for teaching strategies in undergraduate clinical training and a valuable basis for evaluation, feedback, self-assessment and faculty development of clinical teachers. 


\section{INTRODUCTION}

During the clinical years of the medical curriculum students learn and work in an authentic environment where they apply their knowledge to real problems in the context of professional practice (Spencer, 2003). The authenticity of the clinical setting and active participation in professional practice are strong motivators for students' learning (Spencer, 2003). Learning in a professional environment also helps students to understand the purposes and uses of their (new) knowledge (Collins, Brown, \& Newman, 1989). This type of learning can be defined as situated learning (Lave \& Wenger, 1991) because it is characterised by the important role of the (social) setting in which students learn to apply their knowledge. It is claimed that situated learning results in highly meaningful situated cognition and thereby enhances transfer of knowledge to new situations (Brown, Collins, \& Duguid, 1989). Because of the linkage to meaningful practice situations, situated cognition is more powerful than decontextualised knowledge, which, like the theoretical knowledge students acquire during the preclinical phase, is often represented in abstract structures and therefore difficult to translate to concrete situations (Orey \& Nelson, 1994).

Research indicates that effective learning in medical practice, for instance during clerkships, relies strongly on good clinical supervision (Dolmans, Wolfhagen, Essed, Scherpbier, \& Van der Vleuten, 2002; Dornan, 2006). The traditional model of learning in practice settings has been that of apprenticeship learning where students start by observing clinical practitioners and are gradually given more tasks to perform as their competence grows. A drawback of this model is that learning is driven by the day-to-day demands of the workplace where learning opportunities and supervision do not have first priority (Collins et al., 1989; Dornan, 2006; Taylor \& Care, 1999). The changing health care environment and developing insights into learning and teaching in clinical practice warrant new models and methods to provide the optimal learning experience for student during their clerkships (Dornan, 2006). In general, models for (clinical) teaching should be sufficiently specific to guide clinicians in their role as a clinical teacher (Graffam, Bowers, \& Keene, 2008).

The teaching methods described by Collins and colleagues in the 'cognitive apprenticeship model' (Collins et al., 1989) are highly specific and designed to foster situated learning and thus can be assumed to enhance learning in clinical practice. Within the cognitive apprenticeship model there is a pivotal role for the cognitive processes of experts during complex task performance. Making explicit the generally tacit cognitive processes of experts (Sternberg \& Horvath, 1999) can elucidate complex task performance and help students in observing, enacting and practising such tasks. Especially in highly cognitive professions, such as medicine, students can benefit from insight into the cognitive processes underlying expert performance; it can make it easier for them to reproduce certain procedures on their own (Taylor \& 
Care, 1999). Collins et al. (1989) proposed six teaching methods promoting situated learning by helping students to acquire both cognitive and meta-cognitive skills and focus their observation of expert performance in practice so as to facilitate the development of their own problem-solving skills. Additionally, these methods foster the autonomy of students' learning processes by encouraging students to formulate personal learning goals. In this study we will explore the use of the six teaching methods (modelling, coaching, scaffolding, articulation, reflection, and exploration) of the cognitive apprenticeship model as well as the role of the learning climate. We do so by examining the students' perspective, because based on their first-hand experience of clinical teaching, students as 'consumers' of medical education are uniquely able to provide insights into the effectiveness of these methods in promoting good teaching.

Modelling is embodied by teachers who actively demonstrate and explain skills and procedures to their students. Coaching refers to teachers observing students and providing specific and concrete feedback on their performance. Scaffolding emphasises that support from teachers for students' learning must be tailored to students' individual knowledge levels. As students become more competent support can be gradually reduced and finally withdrawn (fading). Articulation involves teachers questioning students and stimulating them to ask questions. Reflection involves ways of stimulating students to deliberately consider their strengths and weaknesses. Exploration is aimed at encouraging students to formulate and pursue personal learning goals.

As for the learning climate, research has pointed to beneficial effects of a positive learning climate, which clinical teachers can foster by showing an interest in students' learning and making students feel respected (Beckman, Lee, Rohren, \& Pankratz, 2003; Kilminster \& Jolly, 2000; Litzelman, Stratos, Marriott, \& Skeff, 1998).

In summary, we hypothesise that the methods of the cognitive apprenticeship model together with the learning climate constitute a comprehensive theoretical framework for good clinical teaching practices. In the current study we examine whether theory fits practice or, to put it differently, whether students recognise and value the teaching methods of the cognitive apprenticeship model in their experiences of the practices of clinical teaching. In order to examine this, we sought to answer the following research questions:

- Do senior medical students experience these six cognitive apprenticeship methods and the learning climate during clinical training?

- How do senior medical students describe the use of the six cognitive apprenticeship teaching methods and the learning climate in practice during clinical training?

- Which problems do senior medical students perceive concerning the six methods of the cognitive apprenticeship model and the learning climate during clinical training? 
- Which steps do senior medical students suggest to improve the use of the six methods of the cognitive apprenticeship model and the learning climate during clinical training?

\section{METHOD}

\section{Context}

The setting of this study is the six-year undergraduate curriculum of Maastricht Medical School, the Netherlands. During the first two years, students learn basic science knowledge, clinical science knowledge and skills in a problem-based learning environment. Students' first clinical experiences are contacts with real patients in student out-patient clinics which are used as the starting point for their learning in the tutorial groups in Year 3. Years 4 and 5 are devoted to a programme of clerkships in different disciplines in the academic hospital and in affiliated regional hospitals. Rotations differ in duration according to discipline and the sequence of rotations differs between students. Year 6 is divided into two eighteen-week attachments: one to a hospital ward and one to participation in a research project. During clinical training students are supervised by clinical teachers (specialists and postgraduate specialist trainees) using the mini-CEX (Epstein, 2007) in frequent observations of students' performance. Students create a portfolio aimed at the development of reflective skills, which they discuss periodically with their mentor.

\section{Participants}

In the academic year 2006-2007, we invited all students $(\mathrm{N}=344)$ in Year 6 to participate in our study, assuming that more than three years of clinical training create a solid experiential basis for students to engage in in-depth discussion about their clinical training. Via an email all 344 students were invited to participate in focus groups. Selection was based on (near) completion of year 6 and availability for at least two two-hour sessions. The students were asked to sign up for one of three combinations of two dates and times. A small fee was paid for each hour of participation.

Of the total of 24 respondents, 2 students were eventually unable to participate for personal reasons and 1 student only attended the first session. We composed three groups in accordance with students' preferred date-time options. The female to male ratios of the groups were 4:3 (Group A), 6:2 (Group B), and 5:2 (Group C), which is comparable to the overall 60:40 ratio in the Dutch Medical Schools. The mean age of the participants was 23 years, which corresponds to the mean age of Dutch medical students in the last year of the undergraduate medical curriculum. 
The participating students' results on knowledge tests did not differ significantly from those of the other students in the same cohort. All sessions started at 7 p.m. after students had finished in the hospital.

\section{Focus groups}

We used focus groups to explore students' perceptions and ideas about the use of cognitive apprenticeship methods, because we expected them to yield more varied results than individual interviews would (Barbour, 2005). For the six teaching methods described by Collins et al. (1989) and for learning climate we designed vignettes to give the students a clear idea of the themes to be discussed. The vignettes served as the starting point for the group interview and the moderator encouraged the students to tell illustrative anecdotes, discuss problems and offer suggestions for improvement.

With an interval of 1 or 2 weeks the groups met twice for about two hours. At the start of the first session the moderators assured the students that confidentiality was guaranteed. Moderator I (AJJAS) acted as facilitator of the discussions while Moderator II (RES) wrote a summary of what was said and by whom. The sessions were audio taped and transcribed literally. The students received a summary of each session and were invited to offer corrections and comments. Based on this some minor adjustments were made and in the second session more attention was paid to the way in which the teaching methods were used. Because no new topics with regard to the research questions were emerging at the end of the second session, it was decided that saturation had been reached and no further sessions were scheduled.

\section{Analysis}

All group sessions were audio taped and transcribed literally by two studentassistants. The principal investigator (RES) read all the transcripts and wrote a preliminary, descriptive summary of the findings answering the research questions for each teaching method/vignette and learning climate. Next, two independent researchers (DHJMD and IHAPW) read the transcripts and independently wrote a summary for one teaching method. The two researchers and RES then discussed, compared and modified the summaries until consensus was reached on the final version. Finally, RES completed the summaries for the other teaching methods and the learning climate. For respondent validation (Barbour, 2005) all participants were asked to comment on the preliminary findings. Of the 21 participants, 14 responded (67\%), 6 each from groups A and B and 2 from group C. Their comments led to minor modifications and all the respondents stated that the findings accurately reflected the focus group sessions. 


\section{RESULTS}

The students said they had encountered all of the six teaching methods during clinical training and cited both positive and negative examples. Differences between students' experiences are mostly related to individual teachers, hospitals, disciplines and students (pro-active or not, amount of experience).

We present the results for each of the six teaching methods and for learning climate separately. Starting with the vignette in question we present descriptive summaries of students' experiences with the method, their descriptions of the method in action, problems with the method and suggestions for improvement. We illustrate these by quotations from the interviews. A letter number combination identifies the quotations by focus group and student.

\section{Modelling}

\section{Vignette}

The clinical teacher demonstrated different skills. During or after the demonstration the teacher explained the task identifying aspects that are important for task performance. The teacher created opportunities for me to observe him/her. The teacher gave me ideas about how I wanted or did not want to function when working as a doctor in the future.

Students said that looking back on their clinical training they could think of several instances of modelling, especially when new topics or technical skills were introduced. They noted that they could still remember why and how a certain procedure was performed when a teacher had explained it to them very clearly. The main perception of students about role modelling was that they continuously observed clinicians and considered whether they wanted to be like them or not. Students expressed a high regard for teachers who explained and demonstrated things repeatedly and actively involved students in modelling by thinking aloud and by explaining why they performed certain actions.

\footnotetext{
"Yes, well with neurology in Heerlen, I did not particularly like that rotation, but what I did like very much was that the first few days, I think it was the second day when I was shadowing the house officer and she extensively demonstrated the full neurological examination from head to toe. And after that it was like just do it yourself, but that one time, demonstrating it. For of course it is an extensive examination, like what was it like in reality, I really like that. It was only once, but it was really good that they did it just to see how to do it systematically." (B8)
} 
Modelling was not a regular occurrence, however, and students were not always actively engaged in the process. Often clinicians did not take enough time to model activities in a sufficiently explicit manner. Teachers frequently left it largely unexplained why certain actions were performed and certain questions asked. As a result students sometimes felt they were just imitating what they had seen a doctor do during physical examination but did not have a clue as to what they were doing or why they were doing it.

"That you just do what you have seen them doing, and that is often just a poor example of how it is supposed to be done. And that you, just because they do it that way, that you do it that way too ... But actually that is not how it is supposed to be done." (C5)

Students suggested that modelling would be greatly enhanced when teachers would explain the rationale and method of their actions. Most of the time the students just watched procedures being performed without any active involvement on their part.

\section{Coaching}

\section{Vignette}

The clinical teacher observed me on several occasions during my rotation in his/her department. After observing me the teacher gave me feedback, which gave me a better idea of which aspects I could improve and how.

For the students, coaching was mainly associated with being observed during assessments, especially when presenting a patient history. Although the students indicated that they did not always like being observed, there was general appreciation of observation when it was followed by suggestions as to what and how they could do better. Students with more experience in clinical practice were more confident and found it easier to ask for observation and feedback.

"Yes, you really learn from it [being observed], I don't really like it, but you do learn a lot when a person gives you decent feedback afterwards, like hey look, in that part it would have been better if you had done it that way." (B3)

Time constraints played a part and, despite their lack of enthusiasm for being observed, students felt more observation was possible. Students also reported that observation was mostly limited to parts of activities, such as reporting after performing a history and physical examination.

Students said they wanted a stronger emphasis on feedback rather than assessment because the latter offered few concrete directions for improvement. According to 
the students, the assessment checklists were not helpful in providing specific feedback, because the clinicians were only required to check boxes before giving a final judgement.

The students expected that matters would improve when they were assigned to one personal supervisor who could observe them more frequently. Feedback training for clinical teachers was also expected to be helpful. The students asked for more specific feedback in addition to global ratings.

\section{Scaffolding}

\section{Vignette}

The clinical teacher was aware of my previous experience and offered sufficient opportunity for independent activities. The teacher also helped when activities were difficult for me. The teacher gradually reduced support for certain activities so that I could become more independent.

Scaffolding was mainly experienced by the students during longer rotations - for example the ten-week family medicine clerkship - where they had repeated one-onone contact with one supervisor. Some students said they had experienced it during shorter rotations too but this depended on individual supervisors and hospitals' specific approach to students.

Scaffolding motivated students and they appreciated it when supervisors showed an interest in and took account of their level of skills and knowledge.

"I think it mostly occurs during the longer rotations. That at first you are told 'come along and observe in the outpatient clinic, in the operating theatre or an emergency patient or whatever' and after the first two weeks, you were told like 'well, now you have some idea of what to do, come on. '" (B6)

The shorter the rotation, the less likely they were to experience scaffolding according to the students. Because they were always shadowing different people, the students felt that none of the supervisors had a good idea of their knowledge and skills. One student argued that it would be unrealistic for them to expect the teachers to really know their level of knowledge and skill because a teacher would have to be virtually omniscient and omnipresent to manage that.

"It sort of suggests that teachers are like Father Christmas or God, who knows all along whether you can do something or not and who is not just watching you all of the time, but also helps you when things are difficult and otherwise allows you to manage on your own. And well, I think that is very difficult to achieve." (C4) 
Students say they would like to feel that it was safe for them to inform their supervisors of their level of competence so that supervisors can act accordingly. They suggested that things could improve greatly, if teachers would ask them in which year they were and which rotations they had completed. Students also said they liked the concept of 'constructive friction'. In other words they liked to be challenged to make an effort to move to the next level.

"It would actually be quite good if in a manner of speaking you were literally asked at the start "just tell me honestly what you know and don't know, it won't be held against you' but that someone just knows the gaps in your knowledge so that you can do something about it." (A5)

\section{Articulation}

\section{Vignette}

The clinical teachers asked me to explain my actions and helped me become aware of gaps in my knowledge and skills. The teacher questioned me regularly to increase my understanding and encouraged me to ask questions.

The students said they had experienced aspects of articulation throughout the clinical years. Whenever it occurred it deepened their knowledge and experience and enhanced their memory. Articulation did not depend on the amount of time spent with supervisors and occurred right from the start of clerkships.

"(...) That doctor had really made it an art to start with a simple question making you feel like o.k. I know a lot of basic knowledge and then at a certain point start firing challenging questions at you about things you didn't know yet, first brainstorm about that with you and then ask you to take the remaining issues home with you and follow up on them the next day. Yes, well, er that is really an art you would want to cultivate." (C2)

Articulation was not always effective and students noted that occasionally it focused on highly specialised knowledge on a supervisor's pet topic. An experience shared by all students was that supervisors after telling them to 'look it up' rarely followed up on that. This was qualified as frustrating. Students sometimes felt that telling them to 'look it up' was a good way for teachers to be rid of them. Nevertheless, it was also clear that some supervisors were very good at asking probing questions to stimulate students to learn whereas other teachers tended to use articulation primarily to expose gaps in students' knowledge.

Another point made by the students was that they gradually developed a pro-active attitude towards articulation as their confidence and knowledge grew or they felt safer with a supervisor or in a specific learning environment. Nevertheless, it was 
sometimes difficult for them to ask the 'right' questions because of lack of knowledge in a specific domain.

"Also what they ask you to look up. Of course it is easy for a doctor to find lots of gaps in students' knowledge. And then they ask about very specific details, but what is the point for a student to look that up only to find that you will never use it anyway." (A5)

"Yes, but sometimes you just don't know what to ask. For then, for instance when you do not recognise things, you just don't [ask about them]." (C5)

It was the students' final conclusion that articulation should be applied more often because it stimulated learning and that teachers who told them to 'go and look it up' should follow up on this and discuss it with them afterwards.

\section{Reflection}

\section{Vignette}

The clinical teacher encouraged me to become aware of my strengths and weaknesses and to consider what I could do to improve things.

For the students, reflection was mainly associated with the reflective portfolio and their portfolio mentor rather than with their clinical training. During clerkships reflection was generally limited to a few scattered incidents on longer rotations, to one-on-one contacts with supervisors and to contacts with a few supervisors who were interested in reflection. Some of the supervisors who tried to encourage reflection focused exclusively on strengths and weaknesses but failed to give directions for improvement.

The supervisors who engaged in reflective activities were typically those with whom the students had contact for a longer time or who could be characterised as having a proactive approach to education. Students recognised the value of (self)reflection, which in their opinion was stimulated by multi-source feedback, by video-tapes of their performance as a starting point of discussions, and by a favourable climate in the department. According to the students what they appreciated most in reflection was supervisors suggesting ways in which they could address their strengths and weaknesses. 


\section{Exploration}

\section{Vignette}

The clinical teacher encouraged me to formulate learning objectives and pursue them. The teacher challenged me to keep learning new things.

Exploration was experienced infrequently by students and only during longer rotations and only with some supervisors. Students were told to 'go and look things up' more often than they were asked to formulate personal learning goals. Moreover, the students felt they did not have time for personal learning goals because they were too busy with other assignments. There were supervisors who thought learning objectives should be the same for all students, leaving no room for personal learning goals. Other supervisors said they 'did not believe in learning goals'. On the whole, most students perceived exploration as a component of their portfolio or associated it with a particular form for analysing patient cases.

In the few instances where attention was paid to learning goals, the students experienced it as highly simulating and said it helped them focus their learning process. The students also said that documented personal learning goals could be useful in impelling supervisors to provide more meaningful learning experiences.

"Well, in the outpatient clinic it was o.k. when you were sitting there or had actually done things, that was much better of course. But that when you were finished you would talk about the patients who had been seen and why not this and why not that. And that afterwards you would say, hey I don't know this I'll look it up. Or that she sometimes said like that is a really good question, but look it up for yourself first and then we will talk about it tomorrow for that way you will learn more than when I just give you the answer right now." (B6)

As a way of promoting exploration, students suggested teachers should pay more attention to and help them formulate individual learning objectives and opportunities to pursue them.

\section{General Learning Climate}

\section{Vignette}

The clinical teacher created a safe learning environment and took enough time to coach me. The teacher was interested in me as a student and treated me with respect. 
The general learning climate was recognised as an aspect that was always present either in a positive or in a negative way. Students said the general learning climate largely determined to what extent they felt free, for example to ask questions. According to the students, supervisors who created a good learning climate made them feel that they were treated as equals and that the supervisor was genuinely interested in their learning. Feeling respected by their teachers was considered of crucial importance by the students. Additionally, several students said that students could also influence the learning climate by being positive and enthusiastic.

"I mean in my experience there were occasions when I felt more like an equal... . That house officers come up to you like 'hey a new student' and shake hands 'I am ... 'That makes you feel much better (...) then I immediately feel that it is safe to ask questions. . that is much easier than when everybody just waits until you approach them." (B3)

"It is also good ... when there is someone, er someone whose task it is to guide you who says 'when there is a problem, if things aren't going smoothly, just come and see me, it can be quite anonymous" (C1); "A safety net" (C4); "Yes, some sort of safety net, That you can be sure in any case that when you have a confrontation with one of your bosses, that in any case there is someone to whom you can go and talk about it." (C1)

Whenever students felt the learning climate was negative, they did not feel free to ask questions and it hindered their learning. Students also described the learning climate as a delicate balance which was easily disturbed. For instance, when you did something wrong in the eyes of a supervisor, a good learning climate could easily turn into an unpleasant one. Frequently, supervisors showed no interest in students at all, which made students systematically avoid those supervisors.

"As for respect it has happened that I politely asked the ward doctor in the morning 'can I come with you today?' 'Well, is that really necessary? Oh well all right then.' Well then you are following them the whole day with a look on your face like he does not want me along ... Then you don't feel comfortable and you do not feel that you are treated with respect." (B8)

Supervisors being more respectful to students and showing a genuine interest in their presence and learning activities would go a long way towards optimising the general learning climate. 


\section{DISCUSSION \& CONCLUSIONS}

Based on the premise that clinical teaching can be improved when it is supported by a model of clinical teaching that is specific enough to offer practical guidance to clinical teachers, we explored the applicability of the cognitive apprenticeship model to undergraduate clinical training (Brown et al., 1989; Collins et al., 1989). In focus group interviews, we elicited the opinions of senior medical students about the occurrence of the methods during their clerkships, how they valued the methods and how their use might be improved. The views of the students appear to support the applicability of the cognitive apprenticeship model to undergraduate clinical training. The students recognised and narrated experiences with all of the methods, although modelling, coaching and articulation predominated, while scaffolding, reflection and exploration were mostly reported to occur during longer attachments and in contacts with personal mentors. Our additional investigation of the impact of the learning climate on clinical teaching revealed its importance to students, confirming the results of previous studies demonstrating its strong impact on the learning process of students (Kilminster \& Jolly, 2000; Litzelman et al., 1998).

Apart from support for the applicability of the methods of the cognitive apprenticeship model from the point of view of the students, our study revealed insights into problems relating to the methods and ways to resolve them. The main problem reported by the students was the variability in the use of the teaching methods, which they regretted and attributed to clinical teachers not taking enough time for teaching or to lack of teaching skills. This is confirmed by reports from other studies about the negative impact of time constraints and lack of formal teacher training (Cottrell, Killminster, Jolly, \& Grant, 2002; Spencer, 2003). Interestingly, and in line with Dornan's (2006) description of the importance of proactive behaviour of students for learning in a clinical setting, the suggestion was made that students might stimulate the use of certain teaching methods by their own proactive behaviour. Another interesting observation by students is that some teaching methods may require prolonged engagement in one discipline and/or with one individual teacher, which is supported by findings from research into a longitudinal clerkship programme showing that students highly appreciated being attached to one individual teacher and that it helped them to reach a deeper level of engagement (Mihalynuk, Bates, Page, \& Fraser, 2008).

Very practical suggestions for improving clinical teaching made by the students relate to scaffolding, modelling and coaching. In order to remedy a problem that hampers scaffolding, namely teachers being insufficiently informed of students' knowledge and skill levels to gear their teaching to students' needs, the students proposed that teachers should be encouraged to ask them in which year they were and which rotations they had completed. A proposal intended to enhance modelling was for clinicians to pay more attention to explaining to students why and how they 
performed certain procedures. An important recommendation aimed at improving coaching concerned ways, including teacher training, to promote constructive and individual feedback.

A limitation of this study is that our study population consisted of volunteers. Although they resemble their peers in gender, age and test results, it cannot be ruled out that this was a group of students with a stronger than usual interest in education compared to their peers. Another limitation is that we only explored the perceptions of students and not those of other stakeholders in clinical education such as the clinical teachers. Obviously, exploration of the teachers' opinions regarding the usefulness of the cognitive apprenticeship model would widen the scope of our insight.

As we stated earlier, the cognitive apprenticeship model combined with learning climate covers aspects of clinical teaching that resonate with students' experiences and offer leads to improve teaching. Although further research is needed to establish the usefulness of the model, we believe that it is safe to say that the model shows promise as an instrument for studies focusing on evaluation, feedback, self-assessment and faculty development in clinical teaching.

\section{Acknowledgements}

The authors would like to thank all students who participated in the focus group research and provided their feedback on the results. They also wish to thank Mereke Gorsira for editing the final version. 


\section{REFERENCES}

Barbour, R. S. (2005). Making sense of focus groups. Medical Education, 39(7), 742-750.

Beckman, T. J., Lee, M. C., Rohren, C. H., \& Pankratz, V. S. (2003). Evaluating an instrument for the peer review of inpatient teaching. Medical Teacher, 25(2), 131-135.

Brown, J. S., Collins, A., \& Duguid, P. (1989). Situated cognition and the culture of learning. Educational Researcher, 18(1), 32-42.

Collins, A., Brown, J. S., \& Newman, S. E. (1989). Cognitive Apprenticeship: Teaching the crafts of reading, writing, and mathematics. In L. B. Resnick (Ed.), Knowing, learning, and instruction: Essays in honor of Robert Glaser (pp. 453-494). Hillsdale, New Jersey: Lawrence Erlbaum Associates, Inc.

Cottrell, D., Killminster, S., Jolly, B., \& Grant, J. (2002). What is effective supervision and how does it happen? A critical incident study. Medical Education, 36(11), 1042-1049.

Dolmans, D. H. J. M., Wolfhagen, H. A. P., Essed, G. G. M., Scherpbier, A. J. J. A., \& Van der Vleuten, C. P. M. (2002). Students' perceptions of relationships between some educational variables in the outpatient setting. Medical Education, 36(8), 735-741.

Dornan, T. (2006). Experience based learning. Learning clinical medicine in workplaces. [Dissertation]. Maastricht University, Maastricht.

Epstein, R. M. (2007). Assessment in medical education. New England Journal of Medicine, 356(4), 387396.

Graffam, B., Bowers, L., \& Keene, K. N. (2008). Using observations of clinicians' teaching practices to build a model of clinical instruction. Academic Medicine, 83(8), 768-774.

Kilminster, S. M., \& Jolly, B. C. (2000). Effective supervision in clinical practice settings: a literature review. Medical Education, 34(10), 827-840.

Lave, J., \& Wenger, E. (1991). Situated learning: legitimate peripheral carticipation. Cambridge: Cambridge University Press.

Litzelman, D. K., Stratos, G. A., Marriott, D. J., \& Skeff, K. M. (1998). Factorial validation of a widely disseminated educational framework for evaluating clinical teachers. Academic Medicine, 73(6), 688695.

Mihalynuk, T., Bates, J., Page, G., \& Fraser, J. (2008). Student learning experiences in a longitudinal clerkship programme. Medical Education, 42(7), 729-732.

Orey, M. A., \& Nelson, W. A. (1994). Situated learning and the limits of applying the results of these data to the theories of cognitive apprenticeships. Paper presented at the Proceedings of Selected Research and Development Presentations at the 1994 National Convention of the Association for Educational Communication and Technology Sponsored by the Research and Theory Division, Nashville, TN.

Spencer, J. (2003). Learning and teaching in the clinical environment. ABC of learning and teaching in medicine. British Medical Journal, 326, 591-594.

Sternberg, R. J., \& Horvath, J. A. (Eds.). (1999). Tacit knowledge in professional practice. Researcher and practitioner perspectives. Mahwah, New Jersey: Lawrence Erlbaum Associates Inc.

Taylor, T. K., \& Care, W. D. (1999). Nursing education as cognitive apprenticeship: A framework for clinical education. Nurse Education, 24(4), 31-36. 


\section{Chapter 3}

\section{The development of an instrument for evaluating clinical teachers: Involving stakeholders to determine content validity}

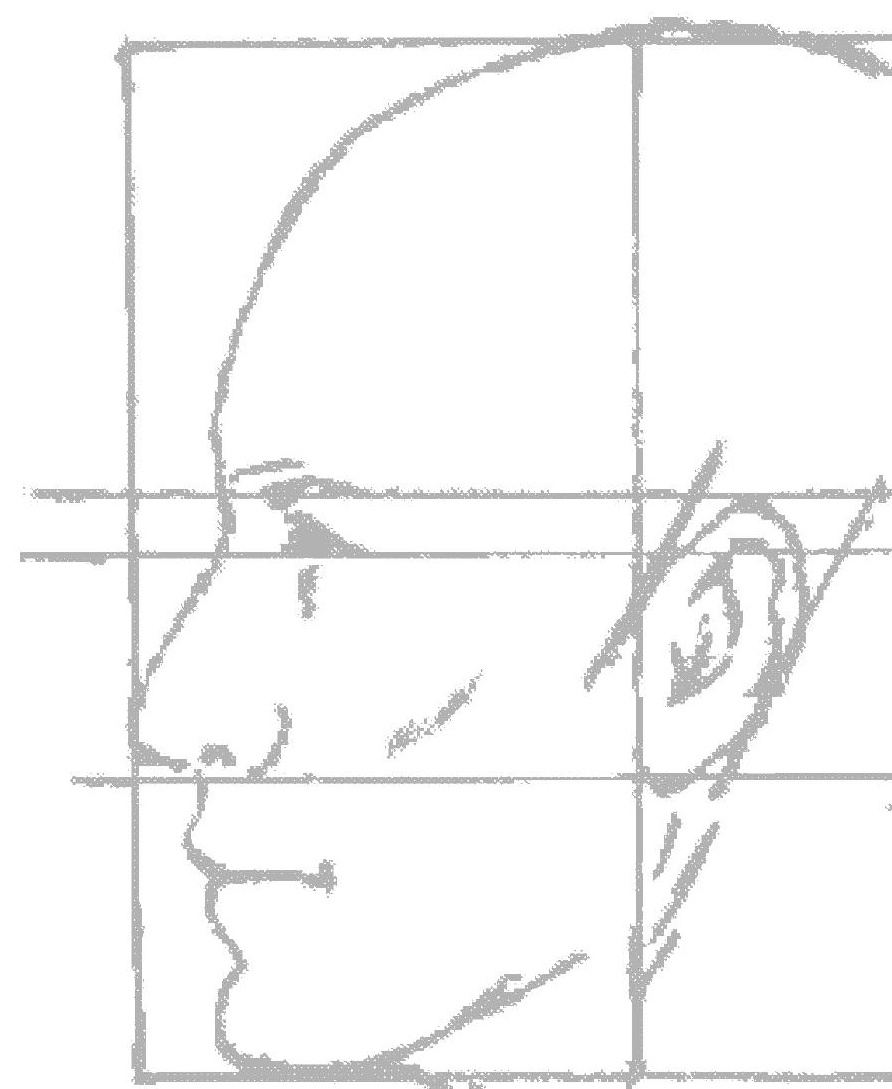

Stalmeijer, R.E., Dolmans, D.H.J.M., Wolfhagen, I.H.A.P., Muijtjens, A.M.M., \& Scherpbier, A.J.J.A. (2008). The development of an instrument for evaluating clinical teachers: Involving stakeholders to determine content validity. Medical Teacher, 30(8), e272-277. 


\section{ABSTRACT}

\section{Background}

Research indicates that the quality of supervision strongly influences the learning of medical students in clinical practice. Clinical teachers need feedback to improve their supervisory skills. The available instruments either lack a clear theoretical framework or are not suitable for providing feedback to individual teachers. We developed an evaluation instrument based on the 'cognitive apprenticeship model'.

\section{Aim}

The aim was to estimate the content validity of the developed instrument.

\section{Method}

Item relevance was rated on a five point scale $(1=$ highly irrelevant, $5=$ highly relevant) by three groups of stakeholders in undergraduate clinical teaching: educationalists $(N=12)$, doctors $(N=16)$, and students $(N=12)$. Additionally stakeholders commented on content, wording and omission of items.

\section{Results}

The items were generally rated as very relevant $(M=4.3, S D=.38$, response $=95 \%)$ and any differences between the stakeholder groups were small. The results led to elimination of 4 items, rewording of 13 items and addition of 1 item.

\section{Discussion}

The cognitive apprenticeship model appears to offer a useful framework for the development of an evaluation instrument aimed at providing feedback to individual clinical teachers on the quality of student supervision. Further studies in larger populations will have to establish the instrument's statistical validity and generalizability. 


\section{INTRODUCTION}

Students spend the final years of undergraduate medical education for the most part in clinical rotations in hospital settings, offering a potentially powerful learning environment because of its high authenticity and opportunities for active participation in clinical work and integrated learning of history taking, physical examination, clinical decision making, and professionalism (Spencer, 2003). However, the core activity of hospitals is patient care rather than clinical teaching. Time pressure, competing demands on staff from service, research, administration and teaching conspire to make the hospital a highly unstructured and complex learning environment (Spencer, 2003). This means that students' learning experiences are largely determined by day-to-day events in the workplace rather than by pedagogical considerations (Collins, Brown, \& Newman, 1989). Research has shown that good supervision is the key to successful learning in clinical practice (Dolmans, Wolfhagen, Essed, Scherpbier, \& Van der Vleuten, 2002). Supervision can be defined as "the provision of monitoring, guidance and feedback on matters of personal, professional, and educational development in the context of the doctor's care of patients"(Kilminster \& Jolly, 2000). The fact that supervision is a relatively infrequent occurrence in the clinical workplace (Grant, Kilminster, Jolly, \& Cottrell, 2006) can be explained by the above-mentioned time pressures and competing demands on doctors but also by most doctors' lack of formal training for their role as a clinical teacher (Cottrell, Killminster, Jolly, \& Grant, 2002).

Doctors need appropriate tools to aid them in selecting and developing effective ways of supervising students so as to create an effective learning environment. Appropriate evaluation of clinical teaching may guide doctors in this. Several instruments have been developed to evaluate clinical teachers' performance. In their 2004 review, Beckman and colleagues (Beckman, Ghosh, Cook, Erwin, \& Mandrekar, 2004) listed 21 articles describing instruments for providing feedback to doctors based on evaluations by undergraduate and graduate students. One of the most commonly used instruments was developed at Stanford University School of Medicine (Litzelman, Stratos, Marriott, \& Skeff, 1998) and contains categories based on educational and psychological theories of learning environments and empirical observations of clinical teaching. Although this is a validated instrument, its focus on different dimensions of teaching effectiveness in various settings, including small group sessions, makes it less suitable for specific feedback on individual supervision in the clinical setting. Another widely cited instrument, the Cleveland Clinic's Clinical Teaching Effectiveness Instrument (CCCTEI) (Copeland \& Hewson, 2000), was developed in cooperation with many stakeholders and tested for validity and reliability, but the theoretical dimensions underlying the items of this instrument are not clearly specified. Bowden and Marton (1998) observe that, for evaluation results to be helpful to teachers in optimising their teaching practice, the evaluation instru- 
ment should have solid theoretical underpinnings. When evaluations are not grounded in theories of effective teaching, it is difficult to establish in which direction efforts to improve teaching should be headed and, consequently, real improvement is likely doubtful (Bowden \& Marton, 1998).

Medical education has always strongly relied on the 'traditional apprenticeship model' of clinical training, where students mainly learn by observing doctors as role models in day-to-day clinical practice. Although there is no denying that role modelling is a powerful way of transmitting values, attitudes and patterns of thinking and behaviour to students (Elzubeir \& Rizk, 2001), research indicates that effective learning depends strongly on active involvement of students and deliberate attention to cognitive processes underlying task performance. In line with these ideas, Collins et al. (1989) developed the concept of cognitive apprenticeship by rethinking the traditional apprenticeship model. The focus of the cognitive apprenticeship model is on experts' (tacit) cognitive processes when performing complex tasks. In this model, these processes are made explicit and strategies are given to help students observe, enact and practise with support from their teachers. The following methods are proposed for use by teachers to provide guided learning experiences to students.

Modelling: Students observe their teachers as they demonstrate certain parts of a task. Teachers should externalise their thinking processes as they perform the task by thinking aloud and explaining their judgement and reasoning to students. Coaching: Teachers observe and help students in performing a task or in learning a task. The teacher offers feedback, scaffolding, and modelling during the process. Scaffolding: Teachers provide support and selective help to students in performing tasks they have not yet mastered. Teachers diagnose students' skill levels and stimulate students to move beyond their current level, which may mean that students need help. Eventually, as students' mastery advances, teachers reduce the level of support (fading). Articulation: Teachers ask students to articulate their knowledge, reasoning or problem-solving processes. Reflection: teachers stimulate students to reflect on their own problem-solving processes and compare them with those of experts and other students. Exploration: Students are pushed into a mode of problem solving on their own. Teachers formulate general goals for students and encourage them to focus on particular subgoals of interest.

According to research, another prerequisite for successful learning in the clinical environment, apart from the above methods, is a positive learning climate (Kilminster \& Jolly, 2000). Its importance in maximising learning outcomes has also been emphasised by other studies. A way for teachers to create a propitious learning climate is to show that they respect their students and are interested in the students' learning (Beckman, Lee, Rohren, \& Pankratz, 2003; Litzelman, Stratos, Marriott, \& Skeff, 1998). 
We developed an instrument based on the cognitive apprenticeship model to elicit students' evaluations of individual doctors' clinical teaching to be used for feedback and eventually improvement of the quality of teaching performance. In order to investigate the content validity of the instrument we invited stakeholders from different settings to judge the instrument on relevance and wording. Quality being a relative concept (Harvey \& Green, 1993), it is only to be expected that individual experts will take different views of the quality of clinical teaching depending on their personal backgrounds. Therefore we sought the opinions of different groups of stakeholders. We envisaged that this would help us not only to enhance the content validity of the instrument but also to broaden acceptance and support for the eventual implementation of the instrument (Guba \& Lincoln, 1989).

We approached three groups of stakeholders: doctors, educationalists and senior medical students, asking them to complete a questionnaire about the relevance of the instrument. The aim was to investigate and improve the instrument's content validity by addressing the following research question:

- How do three groups of stakeholders rate the relevance and wording of an instrument developed to be used by students to evaluate individual doctors' clinical teaching?

\section{METHOD}

\section{Participants}

Three groups of stakeholders were approached: 12 educationalists, 16 doctors and 12 senior medical students. We chose these groups for their combined theoretical knowledge (educationalists) and practical experience in the domain of clinical teaching (doctors and students). The educationalists were from the 8 Dutch Medical Schools and had expertise in medical education, especially clinical teaching and clerkships. The doctors were from various disciplines (internal medicine, paediatrics, surgery, obstetrics/gynaecology, ENT and dermatology) and were involved in clerkship teaching in different hospitals in the Netherlands. All doctors had had ample experience in supervising medical students and some were clerkship coordinators. Student representatives at Maastricht Medical School recruited student volunteers who had completed at least 6 of the total of 12 clinical rotations and have had experience with being supervised in clinical practice. As soon as 12 volunteers had come forward, recruitment was stopped. Participation was voluntary, participants received no reward and the data were anonymised. In Dutch Medical Schools, it is not required to submit this type of study to the ethics committee for approval. 


\section{Instrument}

We developed a questionnaire about the relevance and quality of the items of the evaluation instrument. The items reflect the teaching methods of the cognitive apprenticeship model (Collins et al., 1989): modelling (4 items), coaching (4 items), scaffolding (4 items), articulation (4 items), reflection (4 items), exploration (4 items), general learning climate ( 3 items), and miscellaneous ( 3 items) (Table 1 ). Items were derived from the extensive description of the teaching methods in the cognitive apprenticeship model as provide by Collins et al. (1989). Respondents were asked to rate item relevance on a five-point Likert scale (1= highly irrelevant; $5=$ highly relevant). When they rated an item as 1 or 2 , stakeholders were asked to give a written explanation in the space provided under the item in question. They could use the same space to write comments about item quality and wording. Finally, the participants were asked to indicate whether they had noticed any omissions and/or would like to add an item or items to the questionnaire.

\section{Procedure}

The questionnaire was sent by post with a return envelope and a letter informing the stakeholders of the purpose of the study. In the letter it was explained that they were invited to participate because of their particular expertise in clinical teaching. After three weeks, a reminder was emailed to the non-responders with the questionnaire attached and requesting them to complete and return the questionnaire online.

\section{Analysis}

We used SPSS 14.0 to analyse the data. First, we checked for outliers and nonnormality. Means and standard deviations of the relevance ratings were calculated by item, by teaching method and by stakeholder group. Because the data distribution was skewed, we used non-parametric analysis to examine the differences between the stakeholder groups in their ratings of the teaching methods. We determined frequencies, cross tabulations (ratings of relevance per teaching method for three groups of stakeholders) and Pearson chi-square. Additionally, Bonferroni correction was performed. Finally, effect sizes were calculated based on the formula described by Hojat \& Xu (Hojat \& Xu, 2004) to estimate effect sizes for chi-square:

$$
\text { Effect Size }=v C^{2} /\left(1-C^{2}\right)
$$

where $C$ is '(...) the coefficient of contingency, which is a widely used measure of association between discrete measures in contingency tables, which can be derived from $\chi^{2,}$. Stakeholders' comments on the items they considered less relevant were 
collected in a word file and analysed to see if the item should be retained, illuminated or reworded.

\section{Criteria for item inclusion/exclusion}

We eliminated from the questionnaire all the items that were rated below 3.5 by all three stakeholder groups. This prevented automatic exclusion of items receiving low ratings from one stakeholder group only. When an item gave rise to strong negative comments about the quality of item focus or wording, it was also eliminated.

\section{RESULTS}

\section{Response}

10 out of 12 educationalists responded (83\%), all 16 doctors responded (100\%) and all 12 senior medical students responded (100\%).

\section{Descriptive statistics}

Generally, item relevance is rated highly by all three stakeholder groups, with ratings varying between 3.4 and 4.6 (Appendix 1). The stakeholder groups' mean ratings of the relevance of the teaching methods are shown in Appendix 1. The mean overall ratings of the relevance of the teaching methods range from 3.8 to 4.5 .

\section{Pearson chi-square and effect sizes}

After Bonferroni correction, Pearson chi-square analysis revealed significant differences between the stakeholder groups for four teaching methods (Table 1). Because of the non-normality of the data, several columns of the cross tabulations were collated in order to meet the preconditions for Pearson chi-square. For 'modelling', 'scaffolding', 'reflection', and 'exploration', points 1 and 2 of the five-point scale were collated, leaving 4 dimensions. For 'coaching', 'articulation' and 'miscellaneous', we collated 1, 2 and 3 into one column, which left 3 scoring dimensions. 'General learning climate' was excluded from further analysis because, even after 1, 2 and 3 were collated, the cross tabulation showed empty cells and thus did not satisfy the preconditions for Pearson chi-square. The results of the Pearson Chi-square analyses of the three stakeholder groups are shown in Table 1.

'Coaching', 'articulation' and 'miscellaneous' show no significant differences between the three groups. Compared to the other groups, the students give lower ratings for 'modelling' and 'reflection' and the doctors and the educationalists give 
higher ratings for 'scaffolding' and 'exploration', respectively. The effect sizes of the significant between-group differences are medium to large, based on an interpretation of effect sizes for chi-square of around $0.10,0.30$ and 0.50 as indicative of negligible practical importance, moderate practical importance, and crucial practical importance, respectively (Hojat \& Xu, 2004) (Table 1).

Table 1: Pearson Chi-Square and Effect Sizes (ratings of relevance per teaching method for three groups of stakeholders)

\begin{tabular}{lccc} 
Teaching Method & $X^{2}$ & df & Effect Size \\
Modelling & $33.521^{*}$ & 6 & 0.47 \\
Coaching & 8.276 & 4 & - \\
Scaffolding & $23.004^{*}$ & 6 & 0.39 \\
Articulation & 5.162 & 4 & - \\
Reflection & $27.123^{*}$ & 6 & 0.42 \\
Exploration & $28.255^{*}$ & 6 & 0.43 \\
General Learning Climate & - & - & - \\
Miscellaneous & 6.806 & 4 & - \\
\hline
\end{tabular}

*Bonferonni corrected significance level $p<.01$

+ Preconditions for Pearson Chi-Square not met

\section{Qualitative suggestions}

The number of stakeholders' comments on the teaching methods varies between 7 and 18 per method. Comments pertain to the relevance and wording of items and most are from the educationalists. We cite some of the stakeholders' comments on the content of teaching methods to illustrate how qualitative considerations, in addition to the quantitative criterion led to elimination of items. The numbers refer to individual participants.

\section{Coaching}

Two of the items relating to 'coaching' focus on the importance of feedback (items 6 and 7). It is mainly educationalists who observe overlap of these items and point out that it is important for feedback to be given immediately after observation of the activity in question.

'(...) I think that feedback should be provided as quickly as possible after a presentation in order for the feedback to be effective.' (Educationalist 9.10) 


\section{Reflection}

All three groups of stakeholders comment on items 19 and 20. A doctor and a student highlight the risk of a counterproductive effect of item 19.

'With this aspect one risks counterproductive results. When you compare yourself to more experienced doctors you can end up discouraging yourself, especially in a learning climate that is not safe.' (Doctor 1.16)

'(...) Of course the approach of an experienced doctor differs from that of a student, that is self-evident, and this comparison does not give you much.' (Student 1.12)

Respondents from each group comment that item 20 is formulated too broadly.

'It is not clear to me what is meant exactly. Is this an overarching question about what it means to be a doctor?' (Student 12.12)

\section{Exploration}

Item 24 is critiqued by educationalists and doctors for its suspected potential to stimulate irresponsible behaviour.

'(...) I think this item is too 'wild' and dangerous. Possibly stimulates irresponsible behaviour.' (Educationalist 3.10)

'I think (...) item 24 depends on the individual. Ninety percent of students already extend their boundaries and when a very enthusiastic supervisor comes along and adds new (boundary crossing) tasks, it may be counterproductive to the learning process.' (Doctor 15.16)

\section{Modifications of the questionnaire}

Items 19 and 20 were removed in response to low ratings by all stakeholders. Item 7 was removed because of overlap with item 6 , which is retained as the more important item because of its focus on feedback immediately after or during observation. Concerns about incitement to irresponsible behaviour led to the removal of item 24 . The wording of several items was altered and 1 item was added to 'General Learning Climate': 'The clinical teacher took enough time to supervise me'.

\section{DISCUSSION AND CONCLUSION}

Hospitals are potentially very powerful learning environments for medical students (Spencer, 2003). To fully realise this potential, high-quality supervision of students is of the essence and this can be improved when clinical teachers are evaluated and 
provided with feedback (Dolmans et al., 2002). As part of the development of a valid and reliable instrument to evaluate clinical teachers, we asked three groups of stakeholders in undergraduate clinical training to assess the content validity of an instrument based on the cognitive apprenticeship model of Collins et al. (1989).

The generally high ratings of the relevance of questionnaire items by all the stakeholders not only support the content validity of the instrument, but also bode well for its broad acceptance when it is implemented (Guba \& Lincoln, 1989). As a consequence of both the qualitative and the quantitative results of this study, 4 of the total of 30 items were eliminated, 13 were modified and 1 was added. All three stakeholder groups contributed to modifications of the questionnaire. Of two 'coaching' items on feedback, which overlapped according to educationalists, the one item referring to the importance of immediate feedback after or during observed task performance was retained. Although students gave low ratings for reflection and commented that they considered stimulation of reflection more a task for mentors than for clinical supervisors, their ratings were offset by higher ratings from educators and doctors. This was not the case with students' low ratings of 'reflection' items about comparing student performance with that of more experienced doctors and reflecting on the profession of a medical doctor. An additional reason for removing these items were stakeholders' comments that these items were too vague and general. Concern expressed by doctors and educationalists about potential harmful effects of encouraging students to extend their boundaries was the decisive factor in the removal of item 24 .

The results of this study are encouraging in that they support and helped improve the content validity of the instrument based on the cognitive apprenticeship model which we developed to evaluate clinical teachers' performance. Future studies will have to address the statistical validation of the instrument and the generalizability of results to determine the number of students needed to provide reliable feedback to doctors about their supervisory skills. After statistical validation of the instrument, further studies should investigate whether the feedback based outcomes of the evaluation instrument is beneficial to clinical teachers and can help them improve their teaching performance. Because research has demonstrated that feedback from students on clinical teachers' performance can have mixed effects on teaching effectiveness (Litzelman, Stratos, Marriott, Lazaridis, \& Skeff, 1998), it is also important to investigate how feedback from student evaluations is best communicated to clinical teachers to facilitate improvement of teaching effectiveness. The role of faculty development programmes in this respect should also be addressed.

\section{Acknowledgements}

The authors would like to thank all the stakeholders for their feedback on the instrument. They also wish to thank Mereke Gorsira for editing the final version. 


\section{REFERENCES}

Beckman, T. J., Ghosh, A. K., Cook, D. A., Erwin, P. J., \& Mandrekar, J. N. (2004). How reliable are assessments of clinical teaching? A review of the published instruments. Journal of General Internal Medicine, 19(9), 971-977.

Beckman, T. J., Lee, M. C., Rohren, C. H., \& Pankratz, V. S. (2003). Evaluating an instrument for the peer review of inpatient teaching. Medical Teacher, 25(2), 131-135.

Bowden, J., \& Marton, F. (1998). Quality and qualities. In J. Bowden \& F. Marton (Eds.), The university of learning (pp. 211-245). London: Kogan Page Limited.

Collins, A., Brown, J. S., \& Newman, S. E. (1989). Cognitive Apprenticeship: Teaching the crafts of reading, writing, and mathematics. In L. B. Resnick (Ed.), Knowing, learning, and instruction: Essays in honor of Robert Glaser (pp. 453-494). Hillsdale, New Jersey: Lawrence Erlbaum Associates, Inc.

Copeland, H. L., \& Hewson, M. G. (2000). Developing and testing an instrument to measure the effectiveness of clinical teaching in an academic medical centre. Academic Medicine, 75(2), 161-166.

Cottrell, D., Killminster, S., Jolly, B., \& Grant, J. (2002). What is effective supervision and how does it happen? A critical incident study. Medical Education, 36(11), 1042-1049.

Dolmans, D. H. J. M., Wolfhagen, H. A. P., Essed, G. G. M., Scherpbier, A. J. J. A., \& Van der Vleuten, C. P. M. (2002). Students' perceptions of relationships between some educational variables in the outpatient setting. Medical Education, 36(8), 735-741.

Elzubeir, M. A., \& Rizk, D. E. E. (2001). Identifying characteristics that students, interns and residents look for in their role models. Medical Education, 35(3), 272-277.

Grant, J., Kilminster, S., Jolly, B., \& Cottrell, D. (2006). Clinical supervision of SpRs: where does it happen, when does it happen and is it effective? Medical Education, 37(2), 140-148.

Guba, E. G., \& Lincoln, Y. S. (1989). Fourth generation evaluation. Newbury Park, London: Sage Publications.

Harvey, L., \& Green, D. (1993). Defining quality. Assessment and Evaluation in Higher Education, 18(1), 934.

Hojat, M., \& Xu, G. (2004). A visitor's guide to effect sizes. Statistical significance versus practical (clinical) importance of research findings. Advances in Health Sciences Education: Theory and Practice, 9(3), 241-249.

Kilminster, S. M., \& Jolly, B. C. (2000). Effective supervision in clinical practice settings: a literature review. Medical Education, 34(10), 827-840.

Litzelman, D. K., Stratos, G. A., Marriott, D. J., Lazaridis, E. N., \& Skeff, K. M. (1998). Beneficial and harmful effects of augmented feedback on physicians' clinical-teaching performances. Academic Medicine, 73(3), 324-332.

Litzelman, D. K., Stratos, G. A., Marriott, D. J., \& Skeff, K. M. (1998). Factorial validation of a widely disseminated educational framework for evaluating clinical teachers. Academic Medicine, 73(6), 688695.

Spencer, J. (2003). Learning and teaching in the clinical environment. ABC of learning and teaching in medicine. British Medical Journal, 326, 591-594. 


\section{APPENDIX 1}

Mean ratings and standard deviations, on a Likert scale ( 1 =highly irrelevant; $5=$ highly relevant), of the relevance of the items relating to 8 supervision methods by stakeholder group and for the three stakeholder groups combined and overall group ratings per supervision method.

\begin{tabular}{|c|c|c|c|c|c|c|c|}
\hline \multicolumn{8}{|c|}{ Total item } \\
\hline & \multicolumn{2}{|c|}{ Educationalists } & \multicolumn{2}{|c|}{ Doctors } & \multicolumn{2}{|c|}{ Students } & score \\
\hline Supervision methods & $\mathbf{M}$ & Sd & $\mathbf{M}$ & Sd & M & Sd & $\mathbf{M}$ \\
\hline
\end{tabular}

\section{Modelling}

The clinical teacher:

\begin{tabular}{|c|c|c|c|c|c|c|c|}
\hline 1. & $\begin{array}{l}\text { demonstrated how different tasks should be } \\
\text { performed. }\end{array}$ & 4.5 & 0.53 & 4.5 & 0.63 & 3.6 & 0.80 \\
\hline 2. & $\begin{array}{l}\text { explained, while performing a task, which } \\
\text { aspects were important and why. }\end{array}$ & 4.4 & 0.84 & 4.7 & 0.48 & 4.2 & 1.00 \\
\hline 3. & $\begin{array}{l}\text { created sufficient opportunities for me to } \\
\text { observe him or her. }\end{array}$ & 4.4 & 0.70 & 4.4 & 0.51 & 3.8 & 0.87 \\
\hline 4. & was a role model for me. & 4.3 & 1.10 & 4.3 & 0.68 & 3.2 & 1.00 \\
\hline \multicolumn{2}{|c|}{ Overall ratings on modelling } & 4.4 & 0.41 & 4.5 & 0.45 & 3.7 & 0.47 \\
\hline
\end{tabular}

\section{Coaching}

The clinical teacher:

5. observed me while I was performing a task.

$\begin{array}{llllll}4.9 & 0.32 & 4.5 & 0.63 & 4.2 & 0.83 \\ 4.6 & 0.70 & 4.7 & 0.48 & 4.5 & 0.70 \\ 4.3 & 1.10 & 4.5 & 0.90 & 4.7 & 0.50 \\ 4.3 & 0.80 & 4.6 & 0.63 & 4.0 & 0.85 \\ 4.5 & \mathbf{0 . 5 0} & \mathbf{4 . 6} & \mathbf{0 . 6 0} & \mathbf{4 . 3} & \mathbf{0 . 5 0}\end{array}$

6. provided me with constructive and concrete feedback during or following direct observation.

7.* provided me with constructive and concrete feedback during my rotation.

8. gave me a better insight into aspects of my performance that needed improvement.

\section{Overall ratings on coaching}

The clinical teacher:

\begin{tabular}{|c|c|c|c|c|c|c|c|c|}
\hline 9. & $\begin{array}{l}\text { adjusted his/her teaching activities to my level } \\
\text { of experience and competence. }\end{array}$ & 4.1 & 1.0 & 4.2 & 0.75 & 3.8 & 0.62 & 4.0 \\
\hline 10. & $\begin{array}{l}\text { allowed me to perform tasks that fit my level of } \\
\text { experience and competence. }\end{array}$ & 4.3 & 1.1 & 4.4 & 0.63 & 4.2 & 1.10 & 4.3 \\
\hline 11. & $\begin{array}{l}\text { was supportive when I experienced difficulties } \\
\text { with a task. }\end{array}$ & 4.0 & 1.2 & 4.5 & 0.73 & 4.1 & 0.51 & 4.2 \\
\hline 12. & $\begin{array}{l}\text { gradually decreased the amount of guidance in } \\
\text { order to bolster my independence. }\end{array}$ & 3.4 & 1.1 & 4.5 & 0.52 & 4.3 & 0.75 & 4.1 \\
\hline \multicolumn{2}{|c|}{ Overall ratings on scaffolding } & 4.0 & 0.66 & 4.4 & 0.47 & 4.1 & 0.44 & \\
\hline
\end{tabular}

Table continues 


\section{Articulation}

The clinical teacher:

\begin{tabular}{|c|c|c|c|c|c|c|c|}
\hline 13. & $\begin{array}{l}\text { asked me to explain my reasoning and argu- } \\
\text { ments. }\end{array}$ & 4.6 & 0.70 & 4.6 & 0.63 & 4.5 & 0.52 \\
\hline 14. & alerted me to gaps in my knowledge and skills. & 4.2 & 0.63 & 4.4 & 0.62 & 3.9 & 1.10 \\
\hline 15. & asked questions to increase my understanding. & 4.3 & 0.71 & 4.6 & 0.62 & 4.5 & 0.70 \\
\hline 16. & $\begin{array}{l}\text { stimulated me to ask questions to increase my } \\
\text { understanding. }\end{array}$ & 4.5 & 0.71 & 4.6 & 0.50 & 4.0 & 1.10 \\
\hline \multicolumn{2}{|c|}{ Overall ratings on articulation } & 4.0 & 0.50 & 4.5 & 0.48 & 4.4 & 0.57 \\
\hline
\end{tabular}

\section{Reflection}

The clinical teacher:

\begin{tabular}{|c|c|c|c|c|c|c|c|c|}
\hline 17. & $\begin{array}{l}\text { stimulated me to think about my own strengths } \\
\text { and weaknesses. }\end{array}$ & 4.4 & 0.84 & 4.4 & 0.62 & 3.4 & 0.90 & 4.1 \\
\hline 18. & $\begin{array}{l}\text { stimulated me to think about how to improve } \\
\text { my own strengths and weaknesses. }\end{array}$ & 4.5 & 0.71 & 4.6 & 0.63 & 3.4 & 1.10 & 4.2 \\
\hline 19.* & $\begin{array}{l}\text { stimulated me to compare my own approach to } \\
\text { that of a more experienced doctor. }\end{array}$ & 3.9 & 1.20 & 3.7 & 1.10 & 2.8 & 0.87 & 3.4 \\
\hline 20.* & $\begin{array}{l}\text { stimulated me to reflect on the profession of a } \\
\text { medical doctor. }\end{array}$ & 3.5 & 0.85 & 3.8 & 1.0 & 3.0 & 1.3 & 3.4 \\
\hline \multicolumn{2}{|c|}{ Overall ratings on reflection } & 4.4 & 0.66 & 4.1 & 0.70 & 3.1 & 0.63 & \\
\hline \multicolumn{9}{|c|}{ Exploration } \\
\hline \multicolumn{9}{|c|}{ The clinical teacher: } \\
\hline 21. & stimulated me to formulate my own goals. & 4.7 & 0.50 & 4.1 & 0.85 & 3.5 & 0.67 & 4.1 \\
\hline 22. & stimulated me to achieve my own goals. & 4.8 & 0.42 & 4.3 & 0.45 & 3.8 & 0.75 & 4.2 \\
\hline 23. & $\begin{array}{l}\text { challenged me to explore new tasks and possi- } \\
\text { bilities. }\end{array}$ & 4.5 & 0.85 & 3.9 & 0.72 & 4.3 & 0.75 & 4.2 \\
\hline $24 .^{*}$ & challenged me to extend my boundaries. & 3.6 & 1.50 & 3.8 & 0.83 & 4.1 & 0.90 & 3.8 \\
\hline Over & all ratings on exploration & 4.5 & 0.41 & 4.0 & 0.59 & 3.9 & 0.54 & \\
\hline \multicolumn{9}{|c|}{ General Learning Climate } \\
\hline \multicolumn{9}{|c|}{ The clinical teacher: } \\
\hline 25. & established a safe learning environment. & 4.4 & 0.84 & 4.8 & 0.45 & 4.1 & 0.67 & 4.4 \\
\hline 26. & showed an interest in me as a student. & 4.4 & 0.70 & 4.7 & 0.48 & 4.2 & 0.83 & 4.4 \\
\hline 27. & treated me with respect. & 4.7 & 0.50 & 4.9 & 0.34 & 4.3 & 0.62 & 4.6 \\
\hline \multicolumn{9}{|c|}{ ** took enough time to supervise me. } \\
\hline Over & all ratings on general learning climate & 4.3 & 0.50 & 4.8 & 0.38 & 4.2 & 0.56 & \\
\hline \multicolumn{9}{|c|}{ Miscellaneous } \\
\hline 28. & $\begin{array}{l}\text { Give an overall mark (1-10) for this doctor as a } \\
\text { clinical teacher. }\end{array}$ & 3.7 & 1.60 & 4.2 & 0.83 & 3.6 & 1.20 & 3.9 \\
\hline 29. & $\begin{array}{l}\text { What are the strengths of this clinical teacher? } \\
\text { (open-ended question) }\end{array}$ & 4.7 & 0.49 & 4.6 & 0.62 & 4.4 & 0.52 & 4.6 \\
\hline 30. & $\begin{array}{l}\text { Which aspects of the performance of this clinical } \\
\text { teacher can be improved? (open-ended ques- } \\
\text { tion) }\end{array}$ & 4.7 & 0.52 & 4.8 & 0.40 & 4.3 & 0.67 & 4.6 \\
\hline \multicolumn{2}{|c|}{ Overall ratings on miscellaneous } & 4.3 & 0.85 & 4.5 & 0.36 & 4.1 & 0.49 & \\
\hline
\end{tabular}





\section{Chapter 4}

\section{The Maastricht Clinical Teaching Questionnaire (MCTQ) as a valid and reliable instrument for the evaluation of clinical teachers}

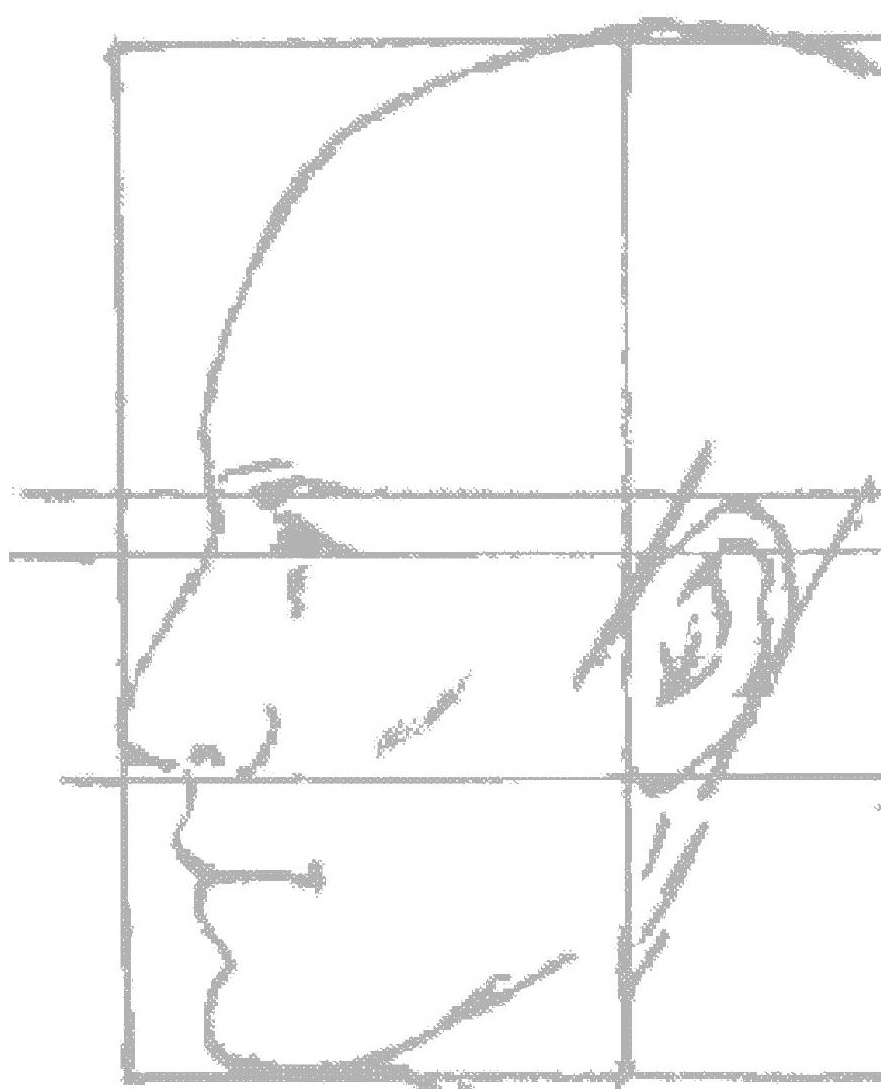




\section{ABSTRACT}

\section{Purpose}

Clinical teaching's importance in the medical curriculum has led to increased interest in its evaluation. Instruments for evaluating clinical teaching must be theorybased, reliable, and valid. The Maastricht Clinical Teaching Questionnaire (MCTQ), based on theoretical constructs of cognitive apprenticeship, elicits evaluations of individual clinical teachers' performance at the workplace. The authors investigated its construct validity and reliability, and they used the underlying factors to test a causal model representing effective clinical teaching.

\section{Method}

The authors asked students who had completed clerkship rotations in different departments of two teaching hospitals to use the MCTQ to evaluate their clinical teachers. To establish construct validity, the authors performed a confirmatory factor analysis of the evaluation data, and they estimated reliability by calculating the generalizability coefficient and standard error measurement. Finally, to test a model of the factors, they fitted a structural linear model to the data.

\section{Results}

Confirmatory factor analysis yielded a five-factor model which fit the data well. Generalizability studies indicated that seven to ten student ratings can produce reliable ratings of individual teachers. The hypothesized structural linear model underlined the central roles played by modelling, and coaching (mediated by articulation).

\section{Conclusions}

The MCTQ is a valid and reliable evaluation instrument, thereby demonstrating the usefulness of the cognitive apprenticeship concept for clinical teaching during clerkships. Furthermore, a valuable model of clinical teaching emerged, highlighting modelling, coaching, and stimulating students' articulation and exploration, as crucial to effective teaching at the clinical workplace. 


\section{INTRODUCTION}

The importance of clerkships in the medical curriculum has given rise to the development of several evaluation instruments to measure the quality of the clinical teaching of medical students at the workplace (i.e., the ambulatory or in-patient clinic). Although most instruments used today have clear strengths, they also have weaknesses. Some lack sound underpinning theories of effective clinical teaching; some developed without the input of crucial stakeholders; and some include items that are too broadly defined, limiting their value for evaluating individual teachers. Two of the most cited instruments in the medical education literature, the Stanford List (Litzelman, Stratos, Marriott, \& Skeff, 1998) and the Cleveland Clinical Teaching Effectiveness Instrument (CCTEI) (Copeland \& Hewson, 2000), have both strengths and weaknesses. The strength of the CCTEI lies in the involvement of stakeholders in its design process; however, the lack of clearly specified theoretical dimensions could hamper feedback effectiveness (Bowden \& Marton, 1998). The Stanford List, on the other hand, has a clear theoretical basis, but it focuses on a broad collection of teaching arrangements that reflects teaching effectiveness for different teaching settings, including organized small-group sessions (Litzelman et al., 1998). This broad focus makes the instrument less suitable for individualized feedback for physicians teaching at the clinical workplace.

The theoretical constructs of cognitive apprenticeship (Collins, Brown, \& Newman, 1989) underpin the Maastricht Clinical Teaching Questionnaire (MCTQ), the aim of which is to provide individual clinical teachers with feedback about their teaching skills with regard to supervising medical students rotating through clerkships at the workplace. The appeal of cognitive apprenticeship for clinical teaching resides in its aim to teach and make explicit the often tacit processes involved in experts' handling of complex cognitive tasks. Based on apprentice-type learning and teaching methods, cognitive apprenticeship principles advocate "learning through guided experience."(Collins et al., 1989) At its centre are several teaching methods (modelling, coaching, scaffolding, and encouraging articulation, encouraging exploration, and encouraging reflection) that clinical teachers use both to externalize the tacit processes underlying their thinking and actions in practice and to model their expert strategies. In cognitive apprenticeship, teaching starts with modelling by a teacher who explicitly demonstrates a task (how to perform a physical exam, for example) and acts as a role model for students, explaining certain elements of the task. In the next step, coaching, the teacher observes students performing a task and gives them feedback. While modelling and coaching, the teacher should be aware of the level of knowledge and skills that their students have already attained and, based on this level, decide whether and when to provide additional guidance. This method is known as scaffolding-providing support to the level of the student and gradually fading that support as the student progresses. In order to access stu- 
dents' problem-solving strategies, the clinical teacher encourages articulation, stimulating students to externalize knowledge and skills. A clinical teacher should also stimulate both reflection, which helps students become aware of their strengths and weaknesses, and exploration, which means that he/she encourages autonomy in students by asking them to formulate and pursue their own personal learning goals(Collins et al., 1989). Because of the established importance of generating a safe learning environment to clinical teaching and learning(Beckman, Lee, Rohren, \& Pankratz, 2003; Kilminster \& Jolly, 2000), we have added this element to the MCTQ on top of the cognitive apprenticeship teaching methods. In summary, cognitive apprenticeship (with the addition of 'safe learning environment') distinguishes among teaching methods that are strongly facilitated by teachers (modelling, creating a safe learning environment), that are aimed at stimulating interactions between teacher and student (coaching and scaffolding), and that are aimed at stimulating self-regulated learning by students (articulation, reflection, exploration).

Previous research has already established the value and content validity of the MCTQ for the undergraduate clinical teaching setting. Focus group research with senior medical students established that the teaching methods were observable and viable during clerkship rotations (Stalmeijer, Dolmans, Wolfhagen, \& Scherpbier, 2009). Further, stakeholders including physicians, educationalists, and medical students, rated the relevance of the MCTQ items as high (Stalmeijer, Dolmans, Wolfhagen, Muijtjens, \& Scherpbier, 2008). In this current study, we will address the MCTQ's construct validity and reliability and investigate how its factors relate to one another.

Additionally, based on research underlining the great importance of (role) modelling (Elzubeir \& Rizk, 2001), we hypothesized that the first tasks of a good clinical teacher are to provide modelling and a safe learning environment. We further hypothesized that after establishing a secure learning environment and being a good model, teachers should interact with students, giving feedback and providing support (coaching and scaffolding), and to make sure that students actively engage in clinical practice (Dornan, Boshuizen, King, \& Scherpbier, 2007; Leinster, 2009). Finally, we hypothesized that providing an appropriate level of autonomy within the learning environment is beneficial to the students' learning experience (Beckman \& Lee, 2009), thus, teachers should encourage students to self-regulate their learning through articulation, reflection, and exploration. We tested how well this hypothesized model fit our data.

The current study focuses on three research questions:

1. What is the construct validity of the MCTQ?

2. How many student ratings of one teacher are required for the ratings to be reliable? 
3. How are the different factors underlying the MCTQ related to one another and to the overall MCTQ score?

\section{METHOD}

\section{Setting}

We conducted this study with students undertaking clerkships in outpatient clinics and on the wards of two teaching hospitals affiliated with Maastricht Medical School. Clinical clerkships occur in years 4 and 5 of the six-year curriculum and consist of nine hospital-based rotations of varying duration (5 to 10 weeks) in internal medicine, surgery, paediatrics, obstetrics/gynaecology, neurology, dermatology, ENT, ophthalmology, and psychiatry.

\section{Participants}

Between March 2007 and December 2008, we asked all students engaged in their clerkship rotations at one of the two teaching hospitals to complete, at the end of each rotation, a maximum of three MCTQs for any of the clinical teachers with whom they had had the most contact at the workplace. Participation was voluntary, and students did not receive an incentive for participating. Other than the request at the end of each rotation, we sent no requests to fill out MCTQ forms. Students needed only about 5 minutes to fill out an MCTQ for an individual clinical teacher. Students completed the MCTQ anonymously.

\section{Steps taken to protect human participants}

Participating students were all responsible adults who spoke Dutch and rotated through one of the indicated clerkships between March 2007 and December 2008. Likewise, clinical faculty were employed between March 2007 and December 2008 by one of the two teaching hospitals where the indicated clerkships took place, and, as mentioned above, participating students completed forms about faculty members based upon the amount of time they spent with each faculty.

Students were recruited non-coercively and participated only after, first, a full explanation of the study goals and procedures and, second, an opportunity to ask questions. Additionally, students responded anonymously to the questionnaires so that neither we, the researchers, nor the clinical faculty of the department knew their identities.

We notified clinical faculty in the department where the study occurred of our intention to conduct the study. We obtained verbal consent from the clinical faculty 
only after we informed them of the study goals and procedures and gave them an opportunity to ask questions about the study. We did not make any data collected about individual faculty members available to the public.

Participation was voluntary for both faculty and students, and we made it clear that there would be no repercussions for not participating or for withdrawing from the study at any given point. Further, we had no professional or personal relationship with any of the participants.

We saved the collected data on a password-protected computer in a secured data warehouse in our department. Nobody could unintentionally get access to the data. The names of the files did not link them in any way to the participants. Only the research team saw the data on individual clinical faculty members and their performance, and the team maintained absolute confidentiality.

We were well aware of potential risks to both students and clinical faculty and therefore put due procedures in place to reduce these risks to an absolute minimum.

\section{Instrument}

We developed the MCTQ based on the previously described principles of cognitive apprenticeship (Collins et al., 1989) and on content validity established through focus groups with and/or surveys of three groups of stakeholders (clinical teachers, educationalists, and senior students)(Stalmeijer et al., 2008; Stalmeijer et al., 2009). The 24 items of the first version of the instrument (i.e., the complete version, some items were removed after analysis), represented cognitive apprenticeship (modelling, coaching, scaffolding, stimulating articulation, stimulating reflection, stimulating exploration) and establishing a safe learning environment. The items were statements that students scored on a Likert scale ( 1 = fully disagree, 5 = fully agree) (Stalmeijer et al., 2008). We also asked students to give an overall judgment of each of their clinical teachers' individual teaching performance at the workplace (a mark out of 10 where below 6 is insufficient) and to provide written comments on these faculty members' strengths and weaknesses.

\section{Analysis}

Because the MCTQ aims at evaluating the performance of an individual clinical teacher at the workplace, we first aggregated the data for those teachers who had received four or more individual student ratings by computing mean scores across students per individual teacher. We determined the construct validity of the MCTQ by confirmatory factor analysis (CFA) using Amos 7.0 (SPSS, Chicago, Illinois)(Arbuckle, 2006). First, we checked the normality of the distribution by calculating skewness (tilt in the distribution) and kurtosis (peakedness of the distribu- 
tion). The skew and kurtosis values of all the data we used were smaller than +/1.5 , or even +/- 1.0 , implying that they were normally distributed; therefore, we could use a maximum likelihood estimation to conduct the CFA. We used the AMOS program to determine whether the data confirmed the theoretical model. We used the following fit indices and criteria (Byrne, 2001):

1. $\chi^{2}$ divided by the degrees of freedom (CMIN/df) is $<2$;

2. the goodness-of-fit index (GFI) is >0.90;

3. the comparative fit index (CFI) is > 0.90;

4. the root mean square residual (RMSEA) is $<0.1$; and

5. the PCLOSE value is $>0.5$.

Additionally, we used SPSS 15 to calculate correlations between the factor scores and the overall judgment. We also used SPSS 15 to determine the generalizability (g-coefficient) of the ratings by estimating the number of student ratings required for a reliable rating per individual teacher. For the subset of 126 teachers who received an overall judgment from four students or more, we calculated G-coefficients for both the overall judgment of teaching and for each factor. This design allowed variance component estimation of two sources: (1) differences between teachers ( $T$ ) (object of measurement) and (2) differences between Students nested within Teachers and general error (S: T, e) (Shavelson \& Webb, 1991). For example, students 1 and 2 give teacher $A$, respectively, a score of 7 and $8(M=7.5)$; Students 3 and 4 give teacher $B$, respectively, a score of 4 and a $6(M=5)$. So the difference between teachers amounts to $2.5(7.5-5)$, while the differences between students nested within teachers amount to $7-7.5,8-7.5,6-5$, and $4-5$, hence $-0,5,+0,5$, +1 , and -1 . For acceptable reliability a G-coefficient of at least 0.70 is necessary (Grönlund, 1988). We calculated Cronbach's alphas to indicate the reliability of each scale (internal consistency).

Finally, we tested a model comprising all the factors and the overall judgment by fitting a linear structural model to the data using the structural equation modelling program AMOS 7.0, with fit indices and criteria identical to those listed above for the CFA.

\section{RESULTS}

\section{Response}

We collected a total of 1,315 questionnaires on 291 faculty members completed by fourth and fifth year medical students. In all, 126 physicians received four or more anonymous ratings. 


\section{Construct validity}

Because CFA demonstrated a suboptimal fit of all cognitive apprenticeship principles as described in Method, we removed from the instrument items that (1) showed possible overlap in wording and meaning and/or (2) were suggested for removal based on the AMOS 7.0-generated modification indices (which indicate the items that could be removed to achieve a better fit of the model). Subsequently, we generated alternative, more parsimonious models representing cognitive apprenticeship, and we subjected those models to stepwise testing. The results (see Table 1) demonstrated that a five-factor model with fourteen items (Appendix 1) provided an excellent fit with CMIN/df 1.09, GFI 0.92, CFI 1.0, RMSEA 0.03, and PCLOSE 0.85.

Table 1: Results for the Confirmatory Factor Analysis of the Maastricht Clinical Teaching Questionnaire with 1-, 2-, 3-, 4-, and 5-Factor solutions

\begin{tabular}{lcccccccc}
$\begin{array}{l}\text { No. of } \\
\text { Factors }\end{array}$ & $x^{2}$ & $D f$ & $p$ & Cmin/df & GFI & CFI & RMSEA & PCLOSE \\
\hline 1 & 474.6 & 77 & 0.00 & 6.16 & 0.58 & 0.76 & 0.20 & 0.00 \\
2 & 264.3 & 76 & 0.00 & 3.48 & 0.72 & 0.89 & 0.14 & 0.00 \\
3 & 221.8 & 74 & 0.00 & 3.00 & 0.78 & 0.91 & 0.13 & 0.00 \\
4 & 157.6 & 71 & 0.00 & 2.22 & 0.83 & 0.95 & 0.10 & 0.00 \\
5 & 73.0 & 67 & 0.30 & 1.09 & 0.92 & 1.00 & 0.03 & 0.85 \\
\hline
\end{tabular}

Because the correlations between the factors were quite high, varying between 0.57 and 0.87 (Table 2), we also tested a one-, two-, three-, and four-factor model based on the correlation data and theoretical assumptions. The five-factor model yielded a better fit (Table 1). We cross-validated the five-factor model by dividing the data set into two random subsets (63 teachers each). The results demonstrated an acceptable fit for both subsets (Table 3).

Table 2: Correlations Between the Five Factor Scores of The Maastricht Clinical Teaching Questionnaire and the Overall Performance Indicator

\begin{tabular}{|c|c|c|c|c|c|c|c|}
\hline Factor & $\mathbf{N}$ & Modelling & Coaching & Articulation & Exploration & $\begin{array}{c}\text { Learning } \\
\text { environment }\end{array}$ & $\begin{array}{c}\text { Overall } \\
\text { judgment }\end{array}$ \\
\hline Modelling & 126 & 1.0 & & & & & \\
\hline Coaching & 126 & $0.76^{+}$ & 1.0 & & & & \\
\hline Articulation & 126 & $0.66^{+}$ & $0.75^{+}$ & 1.0 & & & \\
\hline Exploration & 126 & $0.69^{+}$ & $0.61^{+}$ & $0.74^{+}$ & 1.0 & & \\
\hline Learning environment & 126 & $0.82^{+}$ & $0.74^{+}$ & $0.57^{+}$ & $0.59^{+}$ & 1.0 & \\
\hline Overall judgment & 126 & $0.87^{+}$ & $0.82^{+}$ & $0.76^{+}$ & $0.72^{+}$ & $0.87^{+}$ & 1.0 \\
\hline
\end{tabular}

${ }^{+}$Correlation is significant at the 0.01 level (2-tailed). 
Table 3: Results for the Confirmatory Factor Analysis of the Maastricht Clinical Teaching Questionnaire of the Five-Factor Solution: The Total Dataset and Two Random Subsets

\begin{tabular}{lccccccccc} 
Dataset & $N$ & $X^{2}$ & $d f$ & $p$ & $\mathrm{Cmin} / \mathrm{df}$ & GFI & CFI & RMSEA & PCLOSE \\
Total & 126 & 73.0 & 67 & 0.30 & 1.09 & 0.92 & 1.0 & 0.03 & 0.85 \\
Subset 1 & 63 & 94.0 & 67 & 0.02 & 1.40 & 0.83 & 0.97 & 0.08 & 0.11 \\
Subset 2 & 63 & 89.1 & 67 & 0.04 & 1.33 & 0.83 & 0.98 & 0.07 & 0.18 \\
\hline
\end{tabular}

\section{Reliability}

The results of the generalizability studies demonstrated that the variance associated with teachers for the overall judgment is 0.33 . The variance associated with students within teachers varies per factor between 0.44 and 0.74 (Table 4).

Table 4: Variance Components of the Maastricht Clinical Teaching Questionnaire for Each Factor and for the Overall Judgment

\begin{tabular}{lcc} 
Factor & Teacher (T) & Student : Teacher (S:Te) \\
Modelling & 0.12 & 0.44 \\
Coaching & 0.11 & 0.44 \\
Articulation & 0.12 & 0.46 \\
Exploration & 0.12 & 0.74 \\
Learning environment & 0.14 & 0.48 \\
Overall judgment & 0.33 & 0.88 \\
\hline
\end{tabular}

Table 5 provides the G-coefficients per factor as a function of the number of student responses. To obtain a reliable G-coefficient of at least 0.70 or higher, at least seven student responses are necessary for the overall judgment. Four factors (i.e., modelling, coaching, stimulating articulation, and establishing a safe learning environment) required eight to ten ratings, and stimulating exploration required fourteen ratings (Table 5).

Alpha coefficients for all factors (0.83-0.96; Appendix 1) indicated high internal consistency of all the factors. 
Table 5: Generalizability (G-coefficients) per Number of Student Ratings (N) of the Maastricht Clinical Teaching Questionnaire for Each Factor and for the Overall Judgment

\begin{tabular}{l|cccccc}
\multicolumn{7}{c}{ G- coefficients } \\
No. of ratings & Modelling & Coaching & Articulation & Exploration & $\begin{array}{c}\text { Learning } \\
\text { environment }\end{array}$ & $\begin{array}{c}\text { Overall } \\
\text { judgment }\end{array}$ \\
\hline 6 & 0.61 & 0.59 & 0.61 & 0.50 & 0.64 & 0.69 \\
8 & 0.68 & 0.66 & 0.67 & 0.57 & 0.70 & 0.75 \\
10 & 0.73 & 0.71 & 0.72 & 0.62 & 0.75 & 0.79 \\
12 & 0.76 & 0.75 & 0.75 & 0.66 & 0.78 & 0.82 \\
14 & 0.79 & 0.77 & 0.78 & 0.70 & 0.81 & 0.84 \\
\hline
\end{tabular}

\section{Linear relationships}

Testing of the proposed five-factor model of clinical teaching, based on the CFA, resulted in a good fit to the data: Cmin/df 1.34, GFI 0.90, CFI 1.0, RMSEA 0.05, and PCLOSE 0.43. Path coefficients show that modelling, learning environment, and articulation significantly affect the overall judgment of clinical teaching (Figure 1).

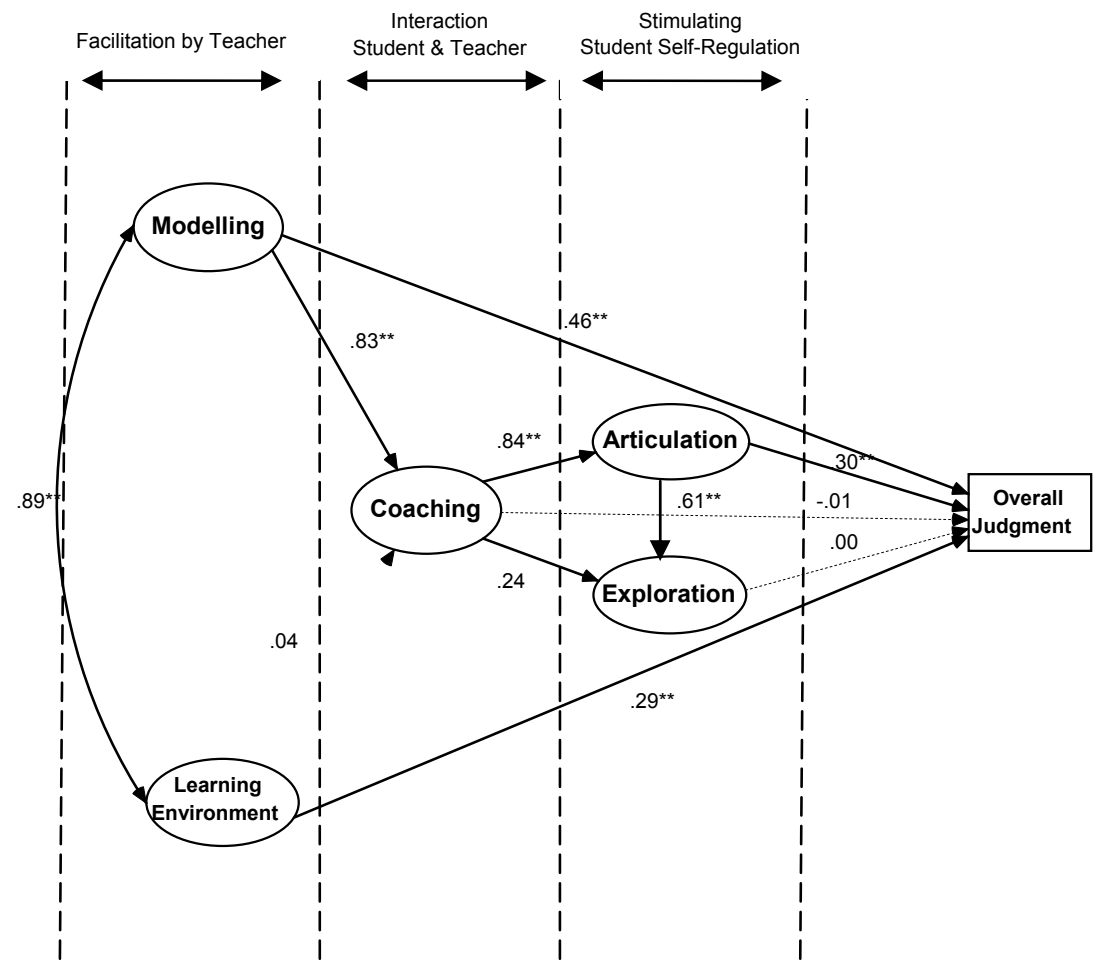

Figure 1: MCTQ Linear Model of Clinical Teaching

** significant at 0.01 level 
Furthermore, modelling plays an important role as it substantially affects coaching, which in turn clearly affects articulation, and articulation substantially impacts exploration. Although learning environment does not significantly affect coaching, it had a direct effect on overall judgment. Coaching and exploration do not seem to directly affect overall judgment, but coaching does have an effect on overall judgment through the mediating variable articulation.

\section{DISCUSSION AND CONCLUSIONS}

First, we tested the construct validity of the MCTQ as an instrument to elicit students' evaluations of the teaching quality of an individual clinical teacher. Based on the teaching methods as suggested by cognitive apprenticeship (Collins et al., 1989), and on the concept of a safe learning environment (Kilminster \& Jolly, 2000), the confirmatory factor analysis yielded a five-factor model with an excellent fit. Moreover, all five factor scores correlate well with the overall judgment (Table 2), which also lends support to the validity of the MCTQ.

Besides validity, the results also confirmed the reliability of the MCTQ. Gcoefficients showed that seven ratings suffice for a reliable overall judgment of the clinical teaching performance at the workplace of an individual clinical teacher. As for the reliability of the individual factors, we need eight to ten ratings to reach reliability with modelling, coaching, stimulating articulation, and establishing a safe learning environment, but exploration needs at least fourteen ratings. An explanation for this latter finding may be that exploration consists of only two items (Appendix 1). Nevertheless, we value exploration as an indispensible element of the MCTQ, not only because confirmatory factor analysis revealed that it is a strong, individual factor, but also because the international literature highly commends exploration as a learning activity (Kaufman, 2003) and research leading up to the design of the MCTQ showed that three groups of stakeholders deemed the two current exploration items to be highly relevant (Stalmeijer et al., 2008).

In order to investigate the mutual impact of the MCTQ factors and their impact on the overall judgment of clinical teaching performance at the workplace, we fitted a structural linear model to the data. Our hypotheses were confirmed because modelling and a safe learning environment appeared to be prerequisite for effective clinical teaching. Previous research corroborates the strength and importance of (role) modelling, by showing that the single most powerful predictor of students' satisfaction with clinical teaching was the effort by a clinical teacher to make his/her own clinical reasoning transparent to students (Smith, Varkey, Evans, \& Reilly, 2004). The importance of a safe learning environment and its profound effect on what students learn was previously established by another study (Kilminster \& Jolly, 2000). In our model, modelling impacts coaching. Through modelling, a clinical 
teacher makes the tacit processes underlying this expertise explicit so that in the next step (coaching) students can observe, enact, and practice these processes with guidance from the teacher (Collins et al., 1989). These coaching activities underline the relevance of the process that Leinster described as engagement (Leinster, 2009), which, he claims, fosters a more meaningful learning experience-or, in Leinster's own words, "clinical exposure is necessary for clinical learning, but not enough." Coaching can stimulate students to engage in articulation and exploration. In our model, articulation appears to be crucial for exploration, which encourages learner autonomy. These findings (i.e., the relation between coaching and articulation, and coaching and exploration) emphasize the value of feedback and of tailoring teaching to individual students (Branch \& Paranjape, 2002). Finally, modelling, a safe learning environment, and articulation all determine the overall judgment of clinical teaching performance at the workplace of an individual teacher, indicating that, from the students' perspective, these three teaching methods are crucial.

Note that, the majority of the path coefficients among the five factors are rather high while those explaining the overall judgment are generally low (Figure 1); however this does not imply that the factors poorly predict the overall judgment. Each of the factors does have quite some power to predict the overall judgment as evidenced by the correlations shown in the last row of Table 2, which range from 0.72 to 0.87 . Table 2 also shows that the intercorrelations of the factors generally are somewhat smaller (0.57-0.82), but still of considerable size. Because the predictors of the overall score in Figure 1 strongly correlate, their contributions may show relatively low path coefficients while the total explained variance is still high as indicated by the high correlations in the last row of Table 2. The overall judgment is a holistic rating of the teacher's performance. As such we would expected it to correlate with each of the factors, but the path coefficients in Figure 1 show how the factors simultaneously contribute to the overall judgment.

A possible limitation of this study lies in the chosen procedure for data collection. We asked students to complete the MCTQ for a maximum of three clinical teachers with whom their contacts had been most extensive. This strategy could have resulted in the evaluation of a select group of physicians-namely those physicians who more naturally engage in clinical teaching-and the relative neglect of physicians who avoid clinical teaching. Further research could focus on this issue. Furthermore, to investigate whether higher teacher performance scores on the MCTQ result in better student learning would be interesting. Finally, we should mention that the structural model is a simplified and linear model of how clinical teachers and medical students interact with each other; in reality, different variables will influence one another to a greater or lesser extent, and some paths could be recursive. Therefore, we will further investigate the model to see how it 'behaves in reality' in different clinical workplace settings. 
The current study supports the validity and reliability of the MCTQ as an instrument for evaluating the teaching skills of individual clinical teachers, provided that evaluators can obtain judgments from a minimum of seven to ten students per individual teacher. In addition, the results of this study appear to present a model that can give direction to effective sequencing of teaching methods. Teaching behaviours aimed at modelling, coaching, and stimulating articulation and exploration in students are crucial to the overall teaching effectiveness of clinical teachers during workplace learning. By presenting this kind of information, the MCTQ model can provide individual clinical teachers with feedback about their teaching at the workplace during clerkships.

\section{Acknowledgements}

The authors wish to thank Mereke Gorsira for editing the final version of the manuscript, and Karen Vreeswijk for her assistance with the data collection.

\section{Previous presentations}

A shorter version of this manuscript has been presented at the American Educational Research Association (AERA) conference in Denver, Colorado April 30 - May 4, 2010. 


\section{REFERENCES}

Arbuckle, J. L. (2006). Amos 7.0 user's Guide. Chicago: SPSS Inc.

Beckman, T. J., \& Lee, M. C. (2009). Proposal for a collaborative approach to clinical teaching. Mayo Clinic Proceedings, 84(4), 339-344.

Beckman, T. J., Lee, M. C., Rohren, C. H., \& Pankratz, V. S. (2003). Evaluating an instrument for the peer review of inpatient teaching. Medical Teacher, 25(2), 131-135.

Bowden, J., \& Marton, F. (1998). Quality and qualities. In J. Bowden \& F. Marton (Eds.), The university of learning (pp. 211-245). London: Kogan Page Limited.

Branch, W. T., \& Paranjape, A. (2002). Feedback and reflection: teaching methods for clinical settings. Academic Medicine, 77(12), 1185-1188.

Byrne, B. M. (2001). Structural Equation Modeling with AMOS. Basic concepts, applications, and programming. Mahwah, New Jersey: Lawrence Erlbaum Associates.

Collins, A., Brown, J. S., \& Newman, S. E. (1989). Cognitive Apprenticeship: Teaching the crafts of reading, writing, and mathematics. In L. B. Resnick (Ed.), Knowing, learning, and instruction: Essays in honor of Robert Glaser (pp. 453-494). Hillsdale, New Jersey: Lawrence Erlbaum Associates, Inc.

Copeland, H. L., \& Hewson, M. G. (2000). Developing and testing an instrument to measure the effectiveness of clinical teaching in an academic medical centre. Academic Medicine, 75(2), 161-166.

Dornan, T., Boshuizen, H., King, N., \& Scherpbier, A. (2007). Experience-based learning: a model linking the processes and outcomes of medical students' workplace learning. Medical Education, 41(1), 8491.

Elzubeir, M. A., \& Rizk, D. E. E. (2001). Identifying characteristics that students, interns and residents look for in their role models. Medical Education, 35(3), 272-277.

Grönlund, N. E. (1988). How to construct achievement tests (4th ed.). Englewood Cliffs, NJ: Prentice-Hall.

Kaufman, D. M. (2003). ABC of learning and teaching in medicine: applying educational theory in practice. British Medical Journal, 326(7382), 213-216.

Kilminster, S. M., \& Jolly, B. C. (2000). Effective supervision in clinical practice settings: a literature review. Medical Education, 34(10), 827-840.

Leinster, S. (2009). Learning in the clinical environment. Medical Teacher, 31(2), 79-81.

Litzelman, D. K., Stratos, G. A., Marriott, D. J., \& Skeff, K. M. (1998). Factorial validation of a widely disseminated educational framework for evaluating clinical teachers. Academic Medicine, 73(6), 688695.

Shavelson, R. J., \& Webb, N. M. (1991). Generalizability Theory. A Primer. London: Sage.

Smith, C. A., Varkey, A. B., Evans, A. T., \& Reilly, B. M. (2004). Evaluating the performance of inpatient attending physicians. A new instrument for today's teaching hospitals. Journal of General Internal Medicine, 19(7), 766-771.

Stalmeijer, R. E., Dolmans, D. H. J. M., Wolfhagen, I. H. A. P., Muijtjens, A. M. M., \& Scherpbier, A. J. J. A. (2008). The development of an instrument for evaluating clinical teachers: involving stakeholders to determine content validity. Medical Teacher, 30(8), e272-277.

Stalmeijer, R. E., Dolmans, D. H. J. M., Wolfhagen, I. H. A. P., \& Scherpbier, A. J. J. A. (2009). Cognitive apprenticeship in clinical practice: can it stimulate learning in the opinion of students? Advances in Health Sciences Education: Theory and Practice, 14(4), 535-546. 


\section{APPENDIX 1}

\section{THE MAASTRICHT CLINICAL TEACHING QUESTIONNAIRE (MCTQ)}

Alpha coefficients, mean score (Scale 1 = Fully Disagree, 5 = Fully Agree) and corresponding standard deviation (SD) per Item of the MCTQ and for the Overall Judgment (Scale 1 - 10)

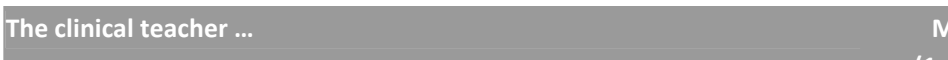

$$
M
$$

Modelling $\alpha=.86$

... Consistently demonstrated how to perform clinical skills.

... Created sufficient opportunities for me to observe him/her.

... Served as a role model as to the kind of doctor I would like to become.

\section{Coaching $\alpha=.83$}

... Gave useful feedback during or immediately after direct observation of my patient encounters.

... Adjusted his/her teaching activities to my level of experience.

... Offered me sufficient opportunities to perform activities independently.

\section{Articulation $\alpha=.89$}

... Asked me to provide a rationale for my actions.

... Asked me questions aimed at increasing my understanding.

... Stimulated me to explore my strengths and weaknesses.

\section{Exploration $\alpha=.94$}

... Encouraged me to formulate learning goals.

... Encouraged me to pursue my learning goals.

Safe Learning Environment $\alpha=.96$

... Created a safe learning environment.

... Was genuinely interested in me as a student.

... Showed that he/she respected me. 



\section{Chapter 5}

\section{Combined student ratings and self-}

assessment provide useful feedback for clinical teachers

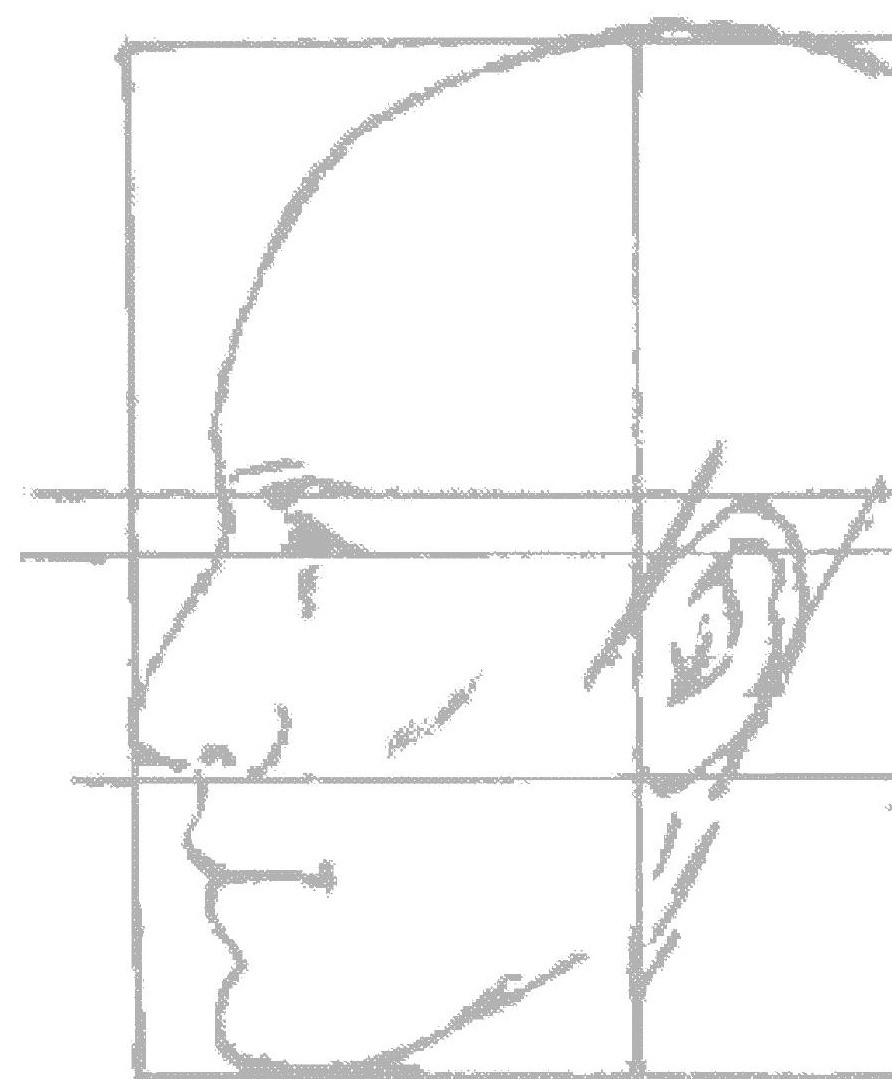

Stalmeijer, R.E., Dolmans, D.H.J.M., Wolfhagen, I.H.A.P., Peters, W.G., van Coppenolle, L., \& Scherpbier, A.J.J.A. (2010). Combined student ratings and self-assessment provide useful feedback for clinical teachers. Advances in Health Sciences Education: Theory and Practice, 15(3), 315-328. E-pub ahead of 


\section{ABSTRACT}

\section{Context}

Many evaluation instruments have been developed to provide feedback to physicians on their clinical teaching, but written feedback alone is not always effective. We explored whether feedback effectiveness improved when teachers' selfassessment was added to written feedback based on student ratings.

\section{Method}

37 physicians (ten residents, 27 attending physicians) from different specialties (Internal Medicine, Surgery, Obstetrics/Gynaecology, Paediatrics, Neurology, Dermatology, Ophthalmology, ENT, and Psychiatry) were invited to fill out a selfassessment questionnaire on their teaching skills. Students completed an almost identical questionnaire to evaluate the same teachers based on their experiences during clerkships. After receiving written feedback incorporating their selfassessment and the student ratings, the teachers indicated their perceptions of the self-assessment exercise and the written feedback in a questionnaire (five-point Likert scale items) and next, in more detail, in semi-structured interviews with a purposive sample of twelve of the participating teachers. 25 physicians participated (67\%).

\section{Results}

The results showed that self-assessment and student feedback were both perceived as useful $(M=3.7, S D=1.0)$ but the latter was considered more effective. The physicians we interviewed considered the combination of self-assessment with student ratings more effective than either self-assessment or written feedback alone. Notably, discrepancies between student ratings and self-assessment were deemed a strong incentive for change.

\section{Conclusion \& Discussion}

We conclude that self-assessment can be a useful tool to stimulate improvement of clinical teaching when it is combined with written feedback based on student ratings. Future research among larger groups is needed to confirm our findings and examine whether these combined tools actually lead to improved teaching. 


\section{INTRODUCTION}

Clinical teachers make an indispensible contribution to the learning of medical students in the clinical workplace (Dolmans, Wolfhagen, Essed, Scherpbier, \& Van der Vleuten, 2002; Dornan, Boshuizen, King, \& Scherpbier, 2007; Stern et al., 2000). This contribution is the more important since research and experience have shown that workplace learning is implicit, haphazard, and dictated by the demands of the workplace (Eraut, 2004) rather than by students' learning needs (Collins, Brown, \& Newman, 1989). Clinical teachers face the daunting task of meeting high performance standards of both service and teaching. Good teachers can optimize students' learning experiences by providing support, direction and feedback (Kilminster \& Jolly, 2000), and they can be helped to do this effectively by feedback to gauge their performance and point out areas for improvement. Although various instruments, mostly written questionnaires, are available for evaluating the teaching skills of clinical teachers (Beckman, Ghosh, Cook, Erwin, \& Mandrekar, 2004), these instruments have limitations, especially regarding the uptake of feedback. Whether feedback is assimilated, accepted, and eventually applied for learning and improvement depends on various internal and external factors (Sargeant, Mann, van der Vleuten, \& Metsemakers, 2008). The latter comprise the nature of feedback - written feedback must be specific, diagnostic and descriptive (Braskamp \& Ory, 1994) -, the credibility of feedback, the professional culture of the organization, and facilitation of feedback. As for internal factors, self perception of performance and personal reflection are equally likely to hamper as stimulate the uptake of feedback. Moreover, research has demonstrated that written feedback alone is not sufficient to convince teachers to change their teaching (Beijaard \& De Vries, 1997). For teachers to effectively change their teaching behaviour they need to be convinced that there is a real problem. Alternatively, change can be the upshot of extensive reflection, which can be triggered by new ideas about effective teaching (Hashweh, 2003; Richardson \& Placier, 2001). Reflection, which has been shown to clarify a person's perceptions (Eva \& Regehr, 2008), including those of teaching skills, can be stimulated by self-assessment. Knowing that feedback alone has limited power to foster improvement while reflection can be instrumental in this, we examined the effectiveness of feedback combined with self-assessment to enhance teaching quality.

In medicine, self-assessment is generally explored from the perspective of the accuracy of physician self-assessment, usually of clinical knowledge or diagnostic accuracy (Davis et al., 2006). Studies are of the "guess your grade" type in which physicians are asked to predict their score on an external examination (Colliver, Verhulst, \& Barrows, 2005). In a teaching context a different perspective seems preferable, one in which self-assessment is interpreted as a learning experience that can be instrumental in stimulating workplace learning by identifying standards of excellence, deficits, and suggestions for improvement (Colliver et al., 2005; Ross \& 
Bruce, 2007). For the present study, we used the following definition of selfassessment (Eva \& Regehr, 2008) p15.:

'(...) a pedagogical process by which one takes personal responsibility for looking outward, seeking feedback and explicit information from external sources, then using these externally generated sources of assessment data to direct performance improvements.'

In a review of studies on the effectiveness of self-assessment, Colthart et al. deplored the general neglect of the views of those who engage in self-assessment (Colthart et al., 2008), calling for research into the acceptability of self-assessment to those who use it as a learning tool. This prompted us to seek medical teachers' views on the potential of self-assessment to supplement and augment the effects of feedback from students in guiding and encouraging their efforts to optimize clinical teaching.

We investigated whether a structured combination of written feedback based on student ratings and teacher self-assessment could be an incentive for clinical teachers to adapt their teaching practice. The following research questions were addressed:

- To what extent do clinical teachers perceive self-assessment as a useful method to obtain insight into their strengths and weaknesses as a clinical teacher and do they think it will help them to improve or change their teaching?

- To what extent do clinical teachers perceive written feedback (based on student ratings) as useful for obtaining insight into their strengths and weaknesses as a clinical teacher and do they think it will help them to improve or change their teaching?

- Do clinical teachers think that a combination of self-assessment and written feedback augments the effectiveness of feedback?

\section{METHOD}

\section{Context}

Between March 2007 and March 2008 we collected data in a non-academic teaching hospital in the Netherlands. First, all the students on clinical rotations in the hospital were asked to complete an evaluation form for each of the three clinical teachers who had been most involved with their learning during the last rotation they had completed. Next, we invited the clinical teachers who had been evaluated by at least six students to participate in our study. The minimum of six ratings was based on evidence that this number is required to obtain reliable student ratings for feedback (Dolmans \& Ginns, 2005). 


\section{Participants}

37 physicians (ten residents and 27 attending physicians) from different specialties (Internal Medicine, Surgery, Obstetrics/Gynaecology, Paediatrics, Neurology, Dermatology, Ophthalmology, ENT, and Psychiatry) were asked to participate. Participation was voluntary and the principal investigator had no professional or personal relation with any of the participants. All research aims and procedures were explained to the participants and data were handled confidentially.

Instruments and Procedure

\section{Self-assessment, written feedback, and evaluation}

In May 2008, the 37 invited physicians received a validated self-assessment questionnaire consisting of 25 Likert-type items (1=fully disagree; $5=$ fully agree) and two open-ended questions inviting comments about their strengths and weaknesses as a teacher (Appendix 1) (Stalmeijer, Dolmans, Wolfhagen, Muijtjens, \& Scherpbier, 2008). The items asked about teaching-related issues, like providing feedback to students, and were identical to those of the student evaluation questionnaire only phrased from the teacher's point of view (student version: 'the clinical teacher stimulated me to ask questions in order to increase my understanding', physician version: 'I stimulate students to ask questions in order to increase their understanding'). Data on age, years of experience in medicine, years of experience as a clinical teacher, and attendance of courses in clinical teaching were also collected. The questionnaires and a letter explaining the goals and procedures of the study were mailed to the physicians; non-responders received an email reminder.

The physicians who returned the completed self-assessment questionnaire received individual, written feedback (Appendix 2) comprising 1) student ratings: mean (M), standard deviation (SD), and number of students; 2) their selfassessment on each item, and 3) the overall score of their colleagues who had received six or more ratings. Attached to the feedback was a ten-item Likert type questionnaire asking the teachers to evaluate the process of self-assessment and written feedback (Table 2).

\section{Interviews}

Based on the outcomes of the self-assessment, the student ratings, and the process evaluation questionnaire, twelve physicians were invited to explore, in a fortyminute interview, the value of self-assessment and feedback as quality improvement tools for clinical teachers. The demographic information enabled purposive sampling of participants to ensure well-balanced representation of the population.

RES (an educationalist) conducted the semi-structured interviews (June 2008 October 2008), which were audio recorded. The interviews were guided by an interview protocol (Appendix 3) directed at the physicians' general views of clinical teaching, factors influencing the effectiveness of self-assessment, the written feed- 
back (Braskamp \& Ory, 1994; Coe, 1998; Sargeant et al., 2008), and the value of selfassessment and feedback from students. Participants were assured of confidentiality and received the transcript of their interview by e-mail with the request to further clarify their comments and the option to withdraw statements if deemed desirable. They were also assured that no statements would be traceable to individuals and conclusions would apply to the population as a whole and not to individuals.

\section{Analysis}

1. Evaluation questionnaire of the self-assessment and the written feedback based on student ratings.

Means and SDs were calculated for all questionnaire items.

\section{Interviews}

The interviews were transcribed verbatim and submitted to the participants for approval. RES summarized the transcripts guided by the interview protocol. Next DHJMD and IHAPW each read half of the interviews, comparing them with the summaries and discussing points of disagreement to reach consensus. Finally, RES used ATLAS-ti (version 5.2) to analyze the data searching for recurring themes and concepts in relation to factors pertinent to the usefulness and effectiveness of the self-assessment and the written feedback.

\section{RESULTS}

\section{Self-assessment and Feedback}

\section{Response}

Of the 37 physicians invited to fill out the self-assessment questionnaire, thirty returned the questionnaire (response $81 \%$ ) and received feedback. Of the respondents $27 \%$ were female and $70 \%$ attending physician. All major disciplines were represented (Internal Medicine (13\%), Surgery (13\%), Obstetrics/Gynaecology (10\%), Paediatrics (7\%), Neurology (17\%), Dermatology (20\%), Ophthalmology (7\%), ENT (7\%), and Psychiatry (7\%)). The median age was 45 years and the average experience in clinical teaching five years or more. Forty per cent had never attended a course on clinical teaching, while $60 \%$ had attended one or more courses (see Table 1 ). 
Table 1: Demographic information respondents $(N=30)$

\begin{tabular}{|c|c|c|c|c|c|}
\hline Sex & $N(\%)$ & Age & $N(\%)$ & Status & $N(\%)$ \\
\hline Male & $22(73 \%)$ & $<30$ & $5(17 \%)$ & Resident & $9(30 \%)$ \\
\hline \multirow[t]{3}{*}{ Female } & \multirow[t]{3}{*}{$8(27 \%)$} & $30-40$ & $9(30 \%)$ & \multirow[t]{3}{*}{ Attending } & \multirow[t]{3}{*}{$21(70 \%)$} \\
\hline & & $40-50$ & $6(20 \%)$ & & \\
\hline & & $>50$ & $10(33 \%)$ & & \\
\hline \multicolumn{3}{|c|}{ Years of experience as a clinical teacher } & & \multicolumn{2}{|c|}{ Number of teaching courses attended } \\
\hline$<1$ & $4(13 \%)$ & & 0 & 12 (40\%) & \\
\hline $1-5$ & $10(33 \%)$ & & 1 & $8(27 \%)$ & \\
\hline \multirow[t]{3}{*}{$>5$} & \multirow[t]{3}{*}{$16(53 \%)$} & & 2 & $6(20 \%)$ & \\
\hline & & & 3 & $3(10 \%)$ & \\
\hline & & & $\geq 4$ & $1(3 \%)$ & \\
\hline
\end{tabular}

\section{Evaluation of Self-assessment and Feedback}

\section{Response}

Of the 30 physicians who received feedback, 25 returned the evaluation questionnaire $(83 \%)$, i.e. $67 \%$ of the initial group. Of the five non-responders, one had switched hospitals. After inquiry, the four other physicians (attending physicians with multiple years of experience) admitted to have forgotten to fill out the evaluation form. Their student ratings did not differ significantly from the overall population.

\section{Questionnaire}

The physicians appreciated the process of self-assessment and written feedback (mean rating 3.7). Student ratings and their written comments on teachers' general strengths and weaknesses were valued the most. Seventy-six per cent of the respondents would like to receive similar feedback in the future (Table 2).

\section{Interviews}

\section{Response}

All twelve invited physicians (three residents, nine attendings, three female, nine male, from nine disciplines) agreed to be interviewed. They received the transcript of their interviews and three made minor textual changes. 
Table 2: Mean ratings and SDs on a Likert scale (1: fully disagree; 5: fully agree), for the perceived effects of self-assessment and feedback

\begin{tabular}{|c|c|c|c|c|}
\hline & & N & M & SD \\
\hline 1. & $\begin{array}{l}\text { The items of the self-assessment questionnaire are in alignment with my } \\
\text { views on clinical teaching. }\end{array}$ & 24 & 3.7 & .8 \\
\hline 2. & $\begin{array}{l}\text { Filling out the self-assessment questionnaire has given me a better idea of } \\
\text { my performance as a clinical teacher. }\end{array}$ & 25 & 3.7 & 1.0 \\
\hline 3. & $\begin{array}{l}\text { Filling out the self-assessment questionnaire has provided me with insights } \\
\text { into how I can improve my performance as a clinical teacher. }\end{array}$ & 25 & 3.8 & 1.1 \\
\hline 4. & The feedback of the students closely resembled my self-assessment. & 25 & 3.6 & 1.0 \\
\hline 5. & $\begin{array}{l}\text { The feedback from the students has provided me with insights into how I } \\
\text { can improve my performance as a clinical teacher. }\end{array}$ & 25 & 3.8 & 1.1 \\
\hline 6. & $\begin{array}{l}\text { Based on the feedback I am planning to change/improve my clinical teach- } \\
\text { ing. }\end{array}$ & 25 & 3.7 & 1.0 \\
\hline 7. & I learned a lot by filling out the self-assessment questionnaire. & 24 & 3.6 & 1.1 \\
\hline 8. & I learned a lot from the student feedback. & 25 & 4.2 & .8 \\
\hline \multirow[t]{2}{*}{9.} & I learned a lot from students' responses to the open-ended questions. & 25 & 4.0 & 1.1 \\
\hline & & Yes & No & \\
\hline
\end{tabular}

10. I would like to receive this type of feedback in the future

$19(76 \%) 6(24 \%)$

\section{A. Self-assessment}

The self-assessments gave rise to three interview themes: 1) Self-assessment in relation to physicians' views on effective clinical teaching; 2) The usefulness of the self-assessment exercise, and 3 ) the extent to which self-assessment promoted teachers' insight and changes in teaching practice.

\section{A1. Self-assessment and views of clinical teaching}

Nine of the participating physicians felt the items of the self-assessment instrument resonated with their personal views on clinical teaching: demonstrating skills and students shadowing them, discussing patients and asking questions, and creating opportunities for students to perform tasks under supervision. Nevertheless, several physicians thought the entire list could only be realized in an ideal situation with sufficient time and opportunity for clinical teaching. One physician referred to the instrument as a list of the basic skills any clinical teacher needs. All physicians thought the instrument offered a useful framework for self-assessment.

\section{A2. Usefulness of self-assessment}

Several physicians felt the self-assessment exercise was useful and provided a framework and standards for good clinical teaching. It stimulated reflection and helped them to look at their teaching in a more structured way. 
"But it is definitely worthwhile to do it because (...) [for you think] hey, should I do something about that? (...) But that way just completing the list shows you where you might make improvements." (Resident 1)

"No, this sort of gives more structure. So what you know about yourself is usually much more general not split into 25 different themes. And with some things you think, God, yes how is that really, so in that sense I think it is useful to look at it that way, definitely." (Attending Physician 6)

Other physicians disliked the subjectivity of self-assessment and preferred feedback from colleagues or students.

"I think it is much more important what others think of me. Whether I think that I do enough in demonstrating things to students, I mean that is totally irrelevant. If the rest of the students or residents here were to say 'You do not demonstrate enough' then I would have to pay attention to it." (Attending Physician 8)

\section{A3. Did self-assessment foster insight and improvement?}

The majority of the teachers thought the self-assessment merely confirmed their existing views and teaching activities and did not shed new light on their strengths and weaknesses. The more experienced clinical teachers in particular said they had learned nothing new. Although the exercise was said to have provided eye-openers and suggestions for improvement, only a few physicians reported actual changes in their teaching. The prevailing opinion was that nothing new could be added to their teaching repertoire and that time constraints prevented changes in teaching. Any reported changes were small and practical like stimulating students to formulate personal learning goals.

\section{B. Written feedback based on student ratings}

Several issues were raised concerning the feedback: 1) physicians' stance toward student ratings, 2) the nature of the feedback, 3) whether the feedback provided new information, and 4) improvements resulting from the feedback.

\section{B1. Physicians' stance toward student ratings}

The written feedback (Appendix 1) was highly appreciated and quite a few physicians said they had been very curious about their personal ratings. Student feedback posed no problems. The physicians felt it kept them on their toes and saw it as a part of today's world. Some teachers said that since they gave feedback to students, students should be entitled to give them feedback too.

"(...) for I see students as clients too. And then you should also ask, well are you satisfied with how things are going? And how are we going to turn you into the best physicians." (Attending Physician 9) 


\section{B2. The nature of the feedback}

The physicians characterized the feedback as specific, informative and illuminating. They liked the additional written comments and some even said they would like face to face feedback from students, but realized this was probably a bit much to ask given the inherent inequality of teacher-student relationships.

\section{B3. Feedback usefulness}

Discrepancies between their self-assessment and student ratings on the item level were experienced as powerful triggers for reflection and action. Occasionally, physicians had been pleasantly surprised, but they all remarked on the confrontational nature of these data. All agreed that item-level discrepancies were highly informative and served as a focus and foundation for improvement. Reported student ratings of colleagues had little impact but did offer a point of reference and helped to define standards. Interest was stronger in ratings of colleagues in the same department and discipline than at the hospital level.

"For you can see whether you are doing worse or better. Yes, on the one hand, interesting, of course it is about the students. But on the other hand I think, if you want more insight into your general functioning then it is a good thing to see; how would you assess yourself and what do your colleagues think, so where is the discrepancy." (Resident 3 )

B4. Improvements made based on the feedback

Steps taken by teachers in response to the feedback were: encouraging students to formulate learning goals, providing a more structured learning experience, and creating more opportunities for students to undertake activities under supervision. Interestingly, some physicians from specialties with shorter clerkships (ENT, Ophthalmology, and Dermatology) commented they had too little time with students for meaningful clinical teaching and it was just not feasible to undertake additional or new teaching activities.

\section{Combining Self-assessment and Feedback}

When asked what was more useful, self-assessment or feedback, all but one physician opted for feedback. However, they also acknowledged that self-assessment did impact on the evaluation process.

"[The feedback] indicates the discrepancies just that little bit more clearly, so I think you learn more than when you just assess yourself (...) because it is specifically [in the feedback] that you can see the differences (with the self-assessment) and I think that tells you more." (Attending Physician 3)

Eleven physicians were in favour of annual or biannual feedback. As for the selfassessment they proposed a repeat every four or five years with the current meas- 
urement as baseline. It was suggested, as an improvement, to enable physicians to discuss their feedback with a supervisor or educationalist. However, asking a colleague for feedback on their clinical teaching was deemed neither desirable nor viable, because colleagues were not considered acceptable judges of their clinical teaching skills, especially since clinical teaching was typically viewed as a 'solo endeavour'. A wish for additional information on clinical teaching, like specific tips and tricks for supervising students, was expressed by some physicians.

\section{DISCUSSION}

There are numerous instruments for eliciting student ratings of clinical teaching as an incentive for improvement (Beckman et al., 2004). However, many factors interfere with the effectiveness of student feedback and much is left to serendipity (Coe, 1998). Looking for ways to increase the impact of student feedback, we sought clinical teachers' perceptions of the effectiveness of supplementing student feedback with teachers' self-assessment.

\section{Self-assessment}

Teachers generally thought that self-assessment as a single tool had a limited impact as a stimulus for change. While the majority valued the self-assessment, only a minority were actually motivated to implement changes. The reported congruence of the self-assessment instrument with the participants' views on teaching is significant, because a feedback instrument can only be effective when it reflects views not too far removed from those of the target group. The instrument also appeared to be effective in achieving one of the aims of self-assessment, i.e. to help define standards of excellence (Ross \& Bruce, 2007), with physicians saying that it afforded a more structured picture of their clinical teaching. While acknowledging the value of self-assessment many physicians saw no need for change. Particularly, the older physicians ( $\geq 50$ years) commented on the instrument's low news value, which is not surprising considering that physicians with many years of teaching experience are likely to have a firmly established sense of self-efficacy as a teacher and thus feel they have little to learn from self-assessment (Colthart et al., 2008). When interpreting these results, one of the questions becomes to what extent the physicians had already engaged in significant reflection on their teaching skills without the encouragement of a formal self-assessment rendering this intervention obsolete. The interview data showed that several physicians were already engaged in some sort reflection on their clinical teaching, but that it was no more than a general idea of their function as clinical teacher. As one of the physicians formulated it 'So what you know about yourself is usually much more general not split into 25 
different themes' meaning that the self-assessment stimulated deeper and more structured reflection about their clinical teaching skills. Additionally, to explain the lack of news value, it should be noted that the instrument was implemented top down and not to meet a specific need or interest expressed by clinical teachers. Meeting a real need is a strong determinant of success of self-assessment as a learning tool (Coe, 1998; Sargeant et al., 2008).

\section{Written feedback based on student ratings}

The physicians took student feedback very seriously and qualified it as specific, informative and illuminating. This suggests that the physicians experienced the feedback as credible and were open to it, which is considered favourable for feedback effectiveness (Coe, 1998).

\section{Written feedback and self-assessment}

Although the effect of self-assessment in itself was limited, the findings on selfassessment in combination with student ratings were more promising. As mentioned above, the physicians were open to student feedback and, even more significantly, experienced discrepancies between student feedback and their selfassessment as a strong incentive to contemplate change. That physicians take student feedback seriously is in line with a study on multi-source feedback by Sargeant et al. (2007), who found that feedback from patients, who judged their physicians based on concrete experience, was a stronger stimulus for physicians to consider modifying their practice than feedback from colleagues or allied health professionals. Perhaps clinical teachers view student feedback in a similar way, as is suggested by the teacher who said 'I see students as clients too.' Similarly, the physicians in Sargeant's study and the clinical teachers in our study appear to share doubts regarding feedback from colleagues (Sargeant, Mann, Sinclair, Van der Vleuten, \& Metsemakers, 2007). There were indications that the potential effectiveness of selfassessment and feedback was hampered by limitations in the teaching environment. Time constraints during brief clerkships were perceived as a barrier to introducing new teaching practices and while physicians' endorsed the intrinsic value of the teaching approach reflected in the self-assessment instrument they also commented that it was not feasible in practice. The latter remark also reflects on the instrument we used, confirming criticism that it is rather specific in nature (Stalmeijer et al., 2008) while the clinical teaching 'style' it advocates is not considered viable for shorter clerkships (Stalmeijer, Dolmans, Wolfhagen, \& Scherpbier, 2009). Perhaps additional coaching may be helpful to physicians in implementing an adapted version of the instrument. The fact that many physicians were interested in additional information on clinical teaching and in being coached can be interpreted 
as a positive outcome of the self-assessment and feedback exercise and as a sign that it has augmented the physicians' interest in improving their clinical teaching in an effective and professional manner.

\section{Strengths and weaknesses}

Feedback effectiveness is a complex issue involving numerous interacting elements and this study addressed only a selection of these elements. However many elements which are known to influence feedback effectiveness, like self-perceptions of performance or beliefs, are difficult to measure because they tap into beliefs and self-efficacy, which are outside the awareness of many people (Pajares, 1992). Although the study was conducted within one teaching hospital and the number of participants was small, the physicians we interviewed were purposively sampled to provide an accurate representation of the population. It is a strength of this study that all the instruments were based on research and thus can provide strong guidance for further research (Bowden \& Marton, 1998). Furthermore, the mixed methods design afforded a deeper understanding of the research topic and the research questions.

\section{Future research}

The results of this study will have to be confirmed by studies among a larger and more varied population of physicians in different hospitals. Larger studies may also shed more light on the influence of self-assessment and feedback effectiveness. It also seems worthwhile to study long-term effects of self-assessment and feedback by 1) examining data on repeated feedback and self-assessment over several years and 2) observation studies to examine whether physicians actually incorporate feedback into their teaching practices. Additionally, research should focus on the deeper understanding of internal and external factors that influence feedback effectiveness. Finally, self-assessment is only one way to optimize feedback and we recommend that other methods be considered too, such as coaching, and extending the combination of self-assessment and student feedback into a multi-source feedback process.

\section{Acknowledgements}

The authors would like to thank: Merel Mulder and Lorette Stammen for their help in transcribing the interviews, Mereke Gorsira for editing the final version of the manuscript, the residents and attending physicians from the Catharina Hospital in Eindhoven, the Netherlands, who so generously donated their time to participate in this research. 


\section{REFERENCES}

Beckman, T. J., Ghosh, A. K., Cook, D. A., Erwin, P. J., \& Mandrekar, J. N. (2004). How reliable are assessments of clinical teaching? A review of the published instruments. Journal of General Internal Medicine, 19(9), 971-977.

Beijaard, D., \& De Vries, Y. (1997). Building expertise: a process perspective on the development or change of teachers' beliefs. European Journal of Teacher Education, 20(3), 243-255.

Bowden, J., \& Marton, F. (1998). Quality and qualities. In J. Bowden \& F. Marton (Eds.), The university of learning (pp. 211-245). London: Kogan Page Limited.

Braskamp, L. A., \& Ory, J. C. (1994). Assessing faculty work: enhancing individual and institutional performance. San Francisco, CA: Jossey-Bass.

Coe, R. (1998). Can feedback improve teaching? A review of the social science literature with a view to identifying the conditions under which giving feedback to teachers will result in improved performance. Research Papers in Education, 13(1), 43-66.

Collins, A., Brown, J. S., \& Newman, S. E. (1989). Cognitive Apprenticeship: Teaching the crafts of reading, writing, and mathematics. In L. B. Resnick (Ed.), Knowing, learning, and instruction: Essays in honor of Robert Glaser (pp. 453-494). Hillsdale, New Jersey: Lawrence Erlbaum Associates, Inc.

Colliver, J. A., Verhulst, S. J., \& Barrows, H. S. (2005). Editorial: Self-Assessment in medical practice: A further concern about the conventional research paradigm. Teaching and Learning in Medicine, 17(3), 200-201.

Colthart, I., Bagnall, G., Evans, A., Allbutt, H., Haig, A., Illing, J., et al. (2008). The effectiveness of selfassessment on the identification of learner needs, learner activity, and impact on clinical practice: BEME Guide no. 10. Medical Teacher, 30(2), 124-145.

Davis, D. A., Mazmanian, P. E., Fordis, M., Van Harrison, R., Thorpe, K. E., \& Perrier, L. (2006). Accuracy of physician self-assessment compared with observed measures of competence. Journal of the American Medical Association, 296(9), 1094-1102.

Dolmans, D. H. J. M., \& Ginns, P. (2005). A short questionnaire to evaluate the effectiveness of tutors in PBL: validity and reliability. Medical Teacher, 27(6), 534-538.

Dolmans, D. H. J. M., Wolfhagen, H. A. P., Essed, G. G. M., Scherpbier, A. J. J. A., \& Van der Vleuten, C. P. M. (2002). Students' perceptions of relationships between some educational variables in the outpatient setting. Medical Education, 36(8), 735-741.

Dornan, T., Boshuizen, H., King, N., \& Scherpbier, A. (2007). Experience-based learning: a model linking the processes and outcomes of medical students' workplace learning. Medical Education, 41(1), 8491.

Eraut, M. (2004). Informal learning in the workplace. Studies in Continuing Education, 26(2), 247-273.

Eva, K. W., \& Regehr, G. (2008). "I'll never play professional football" and other fallacies of selfassessment. Journal of Continuing Education in the Health Professions, 28(1), 14-19.

Hashweh, M. Z. (2003). Teacher accommodative change. Teaching and Teacher Education, 19(4), 421434.

Kilminster, S. M., \& Jolly, B. C. (2000). Effective supervision in clinical practice settings: a literature review. Medical Education, 34(10), 827-840.

Pajares, M. F. (1992). Teachers' beliefs and educational research: cleaning up a messy construct. Review of Educational Research, 62(3), 307-332.

Richardson, V., \& Placier, P. (2001). Teacher Change. In V. Richardson (Ed.), Handbook of research on teaching. Washington: American Educational Research Association.

Ross, J. A., \& Bruce, C. D. (2007). Teacher self-assessment: a mechanism for facilitating professional growth. Teaching and Teacher Education, 23(2), 146-159.

Sargeant, J., Mann, K., Sinclair, D., Van der Vleuten, C. P. M., \& Metsemakers, J. (2007). Challenges in multisource feedback: intended and unintended outcomes. Medical Education, 41(6), 583-591. 
Sargeant, J., Mann, K., van der Vleuten, C., \& Metsemakers, J. (2008). “Directed” self-assessment: practice and feedback within a social context. The Journal of Continuing Education in the Health Professions, 28(1), 47-54.

Stalmeijer, R. E., Dolmans, D. H. J. M., Wolfhagen, I. H. A. P., Muijtjens, A. M. M., \& Scherpbier, A. J. J. A. (2008). The development of an instrument for evaluating clinical teachers: involving stakeholders to determine content validity. Medical Teacher, 30(8), e272-277.

Stalmeijer, R. E., Dolmans, D. H. J. M., Wolfhagen, I. H. A. P., \& Scherpbier, A. J. J. A. (2009). Cognitive apprenticeship in clinical practice: can it stimulate learning in the opinion of students? Advances in Health Sciences Education: Theory and Practice, 14(4), 535-546.

Stern, D. T., Williams, B. C., Gill, A., Gruppen, L. D., Woolliscroft, J. O., \& Grum, C. M. (2000). Is there a relationship between attending physicians' and residents' teaching skills and students' examination scores? Academic Medicine, 75(10), 1144-1146. 


\section{APPENDIX 1}

\section{SELF-ASSESSMENT INSTRUMENT}

Fully Fully

disagree agree

$\begin{array}{lllll}1 & 2 & 3 & 4 & 5\end{array}$

1. I consistently demonstrate how to perform clinical skills

2. I clearly explain the important element for the execution of a give task

$\square \square \square \square \square$

$\square \square \square \square \square$

$\square \square \square \square \square$

3. I create sufficient opportunity for the student to observe me

4. I serve as a role model as to the kind of doctor students would like to become

5. I observe students multiple times during patient encounters

6. I give useful feedback during or immediately after direct observation of student's patient encounters

7. I help the student understand which aspects they need to improve

8. I adjust my teaching activities to the level of experience of students

9. I offer sufficient opportunities to students to perform activities independently

10. I support students in activities that they find difficult to perform

11. I gradually reduce the support given, to allow students to perform certain activities more independently

12. I ask students to provide a rationale for their actions

13. I help students become aware of gaps in their knowledge and skills

14. I ask students questions aimed at increasing their understanding

15. I encourage students to ask me questions to increase their understanding

16. I stimulate students to explore their strengths and weaknesses

17. I stimulate students to consider how they could improve their strengths and weaknesses

$\begin{array}{ll}\text { 18. I encourage students to formulate learning goals } & \square \square \square \square \square \\ \text { 19. I encourage students to pursue their learning goals } & \square \square \square \square \square \\ \text { 20. I encourage students to learn new things } & \square \square \square \square \square\end{array}$

21. I create a safe learning environment

22. I take sufficient time to supervise students

23. I am genuinely interested in the students

24. I show respect to students

25. Give yourself an overall assessment $(1-10)$ of your own clinical teaching [] performance

26. What are your strengths as a clinical teacher?

27. What are areas in which you as a clinical teacher could improve? 


\section{APPENDIX 2}

\section{EXAMPLE OF FEEDBACK PROVIDED TO PHYSICIANS}

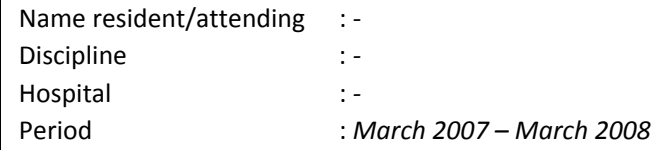

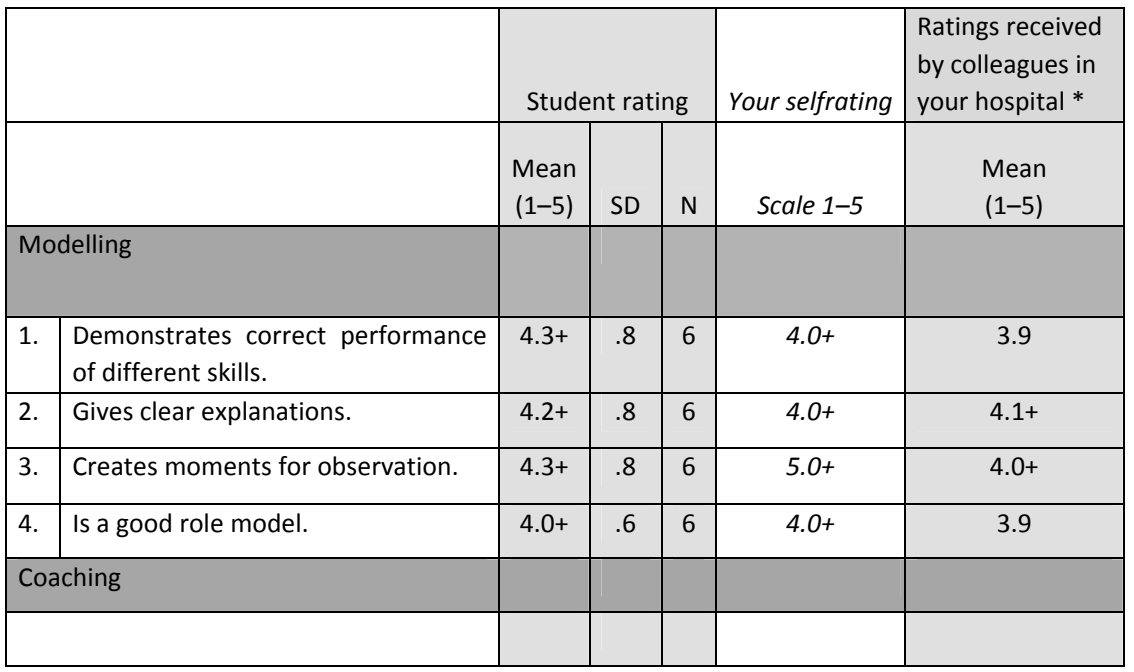

Strengths identified by the students:

- The physician is calm

- $\quad$ Offered many opportunities for students to interview and examine new patients and observe clinical encounters. (2x).

- Excellent mentor! (2x)

- Friendly.

- $\quad$ Detailed explanation of activities.

- $\quad$ Easy to get along with.

- $\quad$ Gives explanations, educates about procedures.

- He creates a safer learning environment.

- I could ask anything and observe everywhere.

\section{Suggestions for improvement made by the students:}

- $\quad$ First see new patients on my own.

- Supervision after an encounter could have been better.

- More evaluation.

* Mean of all student ratings of the clinical teachers in the hospital

+ Strengths = aspects with high ratings $(\geq 4)$

- Weaknesses $=$ aspects with low ratings $(<3)$ requiring attention. 


\section{APPENDIX 3}

\section{INTERVIEW PROTOCOL}

- In what way do you think students can learn the most from you? / What do you have to offer to students?

- $\quad$ Can you describe how you guide students?

- Is there a discrepancy between how you would like to teach and how you are actually teaching?

- $\quad$ Are the items of the self-assessment questionnaire in alignment with your views regarding clinical teaching during clerkships?

- Which items are in good agreement with your approach to clinical teaching?

- Which items are not in agreement with your approach to clinical teaching?

- If items are not in alignment with your views: do you consider them useful? Why/why not?

- Do you think it is helpful to complete a self-evaluation questionnaire?

- Is self-assessment new to you? Have you self assessed in other situations? Did you think selfassessment was useful in those cases?

- Has completing the self-assessment given you a clearer picture of how you function as a clinical teacher for students?

- Has completing the self-assessment given you concrete suggestions for changing or improving your teaching of students?

- Has completing the self-assessment led to concrete changes in the way you teach medical students/ or do you intend to change the way you teach? If yes, how? If no, why not?

- Do you think this combination of written feedback and additional data is useful for you?

- If yes, why, if not, why not?

- Which information do you find particularly useful?

- $\quad$ (useful to receive information from students $\leftarrow$ credibility)

- $\quad$ (How did you experience the feedback (positive/negative $\leftarrow$ acceptance))

- Were there striking discrepancies between your self-assessment, student assessment, and your colleagues' mean ratings?

- If yes, which discrepancies were there? If no, what are your thoughts about that?

- How has this affected your views regarding the teaching of medical students?

- Has the feedback you received given you concrete ideas for changing or improving the way you teach medical students?

- $\quad$ Since you received the feedback have you changed aspects of your teaching of medical students?

- If yes, please give a concrete example? If not, why not?

- $\quad$ Are there any concrete factors that are a barrier to changing your teaching? $\leftarrow$ How might this be resolved?

- How can this type of written feedback be improved?

- Which additional information?

- Which additional judges (besides students)?

- Different presentation? Different form of communication?

- In retrospect, which has been more useful for you: self-assessment, feedback, or the combination of the two? Why? 
Chapter 6

Factors influencing clinical teaching from the perspective of the Maastricht Clinical Teaching Model: Views of experienced clinical teachers 


\section{ABSTRACT}

\section{Background}

Based on principles of cognitive apprenticeship, the Maastricht Clinical Teaching (MCT) model presents a three step approach to clinical teaching. Several studies have proven the validity of the model, but 'the impact' of the clinical learning environment on the teaching methods proposed by the model has remained unexplored.

\section{Aim}

To explore how the MCT model fits with the practice of experienced clinical teachers and which factors influence clinical teaching from the perspective of the MCT model.

\section{Method}

A purposive sample of seventeen experienced clinical teachers from five different disciplines and four different teaching hospitals took part in semi-structured individual interviews. Two researchers independently performed a thematic analysis of the interview transcripts. Coding was discussed within the research team until consensus was reached.

\section{Results}

All participants recognized the MCT model as a structured picture of the practice of clinical teaching during clerkships. Modelling and creating a safe learning environment were seen as crucial factors. Longer attachments were needed to ensure that all teaching methods of the MCT model were applied. Motivation and pro-active behaviour of physicians and students stimulated the use of the teaching methods. Participants indicated that nurses played an important, albeit implicit, role in teaching and in creating a safe learning environment.

\section{Discussion}

The MCT model can offer valuable guidance in structuring clinical teaching activities. It could also supply design principles for effective clerkships and faculty development programmes. 


\section{INTRODUCTION}

Clinical teaching has received much attention in the medical education literature over the last three decades. In a letter to the editor, Crossley, (2006) referred to supervision as the "vital key to unlocking learning from clerkships". A lot of effort has been put into 1) training and giving feedback to clinical teachers to help them optimize their teaching (Ramani \& Leinster, 2008) and into 2) mapping the clinical learning environment in order to identify those elements that can either make or break the learning experience of students during clerkships (Deketelaere, Kelchtermans, Struyf, \& De Leyn, 2006; Hoffman \& Donaldson, 2004).

In order to remedy the lack of instructional models that speak directly to the teaching behaviours of clinical teachers (Graffam, Bowers, \& Keene, 2008), we recently developed the Maastricht Clinical Teaching (MCT) model (Stalmeijer, Dolmans, Wolfhagen, Muijtjens, \& Scherpbier, 2010) (Figure 1), a practical model for clinical teaching based on principles of cognitive apprenticeship (Collins, Brown, \& Newman, 1989). Building on theories of situated cognition and situated learning (Brown, Collins, \& Duguid, 1989), cognitive apprenticeship embraces the strengths of traditional apprenticeship learning and acknowledges the importance of explicating the tacit knowledge that experts use in performing complex cognitive tasks. Cognitive apprenticeship and situated learning have been identified as theories that can facilitate transfer of knowledge, which strengthens their relevance for learning in the clinical setting (Gordon et al., 2000; Kaufman \& Mann, 2010).

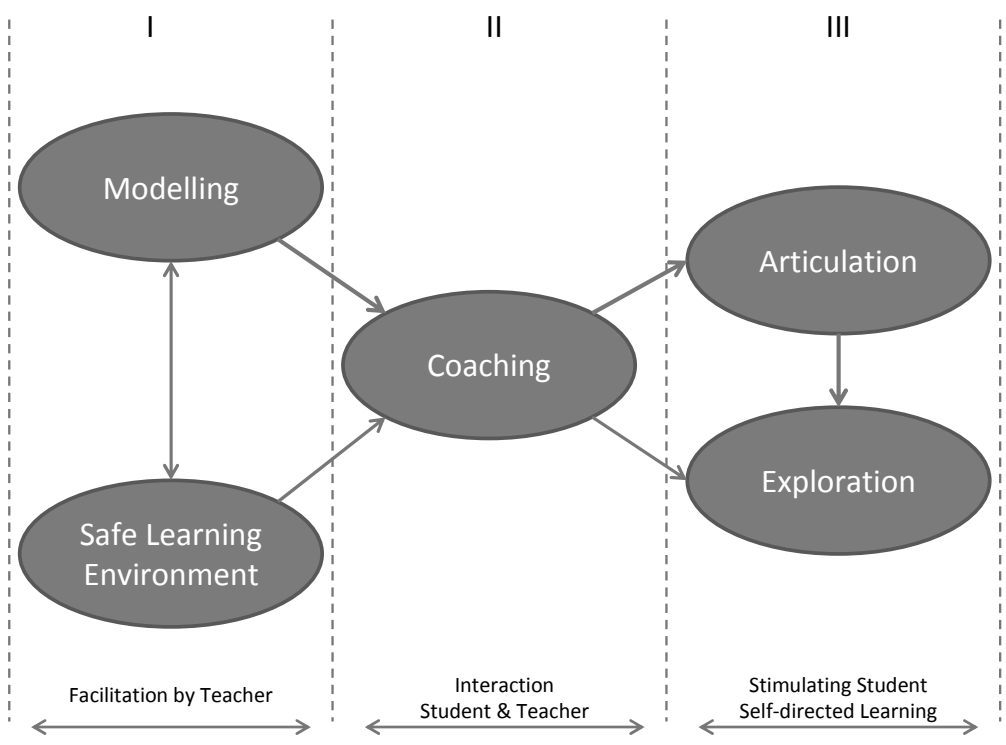

Figure 1: The Maastricht Clinical Teaching model 
The MCT model proposes a three-step approach to clinical teaching based on cognitive apprenticeship teaching methods (Figure 1). Each step proposes several methods to ensure effective teaching, such as modelling, scaffolding and stimulating reflection (Stalmeijer et al., 2010). Although the MCT model is based on cognitive apprenticeship teaching methods (modelling, coaching, scaffolding, articulation, reflection and exploration), the three steps of the model resonate with several teaching activities that are also endorsed in the medical education literature, such as providing a safe learning environment, modelling and stimulating self-directed learning. A safe learning environment is part of step 1 of the MCT model, where the main aim is to facilitate learning. It is the clinical teacher's responsibility to provide a safe learning environment (Beckman \& Lee, 2009; Boor et al., 2008) in which students feel free to ask questions and seek guidance. In the same step the clinical teacher is also expected to be a good role model, modelling relevant skills and behaviours (Elzubeir \& Rizk, 2001). Student-teacher interaction is central to step 2. Interaction is prerequisite to enable teachers to provide guidance at the student's level and to use feedback and observation in coaching the student (Branch \& Paranjape, 2002; Scardamalia \& Bereiter, 1984; Vygotski, 1978). In step 3 the clinical teacher seeks to stimulate the student to engage in self-directed learning by focusing on the articulation of knowledge and encouraging students to reflect on their performance (Schön, 1987). The aim is also to engage students in practice by asking them to formulate and work towards specific learning objectives (Kaufman, 2003; Leinster, 2009). In summary, research from different fields underpins the importance and effectiveness of the teaching methods of the MCT model.

We have demonstrated in earlier studies that cognitive apprenticeship is a valid concept for undergraduate clinical teaching and we have validated the MCT Questionnaire and Model (Stalmeijer et al., 2010; Stalmeijer, Dolmans, Wolfhagen, \& Scherpbier, 2009). What has remained underexposed, however, is how the clinical learning environment influences the teaching activities described in the MCT model. We were alerted to this oversight by a description of clinical teaching as an open system, influenced by multiple forces and continuously interacting with its environment (Hoffman \& Donaldson, 2004). Clinical teaching is shaped by three main forces and their interactions: the environment, the clinical teacher and the student. In the clinical environment, the first and foremost concern is patient care, while student learning takes a back seat (Sandrioni, 1997). In the clinical settings (Ramani \& Leinster, 2008) physicians have to contend with time constraints, patient census (e.g. illnesses and number of patients, pace with which they move through health care system) and more often than not few, if any, incentives and rewards for teaching (Spencer, 2003). Second, clinical teachers' perceptions and general motivation for teaching exert a strong influence on the teaching approaches that are used (Richardson \& Placier, 2001; Skeff et al., 1997). And third, students' attitudes (proactive versus passive) have also been described as an important determinant of 
students' clinical learning experiences (Deketelaere et al., 2006). Research has typically focused on either clinical teaching or the clinical learning environment, but few studies have addressed their interactions. We therefore investigated the effects of the three factors which dynamics shape clinical teaching. The main aim of the study was to verify that the theoretical MCT model is compatible with the practical experiences of clinical teachers. We specifically sought to answer two research questions:

1. How does the MCT model fit with clinical teaching practice as perceived by experienced clinical teachers?

2. Which factors influence the use of the MCT model during clerkship teaching? (Environmental level, Clinical teacher level, Student level)

\section{METHODS}

\section{Context}

The study was conducted among hospital-based clinical teachers in years 4-6 of a six-year undergraduate medical programme at Maastricht University Medical School. Years 4-6 are devoted to clerkships in the academic hospital and affiliated regional hospitals. Rotations differ in duration depending on the type of rotation and the discipline, and the sequence of rotations differs between students. During rotations, students spend time in the wards, out-patient clinics and the accident and emergency department. Clerkships in years 4 and 5 last between four to ten weeks, while students in year 6 undertake an eighteen week 'senior clerkship' in a discipline of their choice.

\section{Research Team}

The research team consisted of three educationists/educational psychologists (RES, DHMJD, IHAPW) and three medical doctors with ample experience in medical/clinical education either in curriculum development (HAMSB \&AJJAS) or in supervising students (MvSH).

\section{Sampling \& Participants}

Key informants from the academic hospital and four regional hospitals contributed to the purposive sampling of participants. We selected only participants who had had several years of experience supervising students during regular and senior clerkships. We will refer to the clerkships in years 4 and 5 as 'regular clerkships' or 'clerkships', and we will use the term 'senior clerkship' to refer to the extended 
rotation in year 6 . We invited participants from departments that offer both types of clerkship (Internal Medicine, Surgery, Paediatrics, Gynaecology/Obstetrics and Neurology), since the regular clerkships in disciplines like dermatology, ophthalmology and ENT give students only limited time in the clinical setting. A letter or email was sent to prospective participants by the researchers or a key informant explaining the goals of the research and requesting them to participate in an interview. RS telephoned those who agreed to participate and set a date and time for the interview. Saturation was reached after seventeen interviews. The participants were three female and fourteen male doctors who had had four to 28 years ( $M=13.4$ years) experience in their discipline (Table 1). All had ample experience in supervising students and had attended at least one faculty development course on clinical teaching skills.

Table 1: Disciplines of the participants

\begin{tabular}{|ccc|ccc} 
Discipline & $\begin{array}{c}\text { Internal } \\
\text { Medicine }\end{array}$ & Surgery & Paediatrics & Obstetrics/Gynaecology & Neurology \\
\hline $\mathrm{N}(\%)$ & $6(35 \%)$ & $4(24 \%)$ & $3(18 \%)$ & $3(18 \%)$ & $1(5 \%)$ \\
\hline
\end{tabular}

\section{Semi-structured interviews}

RES conducted the semi-structured interviews using an interview guide (attachment 1) that was based on the literature and contained factors that had been shown to influence clinical teaching (Hoffman \& Donaldson, 2004). The guide was discussed extensively within the research team. The approach to the current research was a pragmatic one (Cherryholmes, 1992), and the principal aim was to investigate whether the theoretical MCT model was compatible with the practical experiences of clinical teachers.

The participants were interviewed at a location of their choice between February and March 2010. They were requested to block a one hour time slot for the interview but participants were told that they could end the interview at any time. RES used the interview guide as the starting point of the interview but also pursued interesting new information that emerged during the interview. This new information was then included in the subsequent interviews. In addition, the participants were asked to comment on the MCT model (Figure 1).

\section{Ethical approval}

At the time of the study formal approval of medical education research was not within the remit of the ethics committee of the academic hospital. Based on known ethical guidelines for research (Declaration of Helsinki) the following guidelines were adhered to: The goals and procedures of the study were fully explained to the 
participants, who were invited to ask questions. It was explained that participation was voluntary and that they were free to withdraw at any time. All participants signed an informed consent form detailing the goals and the expected outcomes of the study. The participants received no remuneration. The transcripts were anonymized and only discussed within the research team, where strict confidentiality was maintained.

\section{Data analysis}

All interviews were audio taped, transcribed verbatim and submitted to the participants for approval. RES and HAMSB coded the transcripts independently, searching for relevant concepts that recurred within and between transcripts. This process resulted in a codebook, which RES and HAMSB discussed and compared. RES then continued the analysis, identifying recurring themes within and between transcripts. The resulting themes were discussed by the research team until consensus was reached. The analysis was supported by Atlas-ti 6.0 software.

\section{RESULTS}

\section{How well does the MCT- model match the practice of experienced clinical teachers?}

During the interview the participants were asked to comment on a pictorial representation of the three steps of the MCT model (Figure 1): 1) facilitation by the teacher through modelling and providing a safe learning environment, 2 ) interaction between the teacher and the student through coaching activities, and 3) stimulation of students' self-directed learning through articulation, reflection and exploration. All participants acknowledged that the MCT model offered a structured picture of their teaching practice. Two themes featured prominently in the teachers' descriptions of their teaching activities: differences between the regular (6-10 weeks) and senior (18 weeks) clerkships and the ongoing importance of modelling and a safe learning environment.

\section{Short versus long clerkship rotations}

Although all participants agreed that the teaching methods of the model were useful for all clerkships, they specifically commented on the effects of clerkship duration. There was general consensus that teaching during regular clerkships was focused on the first two steps (modelling and safe learning environment). They particularly noted that step 1 was crucial for fourth- and fifth-year students, who 
needed to find their bearings in the department and the discipline. This required repeated modelling and encouragement to give students the confidence to 'move freely' within the clinical setting. One participant described the regular clerkships as synonymous with step 1 . The main reason why teaching did not always make it to step 3 (articulation and exploration) during the shorter clerkships, according to the participants, was time constraints on the part of the student (limited time in the department) and the physician (not enough time to truly focus on observing and coaching the student). One participant explained, however, that one 'clear-cut' patient case could incorporate all three steps even during a short rotation.

"I do recognize that (...) Well, creating a safe learning environment, in fact that is what we do during a student's first two weeks in the department. Go and sit somewhere in the department and observe what is going on, shadow your resident. So, make few demands, give them time to settle in. When they want more, they can do more, but there is no pressure. And then gradually towards more responsibility and so a little more coaching, where we give more feedback or observe them and do a mini-CEX or something. And there you are, that phase 3, you have already reached with students during senior clerkships." (Participant \#4)

All participants agreed that all steps of the MCT model occurred during the longer clerkships, when students spend more time in the department and become part of 'the team', which enables clinical teachers to get to know them better, monitor their learning curves and adapt teaching activities to the level the student should attain. The participants also remarked that step 3, stimulating students' selfdirected learning, was what the senior clerkships were really all about. Not only because the students were more experienced but also because the portfolio introduced by the medical school required students to formulate learning objectives. They stressed, however, that steps 1 and 2 remained very important throughout the senior clerkship as well, even though the focus had shifted to step 3.

"(...) with senior students I really think that you, for them I also have a plan in mind like well I want them to have seen this and this and that by the end of the clerkship and what is a sick child and how do you treat them, how do you approach them and that they get the theoretical background. I monitor this too, so then I also elaborate on content and I have them perform some skills, which I just do not get around to with the other students. So with a senior student my aim is that at the end of the clerkship, that they can do a part of an inguinal hernia in a child, yes perform sounds rather strong somehow." (Participant \#7)

\section{The continuing importance of modelling and a safe learning environment}

The first participant described that both modelling and creating a safe learning environment remained important during steps 1 and 3 . This seemed an interesting no- 
tion, and we probed for the participants' views in this regard during subsequent interviews. Some participants made similar comments spontaneously and others concurred that modelling and a safe learning environment were prerequisite for an effective teacher- student relationship. It was also said that good teaching meant 'going back and forth' between the steps depending on the student's needs.

"Well, yes, I think that is the foundation. I mean, you set a good example and you have to ensure that people feel safe, let's say with regard to making mistakes or doing good things. That is sort of the basis, for if that is missing, things are bound to go wrong. In that case, people keep running into difficulties and are afraid to speak up or afraid to take action." (Participant \#8)

\section{Which factors influence the use of the MCT model in undergraduate clinical teaching practice?}

Following the general discussion of the MCT model, the interview moved on to the various factors that influence how physicians teach and which forms teaching takes during clerkships. We asked participants to reflect, from the perspective of the model, on three factors that might influence clinical teaching practices: elements in the environment (e.g. hospital regulations, the department, the medical school) and teacher and student characteristics. There was general agreement that the three factors encompassed the elements that influenced their teaching.

\section{Environmental elements influencing teaching}

At some point in the interview, most participants mentioned the influence of 'time constraints' and 'lack of facilities where students can see their own patients'. Two additional themes emerged: multiple groups of hospital staff contributing to teaching and division of teaching roles within the department.

Role division and role hierarchy

Specialists, residents, specialized nursing staff and midwives, all these groups were identified as being involved in teaching in at least one of the three steps. The main responsibility for teaching lies with the specialists and the residents, whose teaching covered all three steps. The participants indicated that some physicians were by nature more disposed to teach. They also noted a difference in staff involvement between regular and senior clerkships. Most of the teaching during regular clerkships was done by residents, although a specialist conducted the final assessment. Occasionally, this gave rise to suboptimal learning situations, as when residents are too preoccupied with their own learning to pay attention to the student's learning process. 
"When a student is unlucky, he or she will have a resident who has only one minute on the fly so to speak. So all this resident can do is trying to stay alive, because at five p.m. the supervisor will arrive and start asking all sorts of hard questions and am I going to survive that. So, the resident is not interested in the student at all." (Participant \#13)

Senior students on the other hand were supervised by specialists. This was partly because they were looked upon as 'semi-residents' and occasionally given tasks that could also be undertaken by a resident, such as going on ward rounds with a nurse. Nurses were described as resource people for students on regular clerkships, but in practice they were mainly involved in teaching in the senior clerkship.

"(...) the less experience you have, the more you rely on the nurses' experience at first." (Participant \#15)

Opinions were divided about the teaching role of nurses. There was general agreement that nurses contributed to the learning climate and could help students in their socialization within the department. In other words, the nurses were involved in step 1. Despite nurses not having a formal role in teaching, certain skills (e.g. caring for patients, giving intravenous injections) were more often than not taught by nurses, especially experienced and specialized nurses (e.g. in the brain care unit, intensive care, neonatal intensive care unit). During clerkships in obstetrics/gynaecology, midwives also contributed to all three steps in the delivery rooms.

"Well, it may not actually be a formal role (...), but in practice there definitely is a role, for in the wards, but also in accident and emergency and in the outpatient clinic it is the nurses who will often say like, and these are very small things, hey, the papers are there and no, you had better call so and so or you had better do this or in drawing blood, no, those and those tubes. So it is not so much that they have a very specific, well defined task, it is more in day-to-day practice that they have a guiding role in getting students settled, like, how do you assert yourself in the outpatient clinic and how do you set about that?" (Participant \#10).

"Well, the nurse is, for instance treating decubitus ulcers there are specialized nurses who are trained to treat those and who actually do that. Well, it is excellent to go along with one of those nurses and look at different decubitus ulcers, which phase is it and how do you treat it? They learn a lot from that and they have an eye for that. And what is the best way to handle a patient? Someone whose leg is broken but which has not been repaired yet, whom you have to wash, how do you turn them over, how do you put someone in a wheelchair? Yes, you should not ask a specialist that, well, he does know it, he even does it, but you don't really learn from that from him. For that you really have to go with one of those nurses." (Participant \#13) 


\section{The influence of the clinical teacher on the teaching process}

There was no agreement among the participants with regard to the question whether or not clinical teaching was a special skill. There was general agreement, however, that it depended very much on the characteristics of individual physicians whether they got involved in clinical teaching. The two most frequently mentioned characteristics were 'experience as a physician and as a teacher' and 'motivated to teach/enthusiasm for teaching'.

\section{Experience as a physician and as a teacher}

The majority of the participants said they had actively taught students ever since their own residency. Seeing today's residents teaching students reminded them of their own time as residents. They remembered being so overwhelmed by their own learning that it was all but impossible to move beyond step 1. As their clinical expertise grew, they had gradually become able to pay more attention to the learning of students and move to steps 2 and 3 (coaching and exploration).

"In that sense that role has changed and I am calmer now, I am obviously more efficient in doing consultations and I feel that I see the patient's problem more quickly. So, often I have energy left to observe students. Whereas, at first I was unable to do that, because I had to listen to the patient, but now I usually know, well let me put it this way, I listen to the patient with my left ear, and my right eye and ear are available to observe the student." (Participant \#7)

\section{Motivation/Enthusiasm}

A frequent topic in relation to the division of teaching roles within the department was that some physicians were simply more motivated to teach than others. The physicians who liked teaching deliberately scheduled time for teaching and found ways to cover all three steps of the MCT model. Participants said they were motivated by the reward of seeing students grow and they also felt that as a physician they were kept on their toes by students asking questions. They showed enthusiasm to look for ways to pass on the knowledge and skills of their own discipline.

"(...) for the clinical teacher it is also about being interested in teaching. Wanting to explain things and of course whether you, whether you want to make time for that and some have that and others don't. It also has to do with your own enthusiasm for your specialty. When you really enjoy your work, when you love your work, that is communicated to the students and it seems to me that they enjoy their clerkship much more than when you do your work reluctantly." (Participant \#4) 


\title{
The influence of student characteristics on the teaching process
}

The participants agreed that students could have a significant impact on teaching and the extent to which the three steps were or were not used. The main characteristics that were mentioned were students' levels of experience and motivation and students being proactive.

\section{Level of experience and motivation}

The clerkships in years 4 and 5 and the senior clerkship in year 6 differ not only in students' age but also in students' knowledge, skills and experience in learning in the clinical environment. Participants said that these factors prevented them from progressing beyond steps 1 and 2 with the younger and more inexperienced students, whereas during the senior clerkships they felt they could tackle step 3. Participants also thought that senior students were more motivated because they had applied for a clerkship in a specific discipline. As a result senior students were more likely to be accepted as 'part of the team'. This stimulated physicians to pay more attention to step 3 activities with these students.

\begin{abstract}
"Students you very much take by the hand and you give them clear assignments like, you are now going to do this and you are going to work on that assignment and you answer that question for me, while senior students, in a manner of speaking, are in principle people who are motivated and from a certain choice, they have chosen the discipline in which they are working, they are also more experienced of course (...) and you have to guide them more, well, towards reasoning, the way of thinking, how we do that in internal medicine and towards (...) expanding their knowledge." (Participant \#6)
\end{abstract}

Pro-active behaviour

Pro-active students were generally described as 'easier to work with' than their more 'passive' colleagues. Pro-active students were described as 'good' or 'smart' students. It was easier to use the three steps with them since they asked for specific coaching or modelling and clearly indicated their learning needs. As a result they received more attention and were allowed to undertake more activities independently. Students that were more passive and/or insecure were at risk of getting stuck in step 1 , never progressing beyond the role of passive observer.

\footnotetext{
"Students who show an interest and who make the extra effort will very soon, it will be noticed very quickly in a positive way and they will be accepted and that means they will sort of be taken along to share in the exciting things. But it is definitely possible for a student to behave inconspicuously and low profile and to withdraw from quite a few teaching moments or supervision. In this hospital in particular, the organization is, yes, quite large, so one student, yes one student more or less is bound to go unnoticed if they, yes if the student really tries to escape from supervision." (Participant \#6)
} 


\section{DISCUSSION AND CONCLUSIONS}

While the role of the clinical teacher has received ample attention in medical education research, the interactions between the clinical learning environment and the clinical teacher have remained a relatively uncharted area. The aim of the current study was twofold: 1) To examine whether the MCT model reflects the teaching practices of experienced clinical teachers and 2) to investigate which factors influence how the MCT model is used in practice during clerkships (environmental, clinical teacher and student).

The results confirm findings from previous research that the MCT model fits with teaching activities in clinical practice (Stalmeijer et al., 2009). This adds to the growing evidence that educational principles from situated cognition and situated learning theories are relevant to clinical teaching practice and research (Kaufman \& Mann, 2010). We found that especially modelling and creating a safe learning environment were considered pivotal to all clinical teaching. These results are corroborated by previous research showing that modelling in particular is the foundation on which teaching in the workplace is built (Elzubeir \& Rizk, 2001; C. A. Smith, Varkey, Evans, \& Reilly, 2004), that physicians should support student participation (Dornan, Boshuizen, King, \& Scherpbier, 2007) and that the learning climate to a certain extent predicts the educational outcomes achieved in a particular learning environment (Boor et al., 2008; Roff, McAlleer, \& Skinner, 2005).

The results reveal several factors that influence clinical teaching during regular and senior clerkships. First of all, and quite unsurprisingly, time turned out to be a major factor. This was reflected in the participants' comments about lack of time for teaching and the short duration of clerkships in years 4 and 5 . Although in most studies physicians are reported to complain most frequently that they are too busy to teach (Ramani \& Leinster, 2008), the results of the current study appear to shed a different light on the time aspect. Time affected not only teaching (physicians taking time to teach because they are motivated to teach), but it also related to the students (duration of their presence in the department and their being pro-active in claiming physicians' time and attention). The results indicate that there is a much greater chance that teaching will encompass all steps of the clinical teaching model when physicians devote more time to teaching and students are present in the department for a longer period and make their presence known. Since physicians' schedules are unlikely to become less hectic in the foreseeable future, it seems more feasible and therefore advisable to deal with the time factor by extending clerkship periods to give students more time in one department. Some medical schools have done just that by implementing longitudinal clerkships, which also aim to provide meaningful and longitudinal mentorships for students (Bell, Krupat, Fazio, Roberto, \& Schwartzstein, 2008). Another way to increase time for teaching could lie with the students. When students are specifically prepared for their clerk- 
ship experience or, as Gordon et al. (2000) put it, are equipped with 'survival skills', they might be able to create learning opportunities by being more pro-active. Teaching students to be assertive, to be effective communicators, to provide feedback, develop personal learning objectives and manage time (Gordon et al., 2000; P. Smith \& Morrison, 2006) could prepare them for the clinical learning environment and help them to make the most of their time there.

Another important aspect of clinical teaching turned out to be the division of teaching roles within a department. A variety of staff members, from nurses, midwives and residents to specialists, were engaged to different degrees in role modelling and creating a safe learning environment for students. From this perspective, step 1 of the MCT model seems to require a team effort, which is in line with the notion suggested by Pratt et al. that we need to 'look beyond the power of one' in clinical teaching (Pratt, Harris, \& Collins, 2009). Clinical teaching need not be the exclusive responsibility of specialists. By dividing tasks, a department can make sure that all steps of the model are effectuated. Future research might focus on designing a workable format for team effort in clinical teaching.

The clinical learning environment is a complex setting to study. A limitation of the current study is that it cannot be ruled out that some elements that affect clinical teaching may have been left out, because the participants were not aware of them. A more complete, fully rounded picture might be obtained by triangulating the findings of the current study with the results of observational studies and interviews with other members of departments. It might also be worthwhile to investigate whether different clerkship configurations, such as longitudinal clerkships, could strengthen the evidence of the applicability of the MCT model.

We think that the present study has demonstrated the value of the MCT model, not only as a guideline to help clinical teachers structure their teaching, but also as a theoretical model to be used by researchers in taking a closer look at clinical teaching practices. Finally, it could also be used as a basis for faculty development programmes and provide design principles for the development of more effective clerkships.

\section{Acknowledgements}

The authors would like to thank all the participants for their time and participation. The authors also would like to thank Mereke Gorsira for her editorial help. 


\section{REFERENCES}

Beckman, T. J., \& Lee, M. C. (2009). Proposal for a collaborative approach to clinical teaching. Mayo Clinic Proceedings, 84(4), 339-344.

Bell, S. K., Krupat, E., Fazio, S. B., Roberto, D. H., \& Schwartzstein, R. M. (2008). Longitudinal pedagogy: a successful response to the fragmentation of the third-year medical student clerkship experience. Academic Medicine, 83(5), 467-475.

Boor, K., Scheele, F., Van der Vleuten, C. P. M., Teunissen, P. W., Den Breejen, E. M. E., \& Scherpbier, A. J. J. A. (2008). How undergraduate clinical learning climates differ: a multi-method case study. Medical Education, 42(10), 1029-1036.

Branch, W. T., \& Paranjape, A. (2002). Feedback and reflection: teaching methods for clinical settings. Academic Medicine, 77(12), 1185-1188.

Brown, J. S., Collins, A., \& Duguid, P. (1989). Situated cognition and the culture of learning. Educational Researcher, 18(1), 32-42.

Cherryholmes, C. H. (1992). Notes on pragmatism and scientific realism. Educational Researcher, 21(6), 13-17.

Collins, A., Brown, J. S., \& Newman, S. E. (1989). Cognitive Apprenticeship: Teaching the crafts of reading, writing, and mathematics. In L. B. Resnick (Ed.), Knowing, learning, and instruction: Essays in honor of Robert Glaser (pp. 453-494). Hillsdale, New Jersey: Lawrence Erlbaum Associates, Inc.

Crossley, J. (2006). Do the supervision needs of 'clerkship students' change as they become more experienced? Medical Education, 40(10), 1053.

Deketelaere, A., Kelchtermans, G., Struyf, E., \& De Leyn, P. (2006). Disentangling clinical learning experiences: an exploratory study on the dynamic tensions in internship. Medical Education, 40(9), 908915.

Dornan, T., Boshuizen, H., King, N., \& Scherpbier, A. (2007). Experience-based learning: a model linking the processes and outcomes of medical students' workplace learning. Medical Education, 41(1), 8491.

Elzubeir, M. A., \& Rizk, D. E. E. (2001). Identifying characteristics that students, interns and residents look for in their role models. Medical Education, 35(3), 272-277.

Gordon, J., Hazlett, C., Ten Cate, O., Mann, K., Kilminster, S., Prince, K., et al. (2000). Strategic planning in medical education: enhancing the learning environment for students in clinical settings. Medical Education, 34(10), 841-850.

Graffam, B., Bowers, L., \& Keene, K. N. (2008). Using observations of clinicians' teaching practices to build a model of clinical instruction. Academic Medicine, 83(8), 768-774.

Hoffman, K. G., \& Donaldson, J. F. (2004). Contextual tensions of the clinical environment and their influence on teaching and learning. Medical Education, 38(4), 448-454.

Kaufman, D. M. (2003). ABC of learning and teaching in medicine: applying educational theory in practice. British Medical Journal, 326(7382), 213-216.

Kaufman, D. M., \& Mann, K. V. (2010). Teaching and learning in medical education: how theory can inform practice. In T. Swanswick (Ed.), Understanding medical education: evidence, theory and practice. Oxford, UK: Wiley-Blackwell.

Leinster, S. (2009). Learning in the clinical environment. Medical Teacher, 31(2), 79-81.

Pratt, D. D., Harris, P., \& Collins, J. B. (2009). The power of one: looking beyond the teacher in clinical instruction Medical Teacher, 31(2), 133-137.

Ramani, S., \& Leinster, S. (2008). AMEE Guide no. 34: Teaching in the clinical environment. Medical Teacher, 30(4), 347-364.

Richardson, V., \& Placier, P. (2001). Teacher Change. In V. Richardson (Ed.), Handbook of research on teaching. Washington: American Educational Research Association.

Roff, S., McAlleer, S., \& Skinner, A. (2005). Development and validation of an instrument to measure the postgraduate clinical learning and teaching educational environment for hospital-based junior doctors in the UK. Medical Teacher, 27(5), 326-331. 
Sandrioni, S. (1997). Enhancing clinical teaching with information technologies: what can we do right now? Academic Medicine, 72(9), 770-774.

Scardamalia, M., \& Bereiter, C. (1984). Teachability of reflective processes in written composition. Cognitive Science, 8, 173-190.

Schön, D. A. (1987). Educating the reflective practitioner: toward a new design for teaching and learning in the professions. San Francisco, CA: Jossey-Bass.

Skeff, K. M., Stratos, G. A., Mygdal, W., De Witt, T. A., Manfred, L., Quirk, M., et al. (1997). Faculty development. A resource for clinical teachers. Journal of General Internal Medicine, 12(Supplement 2 april), S56-S63.

Smith, C. A., Varkey, A. B., Evans, A. T., \& Reilly, B. M. (2004). Evaluating the performance of inpatient attending physicians. A new instrument for today's teaching hospitals. Journal of General Internal Medicine, 19(7), 766-771.

Smith, P., \& Morrison, J. (2006). Clinical clerkships: students can structure their own learning. Medical Education, 40(9), 884-892.

Spencer, J. (2003). Learning and teaching in the clinical environment. ABC of learning and teaching in medicine. British Medical Journal, 326, 591-594.

Stalmeijer, R. E., Dolmans, D. H. J. M., Wolfhagen, I. H. A. P., Muijtjens, A. M. M., \& Scherpbier, A. J. J. A. (2010). The Maastricht Clinical Teaching Questionnaire (MCTQ) as a valid and reliable instrument for the evaluation of clinical teachers. Academic Medicine, 85(11), 1732-1738.

Stalmeijer, R. E., Dolmans, D. H. J. M., Wolfhagen, I. H. A. P., \& Scherpbier, A. J. J. A. (2009). Cognitive apprenticeship in clinical practice: can it stimulate learning in the opinion of students? Advances in Health Sciences Education: Theory and Practice, 14(4), 535-546.

Vygotski, L. S. (1978). Mind in society: the development of higher psychological processes. Cambridge: Harvard University Press. 


\section{APPENDIX 1}

\section{EXAMPLES OF QUESTIONS ASKED DURING THE INTERVIEW}

- What do you think of the Maastricht Clinical Teaching Model?

- To what extent is this a reproduction of your approach to teaching regular and senior clerks?

- What do you think is your role in the learning process of regular and senior clerks?

- What influence does your department have on how you supervise regular and senior clerks?

- If you look at your department, which other people than yourself engage in clinical teaching?

- What is the influence of students' characteristics on how you teach them? 

Chapter 7

\section{General discussion}

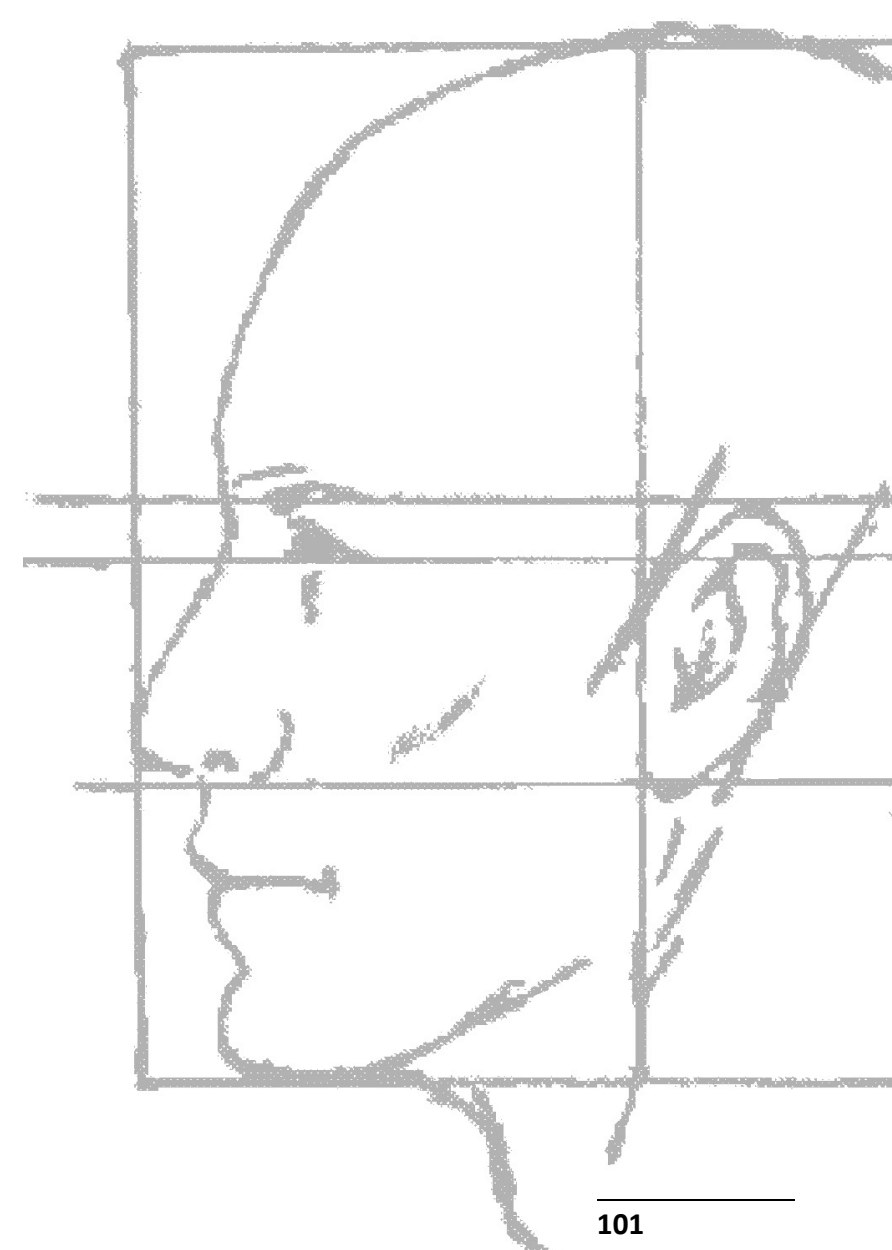




\section{BACKGROUND}

Clerkships introduce students to the realities of working as a doctor in the clinical workplace. They are also the start of students' socialization process as a member of their chosen profession. The extent to which students benefit from the rich and motivating learning environment of the clinical workplace depends largely on the quality of the supervision they receive from clinical teachers (Dolmans, Wolfhagen, Essed, Scherpbier, \& Vleuten, 2002). Good teachers play a vital role in helping students to structure their learning experiences by acting as role models and coaches and creating a safe learning environment. However, clinicians are very well trained to provide excellent patient care, but the development of their supervisory skills is largely left to experience and perhaps the occasional faculty development workshop. Physicians can be supported in their efforts to create an effective clinical learning environment by tools for developing an approach to supervision that benefits both teachers and students. A good evaluation instrument can be such a tool, but most of the existing ones are flawed in various ways. They are lacking in validity, reliability and effectiveness of the related feedback (Beckman, Ghosh, Cook, Erwin, \& Mandrekar, 2004; Fluit, Bolhuis, Grol, Laan, \& Wensing, 2010), but most importantly they are not supported by a sound theoretical framework. It seems rather urgent to remedy these defects, the more so since research indicates that new models and methods are warranted to provide optimal learning experiences for students during their clerkships (Dornan, 2006). The research reported in this dissertation was designed to pursue two aims:

1. To design and validate an instrument and theoretical model to provide feedback and guidance to clinical teachers on how they supervise students in clinical practice;

2. To investigate how clinical teachers evaluate the usefulness of the instrument and the theoretical model.

In this chapter the results of the research are discussed in relation to these two aims and the strengths and limitations are examined. The chapter ends with suggestions for further research and implications for effective clinical teaching practice and clerkship design. 


\section{MAIN FINDINGS AND CONCLUSIONS}

\section{Designing and validating an instrument and theoretical model to promote good clinical teaching}

Of the fairly large number of instruments examined in two literature reviews most were characterized by various flaws most notably the absence of an underlying theoretical model (Beckman et al., 2004; Fluit et al., 2010). A search for such a model led to further investigation of the cognitive apprenticeship model described by Collins and colleagues (1989). This model emphasizes explication of the cognitive component of teachers' expertise and proposes modelling, coaching, scaffolding, articulation, reflection and exploration as teaching methods to enable students to observe, enact and practice clinical tasks under the guidance of clinical teachers. However, the model had not been validated for undergraduate clinical training.

The first study (Chapter 2) investigated whether the teaching methods of cognitive apprenticeship resonated with students' experiences during clinical training. Focus groups of senior medical students were asked to describe instances in which they had experienced these teaching methods and to mention problems and suggestions relating to the methods. The students had experienced all six teaching methods, but modelling, coaching and articulation predominated while scaffolding, reflection and exploration were associated with longer clinical placements. The students generally endorsed the importance of a safe learning environment. The overall conclusion was that cognitive apprenticeship offers a valuable framework of teaching strategies for undergraduate clinical training.

Based on the cognitive apprenticeship methods and the concept of a safe learning environment a student questionnaire was developed aimed at providing feedback to clinical teachers on their teaching performance. In order to ensure content validity, the instrument was based on the theoretical framework of cognitive apprenticeship and different stakeholders contributed to the design process. The research question 'How do three groups of stakeholders rate the relevance and wording of the items of an instrument developed to be used by students to evaluate individual physicians' clinical teaching?' was examined by asking students, clinicians and educationalists to rate the relevance of the questionnaire items and suggest changes or additional items. The high ratings of the items $(M=4.3, S D=0.38)$ appear to warrant the conclusion that the instrument has good content validity. Moreover the high ratings by different groups of stakeholders bode well for broad acceptance of the instrument once it is implemented (Guba \& Lincoln, 1989).

After establishing content validity of the instrument, which was named the Maastricht Clinical Teaching Questionnaire (MCTQ), we investigated its construct validity and reliability (Chapter 4). The research questions 'What is the construct validity of the instrument', 'How many student ratings of one teacher are required 
for the ratings to be reliable', and 'How are the different factors underlying the instrument related to one another' were addressed by asking medical students of Maastricht Medical School to complete the MCTQ for teachers with whom they had frequent contact during clerkship rotations. MCTQ ratings collected during a twoyear period were analyzed using confirmatory factor analysis (CFA) and a generalizability study. The relationship between the factors was tested by means of Structural Equation Modelling (SEM). CFA yielded a five factor model (modelling, safe learning environment, coaching, articulation and exploration) which fitted the data well. Generalizability studies indicated that seven to ten student ratings sufficed to obtain reliable ratings of individual teachers. Eventually, a three step model was confirmed: the Maastricht Clinical Teaching (MCT) model. According to this model clinical teaching starts with modelling and a safe learning environment, moves on to coaching by the clinical teacher to reach the stage in which the main teaching objective is to stimulate students' self-directed learning. It was concluded that, with at least seven student ratings per teacher, the MCTQ is a valid and reliable instrument to evaluate the performance of clinical teachers. The MCT model is proposed as a framework to inform effective clinical teaching practices.

\section{Investigating the usefulness of the MCTQ and the MCT model in practice}

In the study investigating the usefulness of the MCTQ as feedback instrument (Chapter 5) written feedback based on students' MCTQ ratings of teaching performance was given to physicians and residents. However, since previous studies had shown that written feedback alone is not sufficient to stimulate teachers to reflect on their behaviour (Atwater, Waldman, \& Brett, 2002; Beijaard \& De Vries, 1997), the teachers were also asked to self-asses their teaching behaviour and skills (Ross \& Bruce, 2007). They received the MCTQ ratings together with their self assessment. Data to answer the research question 'Is the combination of written feedback (student ratings) and self-assessment perceived as an incentive to change clinical teaching behaviour?' was obtained from attending physicians and residents by means of a short questionnaire and semi-structured interviews. It emerged that the feedback from the MCTQ was experienced as specific, informative and illuminating, a result that underscores the MCTQ's usefulness as feedback instrument for clinical teachers. The effect of the self-assessment in itself was limited, but the combination of self-assessment and student ratings produced more promising results: the teachers perceived discrepancies between student ratings and their self-assessment as a strong incentive to contemplate change.

The fifth study (Chapter 6) examined the questions 'How does the MCT model fit with clinical teaching practice as perceived by experienced clinical teachers?' and 'Which factors influence the use of the MCT model during clerkship teaching?' Semistructured interviews with seventeen physicians confirmed the fit of the MCT model 
with teaching activities in clinical practice. Especially modelling and creating a safe learning environment were described as fundamental to clinical teaching. The use of the model was strongly associated with the duration of placements: Longer placements offered more and better teaching opportunities. For example, while teaching in shorter placements generally did not move beyond modelling and creating a safe learning environment (step 1), longer placements afforded more opportunities for coaching (step 2) and stimulation of self-directed learning (step 3). An interesting finding from this study is the involvement of multiple people in clinical teaching: nurses, residents, attending physicians, suggesting that clinical teaching is not an individual but a 'team process'. Finally pro-active behaviour on the part of both student and clinical teacher was found to be a strong determinant of successful clinical teaching.

\section{GENERAL DISCUSSION}

The following discussion of the three main issues that emerged from the research centres around three related questions: 1 ) Should the MCT model be adapted to students' competence levels? 2) What is the role of the student and the physician in applying the model? 3) Do student ratings stimulate clinical teachers to improve their teaching performance?

\section{Should the MCT model be adapted to students' levels of competence?}

In line with the principles of cognitive apprenticeship, the MCT model proposes an approach in which students and teachers gradually move from 'strong' facilitation (step 1) via interaction between student and teacher (step 2) to stimulating students to manage their own learning process in a self-directed manner (step 3). This raises several questions: 'Should all steps be applied in all rotations?', 'Should the steps always follow the same fixed sequence?', and 'Should all physicians be able to apply all the teaching methods?' As for the first question, the results in this dissertation suggest that step 1 , modelling and creating a safe learning environment, is required for all rotations. Step 2 , coaching, appears to apply mostly to summative performance assessments during the four to ten week rotations in years 4 and 5 of the Maastricht undergraduate curriculum. However, for the long senior clerkship in year 6 when students are based in one department for eighteen weeks step 2 appears to be more useful as a formative part of the teaching and learning process. Step 3, stimulating self-directed learning through articulation and exploration, also seems most suitable for longer placements where students and physicians have more frequent contacts. A general comment was that effective supervision and teaching based on the MCT model requires longer clinical placements, because 
clinical teachers need to work with and observe students for a substantial period of time in order to be able to properly estimate their level of skill and knowledge and determine their learning needs accordingly. This leads to the second question, about the sequencing of steps. The results of the studies showed that physicians wish to have some freedom to decide which step is appropriate in which situation. A safe learning climate was considered a prerequisite in all situations, but for the other steps, regardless of the student's stage of training, the teacher should be able to decide which one was appropriate, because in one situation coaching might be more suitable whereas in another situation self-directed learning might be deemed preferable. Physicians explained that flexibility in the use of teaching methods was important to help students attain the required level of competence in certain situations. These findings are in line with studies advocating the need to diagnose the 'students' competence level and learning needs' as a way to provide optimal supervision and teaching (Beckman \& Lee, 2009; Dijksterhuis et al., 2009; Irby, 1994; Kisiel, Bundrick, \& Beckman, 2010; Ramani \& Leinster, 2008). Finally, the question whether all teachers need to be able to use all the teaching methods needs to be answered. The MCTQ and the MCT model are designed to provide specific and descriptive feedback and guidance to individual clinical teachers. The content of both relies on the assumption that all teachers should be able to use all teaching methods. This does not exclude the possibility that some teachers may be better at modelling while others excel at coaching, nor does it deny the wisdom of a team of physicians dividing teaching tasks based on individual teachers' particular strengths and weaknesses (Ramani \& Leinster, 2008). Nevertheless, being constructed to reflect all the relevant teaching methods of cognitive apprenticeship, the MCTQ and the MCT model are aimed at creating awareness in physicians of a full set of activities relating to good clinical teaching.

\section{What are the respective roles of the student and the physician in applying the model?}

Clinical teaching can be described as an 'open system' that is influenced by multiple forces in continuous interaction with the environment (Hoffman \& Donaldson, 2004). This also means that both the physician and the student influence the clinical teaching process. Deketelaere and colleagues (2006) distinguished between students that have a passive versus a proactive stance towards learning in the clinical setting. They contended that 'learning is possible with both attitudes'. Although physicians felt that it was easier to work with and provide learning opportunities for pro-active students, Deketelaere et al. cautioned teachers that a 'wait-and-see' attitude in a student does not necessarily reflect lack of motivation and commitment, but may reflect the student's engagement in a process of trying to fit in. Nevertheless, several authors describe a pro-active attitude of students as prerequisite 
for optimizing student learning during clerkships and as a consequence emphasize the need to prepare students for their clerkship period (Gordon et al., 2000; Teunissen \& Westerman, 2011; Teunissen \& Wilkinson, 2011). The studies in this dissertation also indicate that a pro-active attitude is probably preferable for both student and teacher. The need for physicians' pro-active behaviour when it comes to teaching resonates through the medical education literature and has prompted many faculty development initiatives worldwide (McLean, Cilliers, \& Van Wyk, 2008; Ramani \& Leinster, 2008). Pro-activity in clinical teachers may relate to two areas: actively seeking learning opportunities and trying to accommodate the learning process for the students (Beckman \& Lee, 2009) and soliciting feedback on one's own teaching (Ramani \& Leinster, 2008).

\section{Do student ratings encourage clinical teachers to improve their teaching performance?}

One of the main aims of this dissertation was to design an instrument to provide feedback to clinical teachers on how they supervise students. There are several principles that should be considered in designing a feedback instrument. First of all written feedback should be specific and contain information about a 'targeted performance area'. This makes for more informative feedback than just global ratings. Secondly, feedback should be diagnostic to facilitate choices of alternative behaviour. Thirdly, descriptive information about specific behaviours of individual teachers elicited by open ended questions is more likely to affect teaching behaviour than rating scale items alone (Braskamp \& Ory, 1994). Additionally, evaluation should be firmly grounded in educational theory. Bowden and Marton (1998) argue that building evaluation on a theoretical framework augments feedback effectiveness since more specific suggestions for improvement can be provided. Research indicates, however, that even if all these principles are met, written feedback on its own is not enough to elicit substantial behavioural change (Atwater et al., 2002; Beijaard \& De Vries, 1997). Such a change requires extensive reflection and a perceived need for change (Eva \& Regehr, 2008), which is dependent on many different factors both internal and external to an individual (Sargeant, Mann, van der Vleuten, \& Metsemakers, 2008). In this dissertation self-assessment combined with student ratings was evaluated as a tool to stimulate reflection (Eva \& Regehr, 2008). Although participants agreed that self-assessment provided some standards for excellence (Ross \& Bruce, 2007) only a minority said they felt compelled to make changes based on self-assessment alone. Combining the self-assessment with student ratings, however, resulted in a stronger stimulus for change. Still, many of the participants expressed a need for additional coaching to help them translate feedback to teaching practice. This is in line with research on effective multi-source feedback strategies, 
showing that facilitating reflection based on feedback can promote the use of the feedback (Sargeant, Mann, Sinclair, Van der Vleuten, \& Metsemakers, 2008).

\section{Strengths and limitations}

The MCTQ and the MCT model are based on principles of cognitive apprenticeship (Collins et al., 1989). As described previously, an underlying theoretical framework promotes not only more specific feedback, but also enables more concrete suggestions for improvement (Bowden \& Marton, 1998). Other strengths of this dissertation are the ample attention paid to content and construct validity of the MCTQ and the MCT model and consultation of experienced clinical teachers regarding the extent to which both instrument and model resonated with their clinical teaching practice. A further strength is the use of a mixed method approach to answer the various research questions. The first aim of the dissertation was investigated using an exploratory design (starting with qualitative methods, finishing with quantitative methods). For the second aim an explanatory design was used (mainly qualitative methods to illuminate findings and processes) (Fraenkel \& Wallen, 2006). Finally, the strong focus on the authentic context of clinical teaching during clerkships strengthens the findings and offers the additional advantage of clear and practical implications for clinical teaching practice.

A possible limitation is the fact that the MCT model inevitably presents an oversimplification of reality. The model offers a simplified and linear depiction of the interactions of clinical teachers and medical students. In reality, different variables mutually influence one another and some pathways may be recursive. This was also underlined by the experienced clinical teachers interviewed in Chapter 6. Depending on individual differences between students different pathways along the teaching methods may be indicated. It should therefore be taken into consideration that the model presents a structured picture of reality to help inform clinical teaching practices, not a fixed and prescriptive picture of reality. A second limitation is that most studies in this dissertation rely on respondents' perceptions. Such perceptions are likely to differ because they are affected by individual experiences and beliefs. They present a 'filtered' picture of reality, which also partly accounts for the richness of the information. The findings can be further strengthened when they are confirmed by observation of actual teaching practice. Finally, the results of the research should also be tested in different settings to determine to what extent they can be generalized across different contexts. 


\section{SUGGESTIONS FOR FUTURE RESEARCH}

\section{Clinical teaching is a team effort: investigating the concept of the 'teaching team'}

The MCTQ and MCT model were designed to provide specific and descriptive feedback and guidance for individual clinical teachers. However, some of the results show that physicians may view clinical teaching as a team effort and not primarily a solo endeavour. This is in line with research by Pratt and colleagues (2009), who stated that we need to look beyond the power of just the one individual physician on the clinical teaching process (Pratt, Harris, \& Collins, 2009). The 'team perspective' highlights the notion that attending physicians, residents and nurses can complement one another's individual competencies to create a strong and positive clinical teaching environment. This is not so different from day-to-day practice in hospitals where both patient care and the continuous professional development of team members is a team effort (Ramani \& Leinster, 2008). So examining the role of the clinical team is likely to broaden our understanding of the learning process of medical students in clinical settings. With regard to the influence of 'the team', the concept of 'communities of practice' (Lave \& Wenger, 1991) might shed some interesting light on students' clinical learning. The term 'community of practice' is used to describe 'the activities of a group of people who come together in pursuit of a shared enterprise' (Mann, 2011) and thus can be interpreted as applying to a hospital department or even a team within a department. Essentially, students' introduction to the profession of medicine during clerkships can be seen as a process of learning through socialization (Lave \& Wenger, 1991; Mann, 2011; Teunissen \& Wilkinson, 2011), with students temporarily joining departments and teams as 'legitimate peripheral participants' to observe and gradually engage in clinical practice. Recently, Mann (2011) described the concept of 'communities of practice' as a useful theoretical perspective for the medical education world since it could help to create an explanation and description of learning during clerkships.

\section{Observing actual clinical teaching practice}

Much of the research into clinical teaching has relied heavily on the perceptions of the main stakeholders (e.g. (Elnicki, Kolarik, \& Bardella, 2003; Knight \& Bligh, 2006; Riesenberg, Biddle, \& Erney, 2001). This dissertation is indeed an example in point. However, a gradual trend towards the use of more observational methods can be witnessed (e.g. Graffam, Bowers, \& Keene, 2008; Seabrook, 2003; Stewart, 2008). In line with this trend further research might investigate the validity of the MCT model by examining how the model relates to observed clinical teaching practices. This might provide richer descriptions alongside the highly structured representation by the model. 


\section{Extrapolating findings to different contexts and longitudinal results}

The MCTQ and MCT model were validated for clerkships in hospital settings. It would seem worthwhile to extend the validation and study the applicability of the MCTQ and the MCT model for different workplace settings in undergraduate medical education, such as general practice, and in postgraduate education and training. Furthermore, additional insight into the effects of feedback from the MCTQ could be gained by investigating it from a longitudinal perspective: Do clinical teaching practices actually improve and is improvement maintained in the long run?

\section{IMPLICATIONS FOR PRACTICE}

\section{From merry-go-round to longitudinal clerkships}

The current structure of clerkships (a 'merry-go-round' of brief placements in many departments) is frequently criticized for not enabling students to stay long enough in one place for physicians to spend enough time with them to 'diagnose the student and his learning level' (Dijksterhuis et al., 2009; Ramani \& Leinster, 2008). It is also pointed out in this dissertation that effective supervision and teaching requires longer placements of students in the same department. This is in line with calls for restructuring traditional clinical education from a 'merry-go-round' to a longitudinal and integrated clerkship design (Holmboe, Ginsburg, \& Bernabeo, 2011) and for more continuity in clinical education (Hirsh, Ogur, Thibault, \& Cox, 2007).

\section{Preparing both students and physicians for clerkships}

Earlier in this chapter it was noted that students and physicians share the responsibility for learning during clerkships. Also results from this dissertation suggest that both students and physicians need to be equipped with 'clerkship survival skills'. For students this implies learning how to be more assertive, communicate better, give feedback, develop personal learning objectives and manage time (Gordon et al., 2000; Teunissen \& Westerman, 2011). Physicians on the other hand need to be more aware of students' levels of competence (what can I expect from a student entering my department?) and learning needs (by observing, asking questions and suggesting learning goals to the student).

\section{MCT model as the starting point for faculty development and coaching}

Cognitive apprenticeship as presented within this dissertation has not yet found its way to formal faculty development programmes. Results indicate that the translation of cognitive apprenticeship to the MCT model provides a theoretical framework 
that is appropriate for both medical students and physicians and can yield valuable suggestions to improve teaching. Additionally, the studies have focused on eliciting student ratings based on the MCTQ. Since physicians indicated that they would benefit from coaching based on MCTQ outcomes, it seems that, as a starting point for collecting the views of peers on clinical teachers' performance, the MCTQ could be a valuable tool to improve clinical teaching practices. 


\section{REFERENCES}

Atwater, L. E., Waldman, D. A., \& Brett, J. F. (2002). Understanding and optimizing multisource feedback. Human Resource Management, 41(2), 193-208.

Beckman, T. J., Ghosh, A. K., Cook, D. A., Erwin, P. J., \& Mandrekar, J. N. (2004). How reliable are assessments of clinical teaching? A review of the published instruments. Journal of General Internal Medicine, 19(9), 971-977.

Beckman, T. J., \& Lee, M. C. (2009). Proposal for a collaborative approach to clinical teaching. Mayo Clinic Proceedings, 84(4), 339-344.

Beijaard, D., \& De Vries, Y. (1997). Building expertise: a process perspective on the development or change of teachers' beliefs. European Journal of Teacher Education, 20(3), 243-255.

Bowden, J., \& Marton, F. (1998). Quality and qualities. In J. Bowden \& F. Marton (Eds.), The university of learning (pp. 211-245). London: Kogan Page Limited.

Braskamp, L. A., \& Ory, J. C. (1994). Assessing faculty work: enhancing individual and institutional performance. San Francisco, CA: Jossey-Bass.

Collins, A., Brown, J. S., \& Newman, S. E. (1989). Cognitive Apprenticeship: Teaching the crafts of reading, writing, and mathematics. In L. B. Resnick (Ed.), Knowing, learning, and instruction: Essays in honor of Robert Glaser (pp. 453-494). Hillsdale, New Jersey: Lawrence Erlbaum Associates, Inc.

Deketelaere, A., Kelchtermans, G., Struyf, E., \& De Leyn, P. (2006). Disentangling clinical learning experiences: an exploratory study on the dynamic tensions in internship. Medical Education, 40(9), 908915.

Dijksterhuis, M. G., Voorhuis, M., Teunissen, P. W., Schuwirth, L. W., Ten Cate, O. T., Braat, D. D., et al. (2009). Assessment of competence and progressive independence in postgraduate clinical training. Medical Education, 43(12), 1156-1165.

Dolmans, D. H. J. M., Wolfhagen, I. H. A. P., Essed, G. G. M., Scherpbier, A. J. J. A., \& Vleuten, v. d., C.P.M. (2002). The impacts of supervision, patient mix, and numbers of students on the effectiveness of clinical rotations. Academic Medicine, 77(4), 332-335.

Dornan, T. (2006). Experience based learning. Learning clinical medicine in workplaces. [Dissertation]. Maastricht University, Maastricht.

Elnicki, D. M., Kolarik, R., \& Bardella, I. (2003). Third-year medical students' perceptions of effective teaching behaviors in a multidisciplinary ambulatory clerkship. Academic Medicine, 78(8), 815-819.

Eva, K. W., \& Regehr, G. (2008). "I'll never play professional football" and other fallacies of selfassessment. Journal of Continuing Education in the Health Professions, 28(1), 14-19.

Fluit, C. R., Bolhuis, S., Grol, R., Laan, R., \& Wensing, M. (2010). Assessing the quality of clinical teachers: a systematic review of content and quality of questionnaires for assessing clinical teachers. Journal of General Internal Medicine, 25(12), 1337-1345.

Fraenkel, J. R., \& Wallen, N. E. (2006). How to design and evaluate research in education (6 ed.). New York: McGraw-Hill.

Gordon, J., Hazlett, C., Ten Cate, O., Mann, K., Kilminster, S., Prince, K., et al. (2000). Strategic planning in medical education: enhancing the learning environment for students in clinical settings. Medical Education, 34(10), 841-850.

Graffam, B., Bowers, L., \& Keene, K. N. (2008). Using observations of clinicians' teaching practices to build a model of clinical instruction. Academic Medicine, 83(8), 768-774.

Guba, E. G., \& Lincoln, Y. S. (1989). Fourth generation evaluation. Newbury Park, London: Sage Publications.

Hirsh, D. A., Ogur, B., Thibault, G. E., \& Cox, M. (2007). “Continuity” as an organizing principle for clinical education reform. New England Journal of Medicine, 356(8), 858-866.

Hoffman, K. G., \& Donaldson, J. F. (2004). Contextual tensions of the clinical environment and their influence on teaching and learning. Medical Education, 38(4), 448-454.

Holmboe, E., Ginsburg, S., \& Bernabeo, E. (2011). The rotational approach to medical education: time to confront our assumptions? Medical Education, 45(1), 69-80. 
Irby, D. M. (1994). What clinical teachers in medicine need to know. Academic Medicine, 69(4), 333-342.

Kisiel, J. B., Bundrick, J. B., \& Beckman, T. J. (2010). Resident physicians' perspectives on effective outpatient teaching: a qualitative study. Advances in Health Sciences Education: Theory and Practice, 15(3), 357-368.

Knight, L. V., \& Bligh, J. (2006). Physicians' perceptions of clinical teaching: a qualitative analysis in the context of change. Advances in Health Sciences Education: Theory and Practice, 11(3), 221-234.

Lave, J., \& Wenger, E. (1991). Situated learning: legitimate peripheral carticipation. Cambridge: Cambridge University Press.

Mann, K. V. (2011). Theoretical perspectives in medical education: past experience and future possibilities. Medical Education, 45(1), 60-68.

McLean, M., Cilliers, F., \& Van Wyk, J. M. (2008). Faculty development: yesterday, today and tomorrow. Medical Teacher, 30(6), 555-584.

Pratt, D. D., Harris, P., \& Collins, J. B. (2009). The power of one: looking beyond the teacher in clinical instruction Medical Teacher, 31(2), 133-137.

Ramani, S., \& Leinster, S. (2008). AMEE Guide no. 34: Teaching in the clinical environment. Medical Teacher, 30(4), 347-364.

Riesenberg, L. A., Biddle, W. B., \& Erney, S. L. (2001). Medical students and faculty perceptions of desirable primary care teaching site characteristics. Medical Education, 35(7), 660-665.

Ross, J. A., \& Bruce, C. D. (2007). Teacher self-assessment: a mechanism for facilitating professional growth. Teaching and Teacher Education, 23(2), 146-159.

Sargeant, J., Mann, K., Sinclair, D., Van der Vleuten, C., \& Metsemakers, J. (2008). Understanding the influence of emotions and reflection upon multi-source feedback acceptance and use. Advances in Health Sciences Education: Theory and Practice, 13(3), 275-288.

Sargeant, J., Mann, K., van der Vleuten, C., \& Metsemakers, J. (2008). "Directed" self-assessment: practice and feedback within a social context. The Journal of Continuing Education in the Health Professions, 28(1), 47-54.

Seabrook, M. A. (2003). Medical teachers' concerns about the clinical teaching context. Medical Education, 37(3), 213-222.

Stewart, J. (2008). To call or not to call: a judgement of risk by pre-registration house officers. Medical Education, 42(9), 938-944.

Teunissen, P. W., \& Westerman, M. (2011). Opportunity or threat: the ambiguity of the consequences of transitions in medical education. Medical Education, 45(1), 51-59.

Teunissen, P. W., \& Wilkinson, T. J. (2011). Learning and teaching in workplaces. In T. Dornan, K. Mann, A. Scherpbier \& J. Spencer (Eds.), Medical Education. Theory and practice (pp. 193-209). London: Churchill Livingston Elsevier. 



\section{Summary}

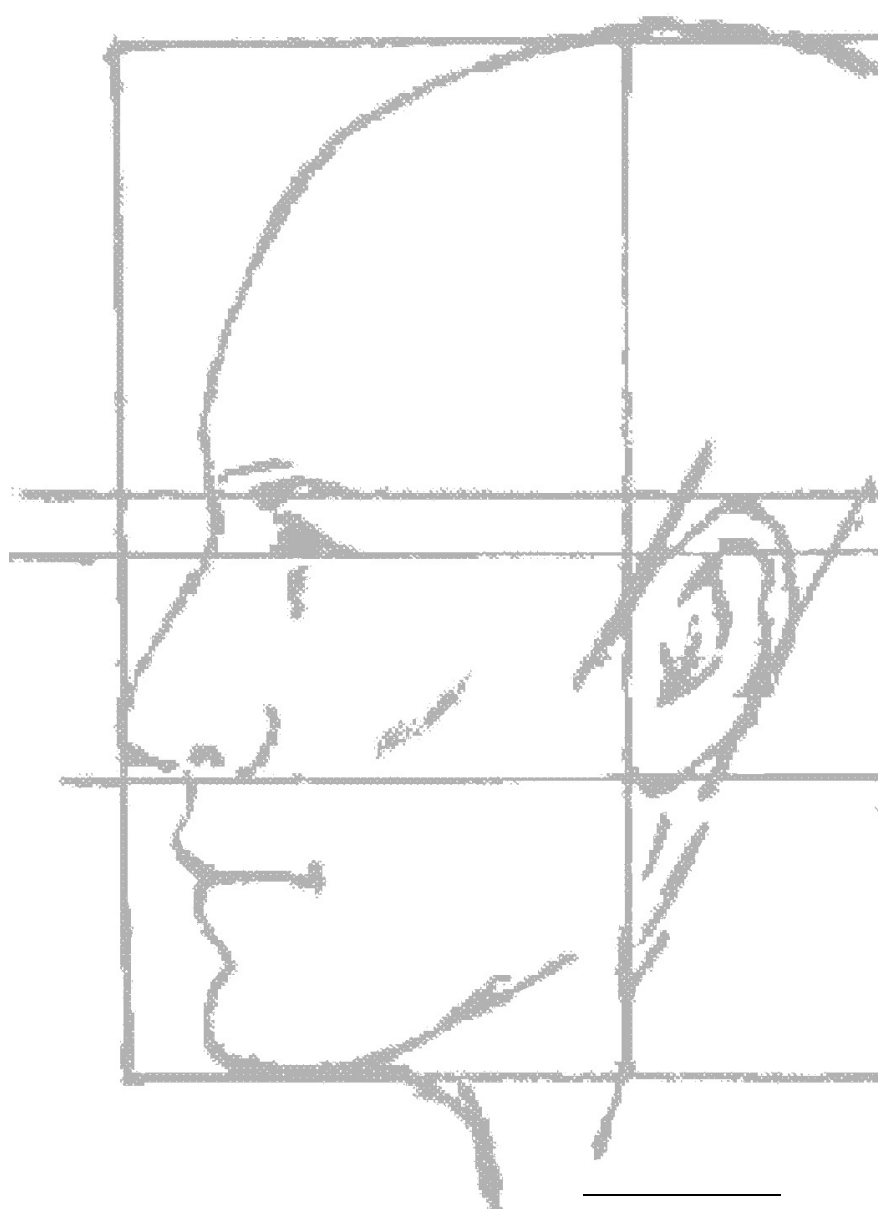


SUMMARY 
Clerkships are an indispensible part of medical curricula world-wide. In various departments in different hospitals and different clinical settings medical students learn how to apply their knowledge and skills to real problems in the context of professional practice (Spencer, 2003). The hospital setting of clerkships offers a potentially powerful learning environment because of its high authenticity and opportunities for active participation in clinical work and integrating learning of history taking, physical examination, clinical decision making and professionalism (Spencer, 2003). Research has shown that good supervision of medical students by attending physicians and residents is the key to successful learning in clinical practice (Crossly, 2006; Dolmans, Wolfhagen, Essed, Scherpbier, \& Van der Vleuten, 2002; Wimmers, Schmidt, \& Splinter, 2006). However, supervision and clinical teaching are a relatively infrequent occurrence in the clinical workplace (Grant, Kilminster, Jolly, \& Cottrell, 2006). Additionally, physicians usually receive little formal educational training for their role as a clinical teacher during their training to become a medical expert (Cottrell, Killminster, Jolly, \& Grant, 2002; Ramani \& Leinster, 2008). In response to this lack of clinical teaching skills, medical education research has focused on faculty development programmes and models that describe practical and specific teaching activities for clinicians. In the wake of these programmes came the rise of evaluation instruments to provide feedback to clinical teachers on how they supervise students in clinical practice. In 2010, a review described 34 individual instruments for providing feedback to physicians (Fluit, Bolhuis, Grol, Laan, \& Wensing, 2010). However, several problems with the currently existing instruments were identified (Beckman, Ghosh, Cook, Erwin, \& Mandrekar, 2004; Fluit et al., 2010), such as lack of validity, failure to consult the opinion of important stakeholders in the design process or too broadly defined items that limit feedback effectiveness. One important additional flaw of currently existing instruments is that they are not underpinned by theories of effective clinical teaching. According to Bowden and Marton (1998), a clear theoretical framework will improve the specificity and effectiveness of feedback because it can direct actions for improvement (Bowden \& Marton, 1998).

In Chapter 1 cognitive apprenticeship (Collins, Brown, \& Newman, 1989) is introduced as a theoretical framework that may be able to guide clinical teaching practices. Based on apprentice-type learning and teaching methods, cognitive apprenticeship advocates 'learning through guided experience'. At its centre are several teaching methods (modelling, coaching, scaffolding, articulation, reflection and exploration), which are used to externalize the tacit processes underlying the thinking and actions of experts as they work in practice and model their strategies. The appeal of cognitive apprenticeship for clinical teaching resides in its aim to teach and make explicit the processes involved in experts' handling of complex cognitive tasks. However, the usefulness of the teaching methods of cognitive apprenticeship 
remains to be established for the field of clinical teaching. Additionally 'providing a safe learning environment' is described as crucial to learning in the clinical environment (Ramani \& Leinster, 2008). Finally, Chapter 1 describes the research aims of this dissertation: 1) To design and validate an instrument and theoretical model to provide feedback and guidance to clinical teachers on supervising students in clinical practice, and 2) To investigate how clinical teachers evaluate the usefulness of the instrument and theoretical model.

The first aim of this dissertation is discussed in Chapters $2-4$.

In Chapter 2 the potential of cognitive apprenticeship as a theoretical model for clinical teaching was explored. In focus group interviews, three groups of $6^{\text {th }}$ year medical students $(\mathrm{N}=21)$ discussed vignettes representing the six teaching methods of cognitive apprenticeship and 'providing a safe learning environment'. The perceived occurrence of the teaching methods, related problems and possibilities for improvement were discussed. The focus groups were audio-taped and transcribed verbatim. Three researchers independently coded the data and discussed the codes until consensus was reached. Results indicated that the students had experienced all six teaching methods during their clerkships. Modelling, coaching and articulation were predominant, while scaffolding, reflection, and exploration were mainly experienced during longer clerkships and with extended attachment to one supervisor. Students also thought that prolonged engagement in one discipline would encourage the use of scaffolding, reflection and exploration. Improvement of the application of the teaching methods was thought to be promoted by faculty development focusing on 'how to give constructive feedback' and 'how to gauge the competence level of the individual student'. All in all the results suggested that the cognitive apprenticeship model is a useful model for informing teaching strategies in undergraduate clinical training.

In Chapter 3 based on the principles of cognitive apprenticeship and safe learning environment a feedback instrument was designed to elicit students' evaluations of individual physicians' clinical teaching. To estimate the content validity of the instrument three groups of stakeholders in undergraduate clinical teaching (twelve educationalists, sixteen physicians and twelve students) rated item relevance on a five-point scale ( $1=$ highly irrelevant, $5=$ highly relevant). Additionally stakeholders commented on content, wording and omission of items. The items were generally rated as very relevant $(\mathrm{M}=4.3, \mathrm{SD}=0.38$, response $95 \%$ ) and any difference between stakeholder groups were small. The results led to elimination of four items, rewording of thirteen items and addition of one item. 
Chapter 4 describes the construct validity and reliability of the evaluation instrument developed in Chapter 3, the Maastricht Clinical Teaching Questionnaire (MCTQ). The underlying factors of the MCTQ were used to test a causal model for effective clinical teaching (the Maastricht Clinical Teaching model (MCT model). The MCTQ was piloted in two teaching hospitals where students who had completed clerkship rotations in different departments were asked to complete the MCTQ for those physicians with whom they had had the most contact. This process yielded four or more ratings for a total of 126 physicians. To establish construct validity, confirmatory factor analysis of the evaluation data was performed. Reliability of the MCTQ was estimated by calculating the generalizability coefficient and standard error measurement. Finally, to test a model of the factors, a structural linear model was fitted to the data. Confirmatory factor analysis yielded a five-factor model (modelling, safe learning environment, coaching, articulation, and exploration) which fitted the data well. Generalizability studies indicated that seven to ten student ratings sufficed to produce reliable ratings of individual teachers. Structural Equation Modelling confirmed a three step model of good clinical teaching. The three steps start with modelling and providing a safe learning environment (step 1), followed by the physician coaching the student (step 3) and ending with physicians stimulating students' self-directed learning (step 3).

The second aim of this dissertation, to investigate how clinical teachers evaluated the usefulness of the evaluation and feedback instrument (MCTQ) and the theoretical model (MCT model), is discussed in Chapters 5 and 6.

In Chapter 5 the usefulness of the instrument was investigated. The MCTQ was used to provide attending physicians and residents with written feedback on their clinical teaching performance. However, since it is known from previous studies that written feedback alone is not sufficient to stimulate teachers to reflect on their behaviour (Atwater, Waldman, \& Brett, 2002; Beijaard \& De Vries, 1997), it was explored whether feedback effectiveness improved when teachers' self-assessment was added to written feedback based on student ratings. Thirty-seven physicians (ten residents, 27 attending physicians) from different specialities were invited to fill out a self-assessment questionnaire on their clinical teaching skills. Students completed an almost identical questionnaire to evaluate the same teachers based on their experiences during clerkships. After receiving written feedback incorporating the self-assessment and the student ratings, the teachers indicated their perceptions of the self-assessment exercise and the written feedback in a questionnaire (five-point Likert scale items, 1 = fully disagree, 5 = fully agree) and subsequently, in more detail, in semi-structured interviews. Twenty-five physicians participated (67\%). The results showed that feedback based on the MCTQ was experienced as specific, informative and illuminating. Furthermore self-assessment and student feedback 
were both perceived as useful $(M=3.7, S D=1.0)$ but the latter was considered more effective. The interviews (with twelve physicians) showed that the combination of self-assessment with student ratings was more effective than either selfassessment or written feedback alone. Notably, discrepancies between student ratings and self-assessment were deemed a strong incentive for change.

Chapter 6 describes the usefulness of the MCT model as perceived by seventeen experienced clinical teachers. The aim of the study was to see to what extent the MCT model fits with the practice of experienced clinical teachers and to describe which factors of the model influence clinical teaching. A purposive sample of seventeen teachers from five different disciplines and four different teaching hospitals with ample experience in undergraduate clinical training took part in semi structured interviews. A pragmatic approach was used to verify the match of the theoretical MCT model with the teachers' experiences. The interview guide was informed by research describing factors that influence clinical teaching. Two researchers independently performed a thematic analysis of the interview transcripts. Coding was discussed within the research team until consensus was reached. All participants recognized the MCT model as a structured picture of how they handled clinical teaching. Modelling and creating a safe learning environment were seen as crucial. Longer placements ensured application of all teaching methods of the MCT model, such as stimulating self-directed learning and reflection on one's own strengths and weaknesses. Motivation and pro-active behaviour of both physicians and students stimulated the use of the teaching methods. Additionally, nurses were described to play an important, though implicit, role in the teaching of clerks and creating a safe learning environment.

Chapter 7 gives an overview of the conclusions of Chapters 2-6, a general discussion of the findings and the strengths and limitations of this dissertation and suggestions for future research and implications for practices.

The first aim of this dissertation was to design and validate an instrument and model that could be used to provide feedback and guidance to clinical teachers. Based on the findings of Chapter 2 it was concluded that the cognitive apprenticeship model is a valuable model to describe teaching strategies in undergraduate clinical training. Chapter 3 led to the conclusion that an instrument based on principles of cognitive apprenticeship was considered relevant by three groups of stakeholders. And finally, in Chapter 4, it was concluded that the MCTQ is a valid and reliable instrument to evaluate clinical teachers on their clinical teaching skills when at least seven ratings are available per teacher. A clinical teaching model based on cognitive apprenticeship (MCT model) was developed to inform effective clinical teaching practices at the clinical workplace. The second aim of the dissertation was to investigate the usefulness of the instrument and model in practice. In Chapter 5 it 
was concluded that feedback based on MCTQ ratings was experienced as specific, informative and illuminating. A combination of self-assessment and student-ratings was perceived as a strong incentive to contemplate change, particularly when there were discrepancies between the two. Chapter 6 ended with the conclusion that the MCT-model fitted with teaching activities in clinical practice. Especially modelling and creating a safe learning environment were described as fundamental to clinical teaching. Longer placements were advocated to ensure the application of all three steps of the MCT model.

The discussion of the conclusion elaborates on three topics. Firstly, the need to adapt clinical teaching based on the MCT model to the level required for individual medical students. This is in line with researchers advocating the need to diagnose the 'student's competence level and learning needs' as a way to provide optimal supervision and teaching (Beckman \& Lee, 2009; Ramani \& Leinster, 2008). Secondly, learning during clerkships appears to be dependent on a pro-active stance taken by students as well as physician. This suggests that students and teachers share the responsibility for effective clerkship teaching and learning. Thirdly, in order for written feedback to be effective, it needs to be specific, descriptive, diagnostic (Braskamp \& Ory, 1994) and based on a theoretical framework (Bowden \& Marton, 1998). Moreover effective feedback also depends on additional measures, such as self-assessment and/or (peer) coaching.

The strengths of this dissertation lie in the use of a theoretical model to underpin instrument and model design, the extensive attention to validity, the use of both quantitative and qualitative methods and attention to the context of clinical teaching. The limitations relate to a possible oversimplification of reality in the MCT model, the exclusive reliance on perceptions as data source and the generalizability of the findings.

Further research is recommended to investigate the concept of the 'teaching team' based on the finding that not only attending physicians but also residents and nurses play an important part in clinical teaching. Secondly, it seems also advisable to conduct observational studies to investigate the nature of clinical teaching and, finally, the findings of the research should be extrapolated to different contexts and longitudinal effects of feedback based on the MCTQ require investigation. Implications for practice include the restructuring of clerkships from a merry-go-round to longitudinal placements to ensure better supervision and teaching as well as continuity of clinical teaching. Also it is proposed to implement measures to prepare both students and physicians for learning and teaching in clerkships. Finally, it is suggested that the MCTQ and MCT model could be used as a starting point for faculty development and faculty coaching. 


\section{REFERENCES}

Atwater, L. E., Waldman, D. A., \& Brett, J. F. (2002). Understanding and optimizing multisource feedback. Human Resource Management, 41, 193-208.

Beckman, T. J., Ghosh, A. K., Cook, D. A., Erwin, P. J., \& Mandrekar, J. N. (2004). How Reliable Are Assessments of Clinical Teaching? A Review of the Published Instruments. Journal of General Internal Medicine, 19, 971-977.

Beckman, T. J., \& Lee, M. C. (2009). Proposal for a Collaborative Approach to Clinical Teaching. Mayo Clinic Proceedings, 84(4), 339-344.

Beijaard, D., \& De Vries, Y. (1997). Building Expertise: a process perspective on the development or change of teachers' beliefs. European Journal of Teacher Education, 20(3), 243-255.

Bowden, J., \& Marton, F. (1998). Quality and qualities. In J. Bowden \& F. Marton (Eds.), The university of learning (pp. 211-245). London: Kogan Page Limited.

Braskamp, L. A., \& Ory, J. C. (1994). Assessing Faculty Work: Enhancing Individual and Institutional Performance. San Francisco, CA: Jossey-Bass.

Collins, A., Brown, J. S., \& Newman, S. E. (1989). Cognitive Apprenticeship: Teaching the crafts of reading, writing, and mathematics. In L. B. Resnick (Ed.), Knowing, learning, and instruction: Essays in honor of Robert Glaser (pp. 453-494). Hillsdale, New Jersey: Lawrence Erlbaum Associates, Inc.

Cottrell, D., Killminster, S., Jolly, B., \& Grant, J. (2002). What is effective supervision and how does it happen? A critical incident study. Medical Education, 36, 1042-1049.

Crossly, J. (2006). Do the supervision needs of 'clerkship students' change as they become more experienced? Medical Education, 40, 1053.

Dolmans, D. H. J. M., Wolfhagen, H. A. P., Essed, G. G. M., Scherpbier, A. J. J. A., \& Van der Vleuten, C. P. M. (2002). Students' perceptions of relationships between some educational variables in the outpatient setting. Medical Education, 36, 735-741.

Fluit, C. R., Bolhuis, S., Grol, R., Laan, R., \& Wensing, M. (2010). Assessing the quality of clinical teachers: a systematic review of content and quality of questionnaires for assessing clinical teachers. Journal of General Internal Medicine, 25(12), 1337-1345.

Grant, J., Kilminster, S., Jolly, B., \& Cottrell, D. (2006). Clinical supervision of SpRs: where does it happen, when does it happen and is it effective? Medical Education, 37, 140-148.

Ramani, S., \& Leinster, S. (2008). AMEE Guide no. 34: Teaching in the clinical environment. Med Teach, $30(4), 347-364$.

Spencer, J. (2003). Learning and teaching in the clinical environment. $A B C$ of learning and teaching in medicine. British Medical Journal, 326, 591-594.

Wimmers, P. F., Schmidt, H. G., \& Splinter, T. A. W. (2006). Influence of clerkship experiences on clinical competence. Medical Education, 40, 450-458. 


\section{Samenvatting}

Summary in Dutch

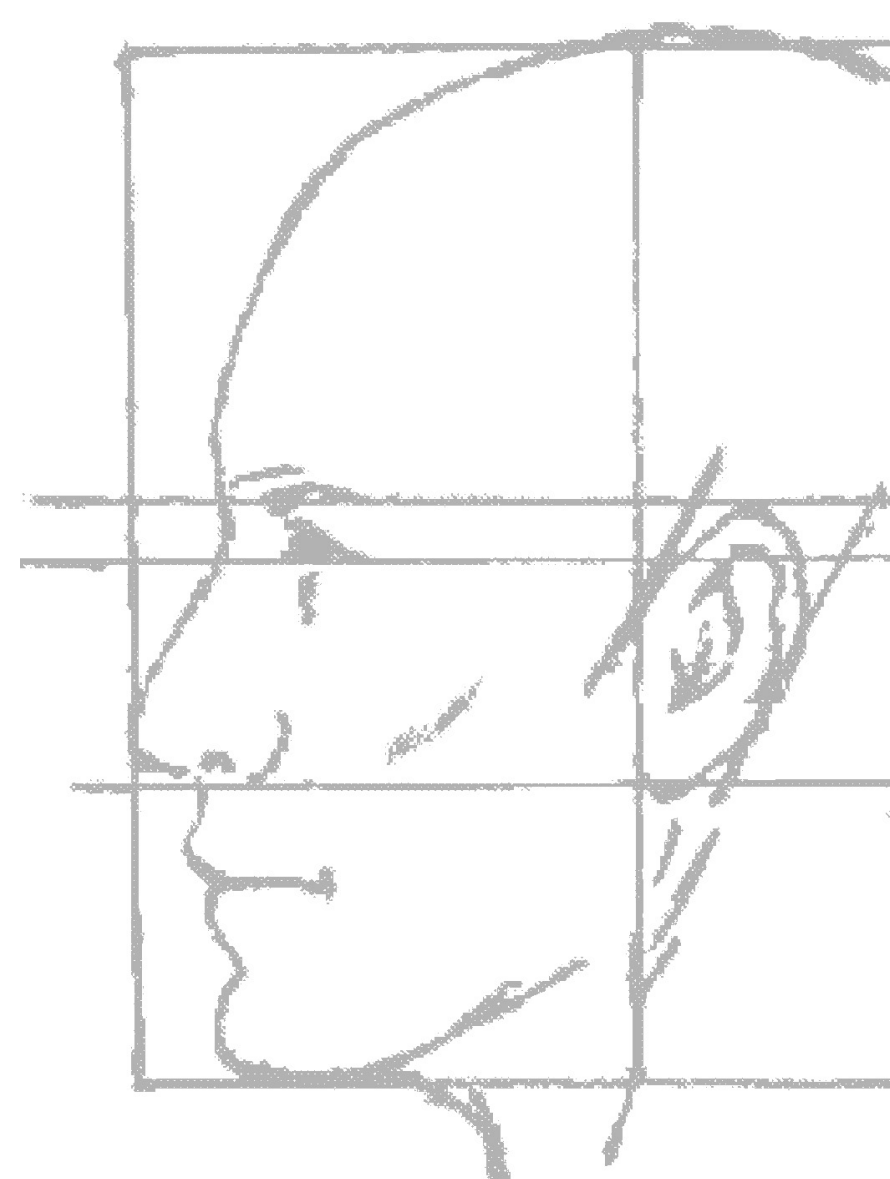


SAMENVATTING 
De co-schappen vormen een onmisbaar onderdeel van medische curricula wereldwijd. Tijdens de co-schappen leren studenten hun kennis en vaardigheden toe te passen op praktijkproblemen binnen de context van verschillende ziekenhuizen, afdelingen en situaties (Spencer, 2003). Het ziekenhuis als leeromgeving heeft een potentieel als krachtige leeromgeving voor studenten door de hoge mate van authenticiteit en de mogelijkheid tot actieve deelname in klinische werkzaamheden waarbij anamnese, lichamelijk onderzoek, het nemen van beslissingen en professioneel gedrag geïntegreerd worden (Spencer, 2003). Onderzoek heeft aangetoond dat goede supervisie van medische studenten door artsen en arts-assistenten de sleutel vormt tot succesvol leren in de klinische praktijk. De klinische praktijk laat echter ook zien dat supervisie en klinische begeleiding relatief weinig en infrequent plaatsvinden (Grant, Kilminster, Jolly, \& Cottrell, 2006). Daarnaast hebben artsen gedurende hun opleiding tot arts over het algemeen weinig tot geen scholing ontvangen om hun rol als klinisch begeleider goed in te kunnen vullen (Cottrell, Killminster, Jolly, \& Grant, 2002; Ramani \& Leinster, 2008). Als reactie op dit gebrek aan klinische begeleidingsvaardigheden heeft medisch onderwijskundig onderzoek zich gefocust op docentprofessionaliserings-programma's en (theoretische) modellen die specifieke en praktijkgerichte activiteiten voor clinici omschrijven. Deze docentprofessionaliserings stroming betekende tevens de opkomst van evaluatie instrumenten waarmee feedback kan worden gegeven aan artsen en arts-assistenten over hoe ze studenten (kunnen) begeleiden in de kliniek. Een review uit 2010 stelde het bestaan vast van 34 verschillende instrumenten gericht op het geven van feedback aan artsen over hun begeleidingsvaardigheden (Fluit, Bolhuis, Grol, Laan, \& Wensing, 2010). Bestaande instrumenten kennen echter diverse tekortkomingen (Beckman, Ghosh, Cook, \& Mandrekar, 2004; Fluit et al., 2010) zoals gebrekkige validiteit, het miskennen van stakeholders in het ontwikkelingsproces en te breed geformuleerde items die de effectiviteit van de feedback beperken. Een aanvullend probleem bij bestaande instrumenten is het gebrek aan onderbouwing vanuit de theorieën over effectieve klinische begeleiding gedurende de co-schappen. Het gebruik van een theoretisch kader vergroot volgens Bowden \& Marton (1998) de specificiteit en effectiviteit van feedback omdat het meer richting kan geven aan verbeterplannen.

In Hoofdstuk 1 wordt cognitive apprenticeship (Collins, Brown, \& Newman, 1989) geïntroduceerd als een theoretisch kader dat richting zou kunnen geven aan klinische begeleidingspraktijken. Gebaseerd op de ideeën van 'leermeester - gezel' stimuleert cognitive apprenticeship 'leren door middel van begeleide ervaring'. De basis wordt gevormd door een aantal doceermethoden (modelling, coaching, scaffolding, articulatie, reflectie en exploratie), die worden ingezet om de onderliggende processen van het denken en handelen van experts te expliciteren tijdens het werken in de praktijk waarbij ze gedrag modelleren. Cognitive apprenticeship is met 
name interessant voor klinisch begeleiden vanwege de focus op het expliciteren en doceren van de processen die experts gebruiken om complexe cognitieve taken op te lossen. De bruikbaarheid van de doceermethoden zoals omschreven in cognitive apprenticeship voor begeleiding tijdens de co-schappen is echter tot dusver nog niet vastgesteld. Daarnaast wordt 'het creëren van een veilige leeromgeving' omschreven als een cruciale factor voor effectief leren in de kliniek (Ramani \& Leinster, 2008). Tot slot worden in Hoofdstuk 1 de onderzoeksdoelen van dit proefschrift beschreven: 1) de ontwikkeling en validatie van een instrument en theoretisch model op basis waarvan feedback en sturing gegeven kan worden aan klinisch begeleiders met betrekking tot hun begeleidingsvaardigheden van studenten in de kliniek, en 2 ) het onderzoeken hoe klinisch begeleiders de bruikbaarheid van het instrument en theoretisch kader ervaren.

Het eerste doel van dit proefschrift wordt besproken in Hoofdstuk $2-4$.

In Hoofdstuk 2 wordt het potentieel van cognitive apprenticeship als theoretisch model voor klinische begeleiding onderzocht. Tijdens focus groep interviews werden drie groepen 6ejaars medische studenten $(\mathrm{N}=21)$ gevraagd vignetten te bespreken die de zes doceermethoden van cognitive apprenticeship en het creëren van een veilige leeromgeving omschreven. Aan de hand van de vignetten bediscussieerden de studenten in hoeverre de methoden voorkwamen in de praktijk, welke problemen ze ervaarden met de begeleiding en eventuele suggesties voor verbetering. De geluidsopnames van de focus groepen werden letterlijk getranscribeerd. Drie onderzoekers codeerden de data onafhankelijk van elkaar en bediscussieerden de coderingen totdat overeenstemming over de codering bereikt werd. Uit de resultaten bleek dat de studenten alle zes de doceermethoden ervaren hadden gedurende hun co-schappen. Modelling, coaching en articulatie kwamen het meeste voor terwijl scaffolding, reflectie en exploratie met name ervaren werden tijdens langere coschappen en indien er sprake was van één vaste begeleider. Studenten waren van mening dat langer verblijf binnen één afdeling het gebruik van scaffolding, reflectie en exploratie zou stimuleren. Verbetering van het gebruik van de doceermethoden zou volgens studenten kunnen worden bereikt middels docentprofessionalisering met een focus op 'hoe geef ik constructieve feedback' en 'hoe kan ik het niveau van de individuele student inschatten'. Over het geheel gezien suggereerden de resultaten dat het cognitive apprenticeship model bruikbaar is voor het vormgeven van begeleidingsstrategieën gedurende de co-schappen.

In Hoofdstuk 3 wordt de ontwikkeling van een instrument gebaseerd op de principes van cognitive apprenticeship en het creëren van een veilige leeromgeving omschreven. Doel van het instrument is om studenten in de gelegenheid te stellen om feedback te geven op de begeleidingsvaardigheden van individuele artsen en arts- 
assistenten. Om de inhoudsvaliditeit van het instrument vast te stellen werden drie groepen stakeholders met betrekking tot de co-schappen (twaalf onderwijskundigen, zestien artsen en twaalf studenten) gevraagd om de relevantie van de items te beoordelen op een vijfpuntsschaal ( $1=$ zeer irrelevant, $5=$ zeer relevant). Daarnaast gaven de stakeholders commentaar op de inhoud, bewoording en ontbrekende items. De items werden over het algemeen beoordeeld als zeer relevant $(M=4.3$, $\mathrm{SD}=0.38$, respons $95 \%$ ) en verschillen tussen stakeholders waren klein. De resultaten van het onderzoek leidden ertoe dat vier items werden verwijderd, dertien items werden geherformuleerd en één item toegevoegd werd.

Hoofdstuk 4 omschrijft de construct validiteit en betrouwbaarheid van het evaluatie instrument zoals ontwikkeld in hoofdstuk 3: de Maastricht Clinical Teaching Questionnaire (MCTQ). De onderliggende factoren van de MCTQ werden gebruikt om een causaal model van effectieve klinische begeleiding te toetsen (het Maastricht Clinical Teaching Model (MCT model)). Er werd een pilot uitgezet met de MCTQ in verschillende afdelingen binnen twee ziekenhuizen en studenten werd gevraagd om na afloop van een co-schap een MCTQ in te vullen voor die artsen en/of artsassistenten met wie ze het meeste contact hadden gehad gedurende het co-schap. Dit leverde vier of meer beoordelingen op voor 126 artsen en arts-assistenten. Om de construct validiteit te bepalen werd een conformatorische factoranalyse uitgevoerd. Betrouwbaarheid van de MCTQ werd vastgesteld aan de hand van het generaliseerbaarheidcoëfficiënt en de standaard meetfout. Tot slot werd, om een causaal model te toetsen, een structureel lineair model op de data toegepast. De conformatorische factor analyse leverde een vijf factor model op (modelling, veilig leerklimaat, coaching, articulatie en exploratie) die een goede fit vertoonde met de data. Het generaliseerbaarheidscoefficient liet zien dat zeven tot tien student oordelen nodig zijn om een betrouwbaar oordeel over een individuele arts/artsassistent te geven. Structural Equation Modelling bevestigde een drie stappen model van goed klinisch begeleiden. De eerste stap wordt gevormd door modelling en het creëren van een veilige leeromgeving (stap 1), gevolgd door de arts die de student coacht (stap 2) en eindigend met de arts die de student stimuleert tot zelfgestuurd leren (stap 3).

Het tweede doel van het proefschrift, het onderzoeken hoe klinisch begeleiders de bruikbaarheid van het instrument (MCTQ) en theoretisch kader (MCT model) ervaren, wordt omschreven in Hoofdstuk 5 en 6.

In Hoofdstuk 5 wordt de bruikbaarheid van de MCTQ onderzocht. De MCTQ werd gebruikt om geschreven feedback te geven aan artsen en arts-assistenten over hun klinische begeleidingsvaardigheden. Omdat onderzoek heeft aangetoond dat geschreven feedback alleen niet genoeg is om docenten te laten reflecteren op hun 
gedrag (Atwater, Waldman, \& Brett, 2002; Beijaard \& De Vries, 1997), werd onderzocht of de effectiviteit van de feedback vergroot kon worden door een zelfevaluatie toe te voegen aan de geschreven feedback gegeven door studenten. 37 clinici (tien arts-assistenten, 27 artsen) uit verschillende disciplines werden uitgenodigd om een zelf-evaluatie vragenlijst over hun klinische begeleidingsvaardigheden gebaseerd op de MCTQ in te vullen. Studenten vulden de MCTQ in om de clinici te evalueren. Nadat de clinici de feedback (bestaande uit hun zelf-evaluatie en de evaluatie door de studenten) hadden ontvangen, werd hen gevraagd hun mening te geven over de zelf-evaluatie oefening, de evaluatie door studenten en de daaruit resulterende geschreven feedback middels een vragenlijst (vijfpuntschaal, 1 = volledig oneens, 5 = volledig eens) en vervolgens, meer in detail, gedurende semigestructureerde interviews. 25 clinici namen deel (67\%). De resultaten lieten zien dat feedback gebaseerd op de MCTQ als specifiek, informatief en verhelderend ervaren werd. Verder werden zowel de zelf-evaluatie als de student feedback als bruikbaar ervaren ( $M=3.7, S D=1.0$ ) maar student feedback werd als meer effectief ervaren. Uit de interviews (met twaalf artsen) bleek dat de combinatie van zelfevaluatie en student evaluaties als meer effectief ervaren werd dan de zelfevaluatie of student evaluaties op zich. In het bijzonder werden discrepanties tussen student en zelf-evaluatie genoemd als sterke stimulans voor verandering.

Hoofdstuk 6 omschrijft de bruikbaarheid van het MCT model vanuit het perspectief van ervaren klinisch begeleiders. Het doel van de studie was om te onderzoeken in hoeverre het MCT model overeenkomt met de praktijk van ervaren klinisch begeleiders en om in kaart te brengen welke factoren het klinisch begeleiden beïnvloeden. Zeventien klinisch begeleiders uit vijf verschillende disciplines, vier verschillende ziekenhuizen en met uitgebreide ervaring op het gebied van begeleiding tijdens de co-schappen werden gevraagd deel te nemen aan een semi-gestructureerd interview. Vanuit een pragmatische optiek werd bekeken in hoeverre het theoretische MCT model overeenkwam met de praktijk zoals ervaren door de clinici. De gespreksgids werd ontwikkeld op basis van onderzoek dat factoren omschrijft die het begeleiding van studenten in de kliniek beïnvloeden. Twee onderzoekers voerden onafhankelijk van elkaar een thematische analyse uit van de interview transcripten. De codering werd besproken in het onderzoeksteam totdat er consensus werd bereikt. Alle deelnemers herkenden het MCT model als een gestructureerde weergave van hun aanpak van klinische begeleiding. Modelling en het creëren van een veilige leeromgeving werden gezien als cruciaal. Langere co-schappen zorgden ervoor dat alle methoden zoals omschreven in het MCT model toegepast konden worden zoals bijvoorbeeld het stimuleren van zelfgestuurd leren en reflectie op sterktes en zwaktes. Motivatie en pro-actief gedrag van zowel de arts als de student stimuleerden het gebruik van de begeleidingsmethoden. Daarnaast werd de rol van verpleegkun- 
digen in het begeleiden van studenten als belangrijk, doch impliciet, gezien bij het creëren van een veilige leeromgeving.

Hoofdstuk 7 geeft een overzicht van de conclusies uit Hoofdstuk 2 - 6, een algemene discussie naar aanleiding van de bevindingen, een omschrijving van de sterktes en zwaktes van dit proefschrift en implicaties voor de praktijk.

Het eerste doel van dit proefschrift was om een instrument en model te ontwikkelen en valideren dat gebruikt kon worden om feedback en sturing te geven aan klinisch begeleiders. Op basis van de bevindingen uit hoofdstuk 2 werd geconcludeerd dat het cognitive apprenticeship model een waardevol model is om begeleidingsstrategieën voor de co-schappen te omschrijven. Hoofdstuk 3 leidde tot de conclusie dat een instrument gebaseerd op principes van cognitive apprenticeship als relevant werd gezien door drie groepen stakeholders. In hoofdstuk 4 werd vervolgens geconcludeerd dat de MCTQ een valide en betrouwbaar instrument is om klinisch begeleiders te evalueren op hun begeleidingsvaardigheden als tenminste zeven student oordelen per begeleider beschikbaar zijn. Een klinisch begeleidingsmodel gebaseerd op cognitive apprenticeship (MCT model) werd ontwikkeld om effectieve klinische begeleiding op de werkplek vorm te geven. Het tweede doel van dit proefschrift was om de bruikbaarheid van het instrument en model in de praktijk te onderzoeken. In hoofdstuk 5 werd geconcludeerd dat feedback gebaseerd op de MCTQ werd ervaren als specifiek, informatief en verhelderend. Een combinatie van zelf-evaluatie en student oordelen werd gezien als een sterke stimulans om verandering te overwegen, met name als er sprake was van discrepanties tussen de twee oordelen. Hoofdstuk 6 sluit af met de conclusie dat het MCT-model past bij de begeleidingsactiviteiten zoals ze uitgevoerd worden in de co-schappen. Met name modelling en het creëren van een veilige leeromgeving werden omschreven als fundamenteel voor klinische begeleiding. Langere co-schappen werden aangeraden om de toepassing van de drie stappen van het MCT-model te verzekeren.

De discussie gaat in op drie onderwerpen. Ten eerste wordt de noodzaak besproken om het MCT-model af te stemmen op het gewenste niveau voor de individuele student. Deze stelling komt overeen met onderzoek dat het belang onderstreept van het 'diagnosticeren' van het competentie niveau en de leerbehoeften van de student als manier om optimale begeleiding te verzorgen (Beckman \& Lee, 2009; Ramani \& Leinster, 2008). Ten tweede lijkt het leren tijdens co-schappen afhankelijk te zijn van een pro-actieve houding van zowel de student als de arts. Dit suggereert dat studenten en artsen een verantwoordelijkheid delen in het realiseren van effectief leren en begeleiden gedurende de co-schappen. Ten derde blijkt dat geschreven feedback specifiek, omschrijvend, diagnostisch (Braskamp \& Ory, 1994) en gebaseerd op een theoretisch kader moet zijn (Bowden \& Marton, 1998) om ervoor te zorgen dat het effect heeft. Bovendien is effectieve feedback mede afhankelijk van additionele instrumenten zoals zelf-evaluatie en/of (peer) coaching. 
De sterktes van dit proefschrift liggen in het gebruik van een theoretisch kader voor het ontwikkelen van instrument en model, de uitgebreide aandacht voor validiteit, het gebruik van zowel kwantitatieve als kwalitatieve methoden en de aandacht voor de context van het klinisch begeleiden. De zwaktes liggen in een mogelijke oversimplificatie van de realiteit in het MCT-model, het uitsluitend gebruikmaken van percepties als databron en de generaliseerbaarheid van de bevindingen.

Toekomstig onderzoek zou zich moeten richten op het concept 'teaching team' gebaseerd op de bevinding dat niet alleen artsen maar ook arts-assistenten en verpleegkundigen een belangrijke rol vervullen binnen klinische begeleiding. Een andere mogelijke richting betreft de inzet van observationele methodes om de aard van klinisch begeleiden te onderzoeken. Bovendien zouden de bevindingen van dit proefschrift geëxtrapoleerd kunnen worden naar verschillende contexten waarbij ook aandacht geschonken kan worden aan de longitudinale effecten van feedback gebaseerd op de MCTQ.

Implicaties voor de praktijk omvatten de herstructurering van co-schappen van een 'carrousel systeem' naar meer longitudinale co-schappen zodat betere en meer continue begeleiding gerealiseerd kan worden. Daarnaast wordt voorgesteld dat er aandacht komt voor de voorbereiding van zowel studenten als artsen op de coschappen. Tot slot wordt aangeraden om de MCTQ en het MCT model te gebruiken als vertrekpunt voor docentprofessionalisering en coaching van artsen. 


\section{REFERENCES}

Atwater, L. E., Waldman, D. A., \& Brett, J. F. (2002). Understanding and optimizing multisource feedback. Human Resource Management, 41, 193-208.

Beckman, T. J., Ghosh, A. K., Cook, D. A., Erwin, P. J., \& Mandrekar, J. N. (2004). How Reliable Are Assessments of Clinical Teaching? A Review of the Published Instruments. Journal of General Internal Medicine, 19, 971-977.

Beckman, T. J., \& Lee, M. C. (2009). Proposal for a Collaborative Approach to Clinical Teaching. Mayo Clinic Proceedings, 84(4), 339-344.

Beijaard, D., \& De Vries, Y. (1997). Building Expertise: a process perspective on the development or change of teachers' beliefs. European Journal of Teacher Education, 20(3), 243-255.

Bowden, J., \& Marton, F. (1998). Quality and qualities. In J. Bowden \& F. Marton (Eds.), The university of learning (pp. 211-245). London: Kogan Page Limited.

Braskamp, L. A., \& Ory, J. C. (1994). Assessing Faculty Work: Enhancing Individual and Institutional Performance. San Francisco, CA: Jossey-Bass.

Collins, A., Brown, J. S., \& Newman, S. E. (1989). Cognitive Apprenticeship: Teaching the crafts of reading, writing, and mathematics. In L. B. Resnick (Ed.), Knowing, learning, and instruction: Essays in honor of Robert Glaser (pp. 453-494). Hillsdale, New Jersey: Lawrence Erlbaum Associates, Inc.

Cottrell, D., Killminster, S., Jolly, B., \& Grant, J. (2002). What is effective supervision and how does it happen? A critical incident study. Medical Education, 36, 1042-1049.

Crossly, J. (2006). Do the supervision needs of 'clerkship students' change as they become more experienced? Medical Education, 40, 1053.

Dolmans, D. H. J. M., Wolfhagen, H. A. P., Essed, G. G. M., Scherpbier, A. J. J. A., \& Van der Vleuten, C. P. M. (2002). Students' perceptions of relationships between some educational variables in the outpatient setting. Medical Education, 36, 735-741.

Fluit, C. R., Bolhuis, S., Grol, R., Laan, R., \& Wensing, M. (2010). Assessing the quality of clinical teachers: a systematic review of content and quality of questionnaires for assessing clinical teachers. Journal of General Internal Medicine, 25(12), 1337-1345.

Grant, J., Kilminster, S., Jolly, B., \& Cottrell, D. (2006). Clinical supervision of SpRs: where does it happen, when does it happen and is it effective? Medical Education, 37, 140-148.

Ramani, S., \& Leinster, S. (2008). AMEE Guide no. 34: Teaching in the clinical environment. Med Teach, $30(4), 347-364$.

Spencer, J. (2003). Learning and teaching in the clinical environment. ABC of learning and teaching in medicine. British Medical Journal, 326, 591-594.

Wimmers, P. F., Schmidt, H. G., \& Splinter, T. A. W. (2006). Influence of clerkship experiences on clinical competence. Medical Education, 40, 450-458. 



\section{Dankwoord}

Acknowledgements

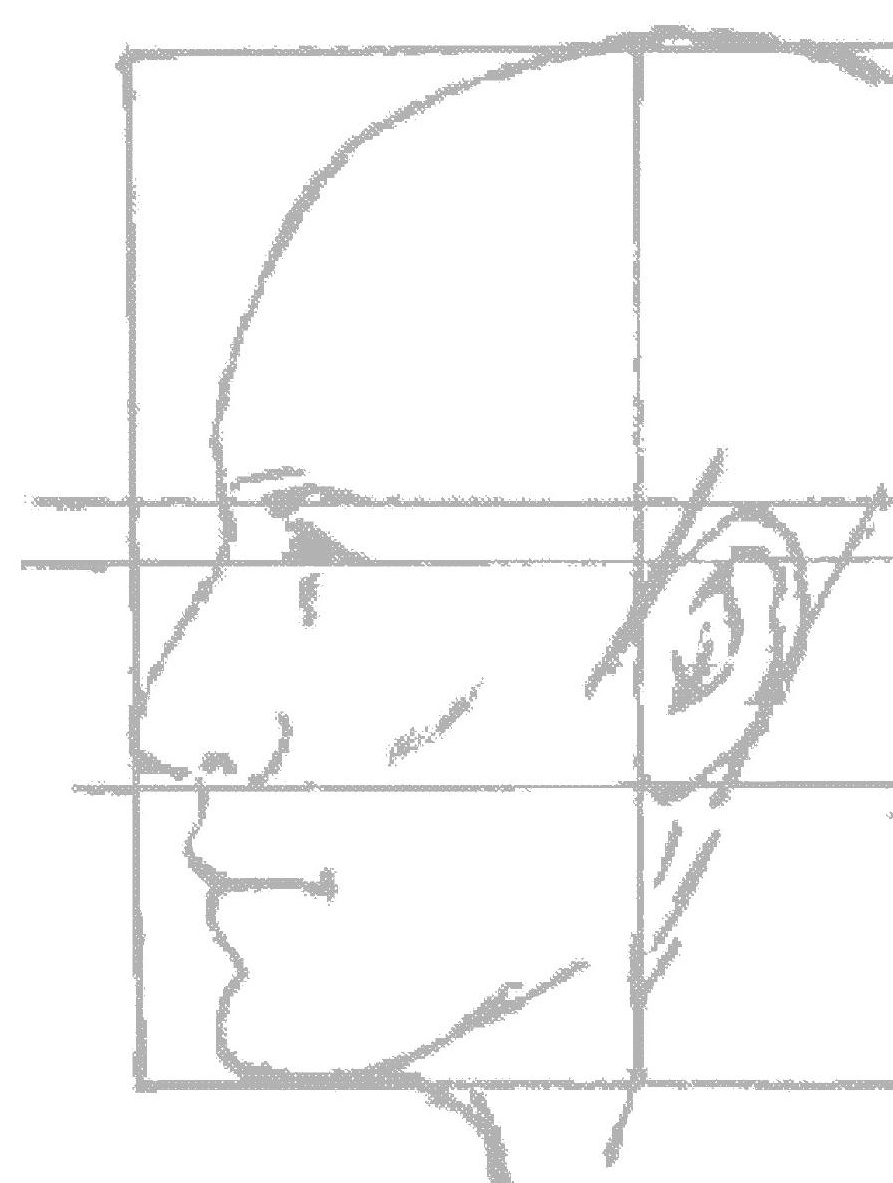


DANKWOORD 
Dankbaarheid is een positieve emotie of attitude in relatie tot de erkenning van alle hulp, steun en giften die een persoon kan krijgen.

Als ik terugkijk op mijn proefschrift periode, kan ik niet anders dan dankbaar zijn voor de ontelbare varianten van hulp, steun en giften die ik heb mogen ontvangen.

Dit project was er niet geweest zonder de hulp van mijn promotor, Albert Scherpbier, en co-promotoren, Diana Dolmans en Ineke Wolfhagen. Albert, de kapitein die ervoor zorgde dat het stoomschip vol kakelende dames rustig op koers bleef. Met af en toe, naar het leek, minieme sturingsmanoeuvres ('Strak plan, A.', 'Tja, A.', 'Sjiek! $A^{\prime}$ ) die grootse uitwerkingen bleken te hebben. Ik heb je bereikbaarheid en bereidheid enorm gewaardeerd. Blijf vooral ook naar 'mooie fietsen' kijken, want dat geeft je flair. Mijn co-promotores, Diana Dolmans en Ineke Wolfhagen, 'the dynamic duo of thesis supervision'. Het is mooi om te zien hoe goed jullie op elkaar zijn afgestemd en een zelfde arbeidsethos te voelen resoneren. Diana, jouw snelle, uitgebreide en specifieke feedback heeft veel betekend voor mijn proefschrift. Ik bewonder jouw professionele aanpak zowel op het werk als privé. Wout, Gijs en Lieke mogen trots zijn op zo'n mama. En oh ja, ik beloof je dat ik je nooit meer per ongeluk in de gevaarlijke achteraf buurten van Genua zal leiden. Ineke, jij zorgde ervoor dat na mijn stage bij O\&O FdEWB er een plaats voor mij bij O\&O FdG kwam. Jouw aandacht voor 'het moraal' met betrekking tot het schrijven van een proefschrift heb ik altijd zeer gewaardeerd. Ook met betrekking tot programma-evaluatie leer ik nog iedere dag van jouw doortastende en no-nonsense aanpak. Als geen ander ken je het belang van een etentje (en bijbehorend wijntje) op zijn tijd.

Cees van der Vleuten, als vakgroepvoorzitter van O\&O deelde je mede dat je vertrouwen had in deze 'Jonge Klare van OWW'. Dank voor je vertrouwen en steun, ik kijk uit naar een inspirerende samenwerking.

Onderwijskundig onderzoek is nergens zonder studenten en docenten. Aan alle studenten die ik lastig heb gevallen met mijn vragenlijsten: zonder jullie was dit proefschrift niet mogelijk geweest. Ik ben mij er wel degelijk van bewust dat ik jullie 'evaluatiemoeheid', die het geneeskunde curriculum toch al neigt te veroorzaken, behoorlijk heb opgeplust. Dank ook aan alle artsen die tijd voor mij en mijn 'onderwijskundige vragen' wilden maken. Met name Bas Verhoeven, Mark van der Hoeven en Jamiu Busari voor hun interesse in mijn werk: jullie passie voor klinisch onderwijs is inspirerend. Een speciaal woord van dank voor Marijke van Santen-Hoeufft, Lieve van Coppenolle en Wim Peters: jullie gaven mij de sleutel naar jullie wereld 'de kliniek'. Jullie enthousiasme en toewijding voor onderwijs doen mijn onderwijskundig hart sneller kloppen.

Hetty Snellen, wat ben ik blij en trots dat je bij de laatste studie hebt mee gedacht en geholpen. Mijn dank is groots, grootser, grootst voor je eindeloze monni- 
kenwerk bij het analyseren en coderen van de transcripten. Je betrokkenheid gedurende mijn proefschrift had ik niet willen missen. Ik ben dankbaar voor je vriendschap.

Als $\mathrm{AiO}$ zou ik verloren zijn geweest zonder alle 'support crews' die OvO rijk zijn. Te beginnen met de statistische support crew: Arno Muijtjens en Ron Hoogenboom. Heren, dank! Ron bedankt voor je ondersteuning bij hoofdstuk 4. Arno, bedankt voor je advies en hulp bij hoofdstuk 3 en 4 . Ik denk niet dat ik ooit nog over factor analyses en kruistabellen na kan denken zonder daarbij aan jou te denken. The 'English Language \& Writing support crew', Mereke Gorsira. Woordenkunstenares en gesprekspartner. Ik bewonder je vermogen nauwgezet werk te combineren met creativiteit. Daarnaast ben ik blij met je vriendschap en betrokkenheid. Ik hoop samen van nog veel films, etentjes en discussies over boeken, de wereld en het leven te kunnen genieten.

Student-assistenten zijn onmisbaar in ieder proefschrift project. Lorette Stammen en Merel Mulder: dames met hart voor de zaak en plezier in het leven. Mijn hemel wat hebben we samen gelachen. Als ik later aan iemand toegewijde en behulpzame artsen kan aanbevelen, dan zijn jullie het wel. Even laten weten welke specialisatie het gaat worden dan zorgen we ervoor dat de juiste hulpvragen beantwoord kunnen worden.

Mijn collega's bij O\&O wil ik danken voor hun betrokkenheid en interesse. Werken op de UNS 60 voelt als een warm bad (daarom blijf ik waarschijnlijk ook vaak te lang plakken) en onze gezamenlijke uitstapjes ieder jaar hebben hele mooie herinneringen opgeleverd. Ik hoop er nog veel met jullie te mogen maken.

Voor de nodige warmte en plezier binnenskamers zorgden kamergenootjes Astrid Pleijers, Ameike Janssen-Noordman en Jill Whittingham. Astrid, in de eerste dagen bij O\&O zorgde je ervoor dat ik me er snel thuis voelde. Ameike, bedankt voor alle gezelligheid, je adviezen en luisterend oor. Jill, samen worstelen we ons door de verschillende 'kwaliteitsculturen' van FHML, wat af en toe lijkt op een regelrechte safari inclusief wilde beesten. Maar naast hard werken is er ook altijd veel ruimte voor veel plezier. 'Quality Ladies to the Rescue!', dank voor je steun en vriendschap, ik ben blij dat we kamergenootjes zijn.

Naast mijn proefschrift ging het leeuwendeel van mijn tijd richting taakgroep programma-evaluatie: Diana Riksen, Daniëlle Moonen, Lilianne Hagens, Paul Gransbergen en Mariska Berends. We zijn een team en samen zetten wij programmaevaluatie hoog op de agenda van FHML. Jullie inzet tijdens de invoer van 'de nieuwe plannen' was en is fenomenaal. Diana, dank voor de dataverwerking voor hoofdstuk 5 , zonder jou had ik nooit zulke mooie feedback kunnen geven aan de artsen en arts-assistenten. 
Lilian Swaen \& Nicky Verleng, het kloppend hart van O\&O. Jullie interesse, luisterend oor, onvermoeibare behulpzaamheid, lach, dropjes, creativiteit en geintjes. Jullie zijn allebei ongelofelijke schatten!

Mascha Verheggen, het begon ooit toen we samen een 'heimiddag' moesten organiseren voor O\&O. Sindsdien hebben we samen vele films gezien maar ook Ghana en Toscane getrotseerd. Ik zal nooit vergeten hoe wij dansend door een Ghanees dorp werden uitgelachen door de locals. Ik hoop nog vele mooie reizen met je te mogen maken.

In de loop der jaren zijn de 'OvO AiO's' binnen O\&O en daarbuiten een waar begrip geworden. Tijdens de AiO leesgroepen, 'Afkick Zittingen' (AfZi) op vrijdagmiddag, congressen en koffie-momenten gaven we feedback, lagen we in een deuk en leefden we met elkaar mee. Ik ga ons 'samen AiO zijn' missen! Nog een paar specifieke woorden van dank: Joost Dijkstra (dank voor je hulp met de lay-out), Floris van Blankenstein (bedankt voor New York), Janneke Frambach, Rachelle Kamp (dames, volgend jaar Vancouver!!), Dominique Waterval (Pannekoek!) Jonne van der Zwet, Irene Slootweg (ik hoop nog vele KO groepen bij te wonen),

De wereld van medisch onderwijskundig onderzoek heb ik leren kennen als een melting pot van verschillende disciplines waar de passie voor onderwijs het bindmiddel vormt en tevens het geheime ingrediënt is voor levendige en (inter)nationale discussies. Twee mensen die met mij de stap waagden naar cognitive apprenticeship als theoretisch kader voor het domein zijn Tobias Boerboom en Pia Strand. Tobias, je noemt mij de 'founding mother of cognitive apprenticeship', jij bent de 'caring and stimulating father' die ervoor gezorgd heeft dat er meer evidence komt om te laten zien dat we zo vreselijk gelijk hebben. Ik hoop in de toekomst samen voor nog meer evidence te kunnen zorgen. I also want to thank the new aunt which has been added to the cognitive apprenticeship family. Dear Pia, thank you for inviting me, to your world, to your home and to lovely Skåne. I am very much looking forward to working with you and your colleagues at 'Lund Universitet'.

Walther van Mook, mijn eerste werkdag in September 2005 viel samen met de AMEE in Amsterdam waar wij elkaar ontmoetten. Beiden stonden we aan het begin van ons proefschrift en sindsdien hebben we nog vele congressen bezocht en gesprekken gevoerd. Ik kijk uit naar de voortzetting van onze samenwerking.

Griet Peeraer, BQB, dank voor de mooie reizen door Toronto, Malaga en Granada (met en zonder stresserende momenten in het Albayzin ... ). Ik denk met veel plezier terug aan onze verhalen over 'de dierentuin' en al haar 'dieren'.

Christoph Berendonk, dear Chris, we had the opportunity to work together on your project while you were at O\&O during 2010. I want to thank you for our discussions both on and off topic, for your insight and advice, and (you probably were not aware of this) for making me see how much I like doing and supervising research. I hope to see you again soon in Bern! 
Wat dichter bij huis zijn er ook een aantal mensen die ik zeker niet ongenoemd wil laten. Simone Meesters wil ik danken voor haar hulp bij het design van de cover. Heel leuk dat we elkaar na al die tijd weer zijn tegengekomen! Mijn buurmannen op het Thorbeckeplantsoen, Jan van Bilsen en Toine Defesche, met jullie aan weerszijden voel ik me veilig en thuis. Heren bedankt voor jullie interesse en 'vaderlijk advies'. Toine, bedankt voor alle keren dat je mijn huis 'bewaakte' als ik weer eens in het buitenland was. Ik hoop nog heel lang op je te mogen rekenen.

Ilske Timmermans, dear Trinny, we hebben bewezen samen een dodelijk duo te kunnen zijn. Als trouwste leden hebben we menig AfZi opgeluisterd, bitterballen beoordeeld, witte wijn geëvalueerd en collega's van 'feedback' voorzien. Dank voor de humor, MSN-advies en gedeelde tv-avonden. Ook dank voor je vriendschap, betrokkenheid en je voorzitterschap van de illustere 'titelcommissie': die vrijdag middag op niet nader te noemen locatie met niet nader te noemen versnaperingen en niet nader te noemen co-conspirators.

Esther Bergman-de Bres, in september 2005 zaten wij gelijktijdig in de PGO en tutor training, beiden aan het begin van onze universitaire carrière. Sindsdien hebben we congrespresentaties overleefd, de Prachovsky Rocks beklommen, huizen verbouwd, de Hoornse kermis bezocht en Schotse Lochs bewonderd. Dank voor je vriendschap en steun. En dank ook dat ik Jan af en toe mag lenen om mijn tuin weer op orde te brengen.

Ludo Costongs \& Lourens Hobbelink: my home away from home in Amsterdam. Ludo, steeds vaker komen we erachter dat het leven een groot toneelstuk is en dat ieder (pijnlijk) moment alleen maar aanleiding is voor een hilarische slapstick of een ingetogen monoloog. Lourens, de fijnste huisarts van de wereld, jammer dat je niet in Maastricht gaat praktiseren. Jullie liggen mij na aan het hart.

Mijn paranimfen, Jeantine de Feijter en Robbert Duvivier. Ik heb ooit gezegd dat ik de rol van paranimf in zijn oorspronkelijke vorm heel belangrijk vind. En ik twijfel er geen seconde aan dat jullie beiden in staat zouden zijn om de verdediging over te nemen als ik dat zou vragen. Robbert, mede 'motto verzinner'. Het begon ooit bij 'focus, intuïtie, prioriteit' en sindsdien zijn er vele motto's de revue gepasseerd. Gezamenlijk laveren we door de wereld die medisch onderwijs heet en analyseren we het werk, het leven en de liefde aan gort. Dank voor vriendschap, je steun, je inspiratie, je glimlach en de glazen wijn op het juiste moment. Jeantine, samen discussiëren, in een deuk liggen, organiseren, Londen snelwandelen, motiveren, delen, stil zijn, passie voor (misschien ook minder verantwoorde) literatuur, genieten van Shiraz op Oxford Street en bosvruchten cheesecake op Plein 1992, er zijn weinig dingen die wij niet samen kunnen. Ik heb er veel vertrouwen in dat jij een arts wordt die er is voor haar patiënten. Bedankt voor je vriendschap. 
Lieve Opa, ik vind het altijd leuk om te horen hoe trots je op me bent in de formulering 'ja, maar dat kan toch ook niet anders met zo'n Opa'. Ik ben heel blij dat je er bij bent op deze dag.

Lieve Pap, Mam en Luc, ik zei jullie al dat het laatste plekje in het dankwoord bewaard wordt voor de belangrijkste mensen. Om te beginnen met de jongste, lil Bro, mijn grote kleine broer. Onderwijs bloed kruipt waar het niet gaan kan, dat blijkt maar weer. Ik heb bewondering voor jouw pure en oprecht aanpak en de keuzes die je maakt. Ik ben heel trots op je en weet zeker dat jij een briljante Meester Luc wordt. Dikke knoevel! Lieve Pap \& Mam, steun en toeverlaat, voor grote en voor kleine dingen, voor de mooie en minder mooie momenten. Beiden gaven jullie mij kwaliteiten mee die me tijdens dit proces en in het dagelijks leven helpen. ledere dag komen we er samen weer achter dat we leren. En iedere dag houd ik ongelofelijk veel van jullie. Laten we genieten en vieren: tijd voor een feest! 

Curriculum vitae

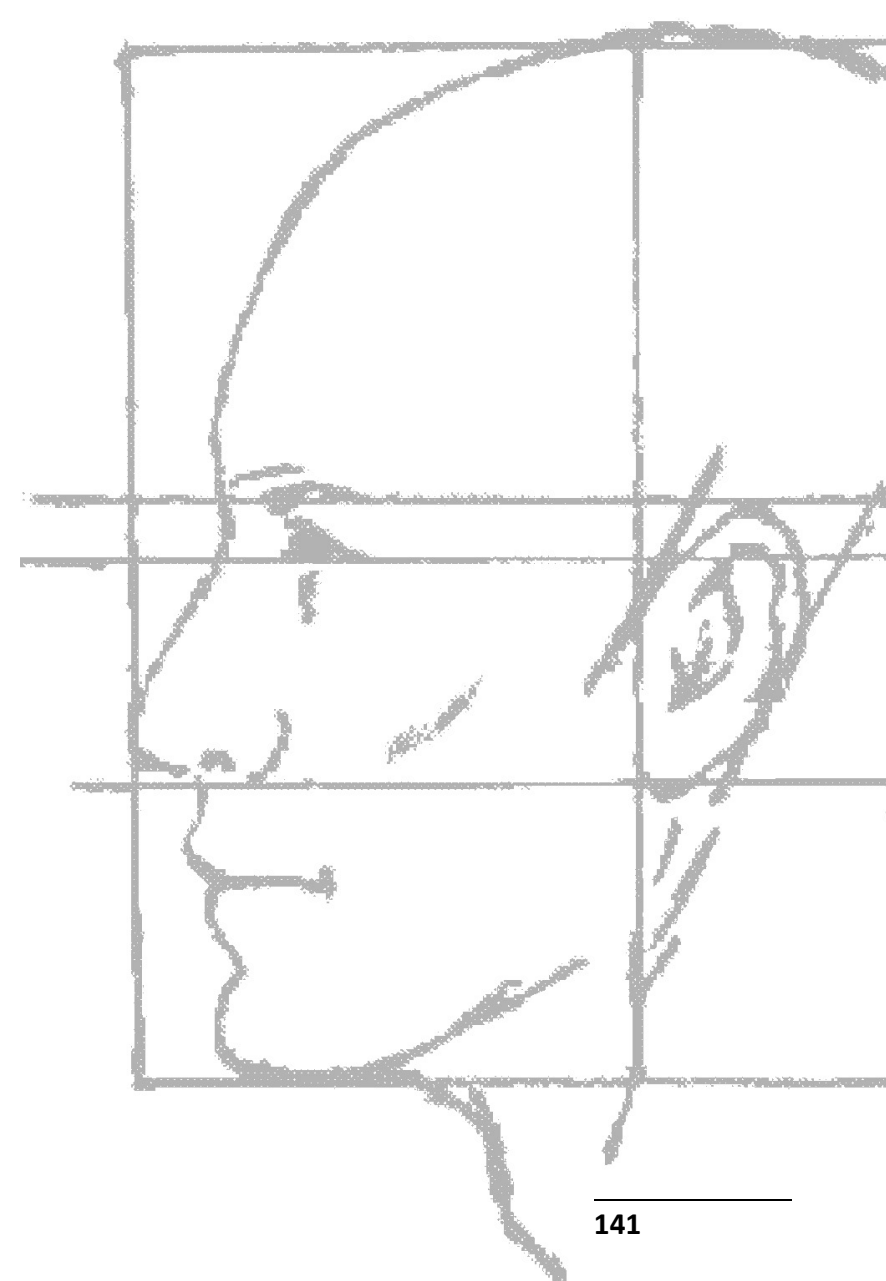


CURRICULUM VITAE 
Renée E. Stalmeijer was born on February $19^{\text {th }} 1982$ in Stein, the Netherlands. She attended Atheneum at Graaf Huyn College in Geleen where she graduated in 2000. She started studying Educational Sciences at Maastricht University in 2001, specializing in 'management of learning', and completed her internship at the department of Educational Development and Research at Faculty of Economics and Business Administration, Maastricht University. She graduated Educational Sciences Cum Laude in September 2005. Directly thereafter she started working as a researcher at the department of Educational Development and Research at the faculty of Medicine (now faculty of Health, Medicine and Life Sciences) at Maastricht University. Since 2006 she is head of the task force programme evaluation and has combined writing her dissertation with educational development projects, course coordination and teaching responsibilities for both the Medical Faculty and the School of Health Professions Education. She has done a number of consultancies on topics ranging from quality assurance to qualitative research. Currently she works at the same department as an assistant professor where she will continue her research, educational development, management and teaching activities.

\section{PUBLICATIONS}

\section{Peer Reviewed Journals}

Stalmeijer, R.E., Dolmans, D.H.J.M., Wolfhagen, H.A.P., Muijtjens, A.M.M., \& Scherpbier, A.J.J.A. (2010). The validity and reliability of the Maastricht Clinical Teaching Questionnaire as a model of effective clinical teaching. Academic Medicine. 85 (11) p. 1732-1738.

Stalmeijer, R.E., Dolmans, D.H.J.M., Wolfhagen, H.A.P., Van Coppenolle, L., Peters, W.G., \& Scherpbier, A.J.J.A. (2010).Combined student ratings and self-assessment provide useful feedback for clinical teachers. Advances in Health Sciences Education: Theory and Practice 15 (3) p 315 - 328. (E-pub ahead of print September 2009)

Stalmeijer, R.E., Dolmans, D.H.J.M., Wolfhagen, H.A.P., \& Scherpbier, A.J.J.A. (2009). Cognitive apprenticeship in clinical practice: Can it stimulate learning in the opinion of the students? Advances in Health Sciences Education: Theory and Practice. 14 (4) p. 535-547. (E-pub ahead of print September 2008)

Stalmeijer, R.E., Dolmans, D.H.J.M., Wolfhagen, H.A.P., Muijtjens, A.M.M., \& Scherpbier, A.J.J.A. (2008). Development of an instrument for evaluating the clinical teacher: Involving stakeholders to determine content validity. Medical Teacher, 30 (8), p. e272-e277. 
Stalmeijer, R.E.,\& de Grave W. (2008). De student als observator en feedbackgever voor docenten: een procesevaluatie. [Students as observers and feedback providers for teachers: a process evaluation.] Tijdschrift voor Medisch Onderwijs [Dutch Journal of Medical Education], 27 (5), p247-256.

Stalmeijer, R.E., Gijselaers, W.H., Wolfhagen, H.A.P., Harendza, S., \& Scherpbier, A.J.J.A. (2007). How Interdisciplinary Teams Can Create Multidisciplinary Education: On the Interplay Between Team Processes and Educational Quality. Medical Education 41(11), p. 1059-1066.

Dolmans, D.H.J.M., Stalmeijer, R.E., \& Wolfhagen, H.A.P. (2006). Feedback ter bevordering van de professionele ontwikkeling van docenten. [Feedback to improve the professional development of teachers] Tijdschrift voor Medisch Onderwijs [Dutch Journal of Medical Education], 25 (6), p.267-272.

\section{Book Chapters}

Dolmans, D.H.J.M., Stalmeijer, R.E., van Berkel, H., Wolfhagen, H.A.P. (2011) Quality assurance in teaching and learning: Enhancing quality culture. In Dornan et al. (eds) Medical Education: Theory and Practice. Churchill Livingston, Elsevier - London, UK.

Stalmeijer, R.E., Dolmans, D.H.J.M., van Berkel, H., \& Wolfhagen H.A.P. (2010) Quality assurance in a PBL curriculum p.157 - 166. In van Berkel et al. (eds.) Lessons from Problems-based Learning. Oxford University Press, Oxford UK.

Wolfhagen, H.A.P., Stalmeijer, R.E., van Berkel, H.,\& Dolmans, D.H.J.M. (2010) Interne kwaliteitszorg in ontwikkeling (Internal Quality Care in Development) p. 105 109 in H. Van Berkel, A. Bax, H. van Hout (eds). Kennis delen en inspireren. Toen, nu en in de toekomst. Noordhoff Uitgevers, Groningen Houten.

\section{Conference Proceedings}

Stalmeijer, R.E., Dolmans, D.H.J.M., Wolfhagen, H.A.P., Muijtjens, A.M.M., van Merriënboer, J., Scherpbier, A.J.J.A. (2010) Validity and reliability of the Maastricht Clinical Teaching Questionnaire: Factors influencing effective clinical teaching. Presented at the AERA meeting 2010 in Denver Colorado. 


\section{Presentations}

Stalmeijer, R.E., Dolmans, D.H.J.M., Wolfhagen, H.A.P., Muijtjens, A.M.M., Van Merriënboer, J., Scherpbier, A.J.J.A. (2010). Validity and reliability of the Maastricht Clinical Teaching Questionnaire: Factors influencing effective clinical teaching. Presented at the AERA meeting 2010 in Denver Colorado, U.S.A.

Stalmeijer, R.E., Dolmans, D.H.J.M., Wolfhagen, H.A.P., Van Coppenolle, L., Peters, W.G., Scherpbier, A.J.J.A. (2009). Student ratings combined with self-assessment provides useful feedback for clinical teachers (in Dutch). Research paper presented at the NVMO conference, November 2009, Egmond aan Zee, the Netherlands.

Stalmeijer, R.E., Dolmans, D.H.J.M., Wolfhagen, H.A.P., Van Coppenolle, L., Peters, W.G., Scherpbier, A.J.J.A. (2009). Student ratings combined with self-assessment provides useful feedback for clinical teachers. Paper presented at the AMEE conference, September 2009, Malaga, Spain.

Stalmeijer, R.E., Dolmans, D.H.J.M., Wolfhagen, H.A.P., Scherpbier, A.J.J.A. (2008). Cogntive apprenticeship in clinical practice: Can it stimulate student learning during clinical rotations in the students' opinion? Research paper presented at the AMEE conference, September 2008, Prague, Czech Republic.

Stalmeijer, R.E., Dolmans, D.H.J.M, Wolfhagen, H.A.P., Scherpbier, A.J.J.A. (2007). Development of an instrument for evaluating the clinical teacher (in Dutch). Research paper presented at the NVMO conference, November 2007, Egmond aan Zee, the Netherlands.

Stalmeijer, R.E., Dolmans, D.H.J.M, Wolfhagen, H.A.P., Scherpbier, A.J.J.A. (2007). Development of an instrument for evaluating the clinical teacher. Paper presented at the AMEE conference, August 2007, Trondheim, Norway.

Stalmeijer, R.E., Gijselaers, W.H., Wolfhagen, H.A.P., Harendza, S., Scherpbier, A.J.J.A. (2006). Evaluation of curricular change processes. Study into factors that facilitate curricular change (in Dutch). Paper presented at the NVMO conference, November 2006, Egmond aan Zee, the Netherlands.

Stalmeijer, R.E., Gijselaers, W.H., Wolfhagen, H.A.P., Harendza, S., Scherpbier, A.J.J.A. (2006). Evaluation of curricular change processes. Study into factors that facilitate curricular change. Paper presented at the AMEE conference, Genoa, Italy.

Stalmeijer, R.E., Gijselaers, W.H., Wolfhagen, H.A.P., Harendza, S., Scherpbier, A.J.J.A. (2005). The Quality of Medical Education; Influences of Team processes and 
Organizational Facilitation. Paper presented at the AMEE conference, September 2005, Amsterdam, the Netherlands.

Stalmeijer, R.E., Gijselaers, W.H., Wolfhagen, H.A.P. (2005). Why some teacher teams are more successful than others in creating integrated multidisciplinary education. Paper presented at the Edineb Conference, June 2005, Antwerp, Belgium. 


\section{SHE Dissertation Series}

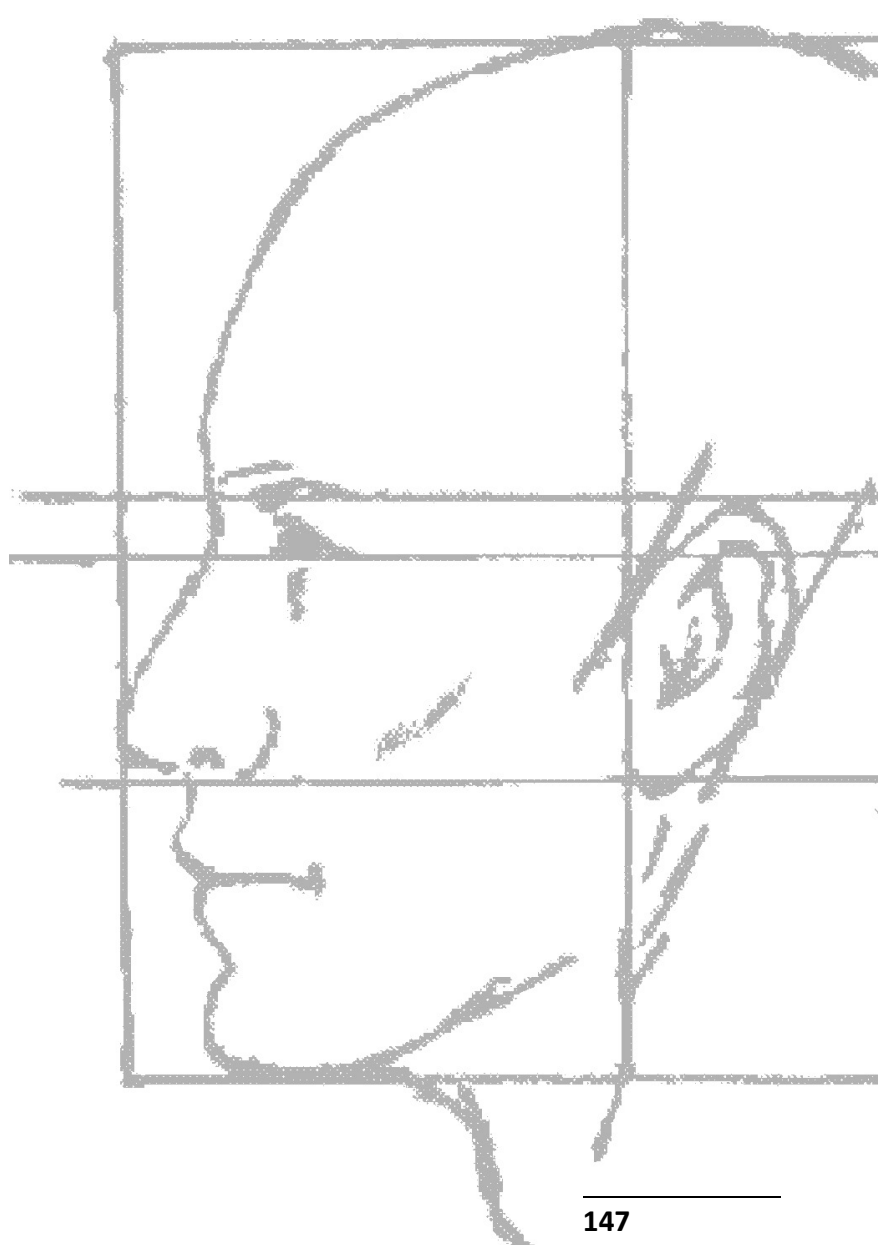


SHE DISSERTATION SERIES 
In the SHE Dissertation Series dissertations are published of $\mathrm{PhD}$ candidates from the School of Health Professions Education (SHE) who defended their PhD thesis at Maastricht University. The most recent ones are listed below. For more information go to www.maastrichtuniversity.nl/she.

van Blankenstein, F. Elaboration during problem-based, small group discussion: A new approach to study collaborative learning. (18-05-2011)

van Mook, W. Teaching and assessment of professional behaviour: Rhetoric and reality. (13-05-2011)

De Leng, B. Wired for learning. How computers can support interaction in small group learning in higher education. (8-12-2009).

Maiorova, T. The role of gender in medical specialty choice and general practice preferences. (29-05-2009)

Bokken, L. Innovative use of simulated patients for educational purposes. (04-032009)

Wagenaar, A. Learning in internships. What and how students learn from experience. (18-09-2008)

Driessen, E. Educating the self-critical doctor. Using portfolio to stimulate and assess medical students' reflection. (25-06-2008)

Derkx, H. For your ears only. Quality of telephone triage at out-of-hours centres in the Netherlands. (18-06-2008)

Niessen, Th. Emerging epistemologies: making sense of teaching practice. (30-112007)

Budé, L. On the improvement of students' conceptual understanding in statistics education. (05-10-2007)

Niemantsverdriet, S. Learning from international internships: A reconstruction in the medical domain. (26-07-2007)

Marambe, K. Patterns of student learning in medical education - A Sri Lankan study in traditional curriculum. (20-06-2007)

Pleijers, A. Tutorial group discussion in problem-based learning. (19-01-2007)

Sargeant, J. Multi-source feedback for physician learning and change. (21-09-2006)

Dornan, T. Experience-based learning. (12-06-2006)

Wass, V. The assessment of clinical competence in high stakes examinations. (1205-2006)

Prince, K. Problem-based learning as a preparation for professional practice. (2104-2006) 